\title{
Clouds and Hazes of Venus
}

\author{
Dmitrij V. Titov ${ }^{1} \cdot$ Nikolay I. Ignatiev ${ }^{2}$. \\ Kevin McGouldrick ${ }^{3}$. Valérie Wilquet ${ }^{4}$. \\ Colin F. Wilson ${ }^{5}$
}

Received: 30 September 2018 / Accepted: 5 October 2018 / Published online: 27 November 2018 (C) The Author(s) 2018

\begin{abstract}
More than three decades have passed since the publication of the last review of the Venus clouds and hazes. The paper published in 1983 in the Venus book summarized the discoveries and findings of the US Pioneer Venus and a series of Soviet Venera spacecraft (Esposito et al. in Venus, p. 484, 1983). Due to the emphasis on in-situ investigations from descent probes, those missions established the basic features of the Venus cloud system, its vertical structure, composition and microphysical properties. Since then, significant progress in understanding of the Venus clouds has been achieved due to exploitation of new observation techniques onboard Galileo and Messenger flyby spacecraft and Venus Express and Akatsuki orbiters. They included detailed investigation of the mesospheric hazes in solar and stellar occultation geometry applied in the broad spectral range from UV to thermal IR. Imaging spectroscopy in the near-IR transparency "windows" on the night side opened a new and very effective way of sounding the deep atmosphere. This technique together with near-simultaneous UV imaging enabled comprehensive study of the cloud morphology from the cloud top to its deep layers. Venus Express operated from April 2006 until December 2014 and provided a continuous data set characterizing Venus clouds and hazes over a time span of almost 14 Venus years thus enabling a detailed study of temporal and spatial variability. The polar orbit of Venus Express allowed complete latitudinal coverage. These studies are being complemented by JAXA Akatsuki orbiter that began observations in May 2016. This paper reviews the current status of our knowledge of the Venus cloud system focusing mainly on the results acquired after the Venera, Pioneer Venus and Vega missions.
\end{abstract}

Venus III

Edited by Bruno Bézard, Christopher T. Russell, Takehiko Satoh, Suzanne E. Smrekar and Colin F. Wilson

C.F. Wilson

colin.wilson@physics.ox.ac.uk

1 ESA/ESTEC, Noordwijk, The Netherlands

2 Space Research Institute (IKI), Moscow, Russia

3 LASP, University of Colorado, Boulder, USA

4 Belgian Institute for Space Aeronomy (IASB-BIRA), Brussels, Belgium

5 Dept. of Physics, Oxford University, Oxford, UK 
Keywords Venus $\cdot$ Venus atmosphere $\cdot$ Clouds $\cdot$ Aerosols

\section{Introduction}

The last comprehensive review of the clouds and hazes on Venus was published more than thirty years ago in the Venus book (Esposito et al. 1983). Some updates on the cloud top structure were made by Esposito et al. (1997) in the Venus-II book. These papers summarized our knowledge about the greatest cloud system on terrestrial planets on the basis of the results from Venera and Pioneer Venus orbiters and descent probes. The early investigations provided basic understanding of the Venus cloud system, but lacked details on the cloud morphology, vertical structure, composition and their variability. The era after the Venera and Pioneer Venus missions featured remarkable progress in the study of Venus clouds by the orbiters Venera-15, -16 in 1983, Venus Express in 2006-2014, and Akatsuki since 2016, balloons and descent probes (Vega-1, -2 in 1985), as well as Galileo (1990) and Messenger (2007) flyby supported by numerous ground-based observations, numerical modeling, and theoretical investigations.

This chapter provides an overview of the new results on the Venus clouds and hazes published after Venus II book. The introduction section gives a brief summary of the missions, instruments and techniques that enabled progress in cloud investigations after Pioneer Venus, Venera and Vega missions. Section 2 describes vertical structure of the cloud. Section 3 reviews the cloud morphology through the entire cloud deck. Section 4 describes the progress on observations of microphysical properties of the cloud population. It is followed by discussion of the modelling of cloud chemistry and microphysics in Sects. 5 and 6. Radiative effects directly related to the cloud layer and its variability are described in Sect. 7. This section complements more detailed description of the radiative energy balance in the dedicated chapter (Limaye et al. 2018a). Section 8 is devoted to lightning in the Venus atmosphere. Sections 9 and 10 give a synthesis of the Venus cloud system and outline outstanding remaining science issues and perspectives for future studies.

The Fourier Spectrometer Experiment (FSE) onboard the Soviet Venera-15, -16 orbiters (Moroz et al. 1986; Oertel et al. 1987) provided about 1500 moderate resolution $\left(4.5 \mathrm{~cm}^{-1}\right.$ and $\left.6.5 \mathrm{~cm}^{-1}\right)$ spectra of Venus thermal radiation in the range of $200-1600 \mathrm{~cm}^{-1}$ $(50-6.25 \mu \mathrm{m})$ that so far remains unique data set of this kind. The measurements covered morning and evening sectors mainly in the Northern hemisphere. The data analysis included retrievals of the temperature structure, calculation of the thermal winds in the mesosphere, determination of $\mathrm{H}_{2} \mathrm{O}$ and $\mathrm{SO}_{2}$ abundance at the cloud top, and assessment of the upper cloud parameters (see Zasova et al. 2007 and references therein).

In 1985 two Soviet Vega spacecraft en route to comet Halley delivered descent probes and balloons to the Venus atmosphere (Sagdeev et al. 1986; Moroz 1987; Crisp et al. 1990; Lorenz et al. 2018). The mission science program included in situ measurements of particle size distribution during descent through the clouds as well as measurements of the backscattering coefficient (nephelometry) on both descent probes and balloons that allowed characterization of aerosols optical properties (see Zasova et al. 1996 and references therein). The Vega probes also included gas chromatographs, mass spectrometers, and X-ray fluorescent spectrometers to study chemical composition of the clouds. Some results of those studies were questionable and controversial (Krasnopolsky 1989).

The NASA Galileo spacecraft en route to Jupiter flew by Venus on February 10, 1990 (Johnson et al. 1991). The NIMS experiment performed pioneering spatially resolved observations of the Venus night side in the near-IR transparency windows (Carlson et al. 1991) 
discovered by Allen and Crawford (1984). They allowed characterization of spatial variability of the total cloud opacity, assessment of microphysical properties in the deep cloud, and determination of the upper cloud structure. Imaging of Venus at $0.418 \mu \mathrm{m}$ and $0.986 \mu \mathrm{m}$ by the SSI camera (Belton et al. 1991) provided the first simultaneous observations of the cloud morphology and dynamics in the violet and near-IR spectral ranges that sounded the upper and middle/lower cloud layers respectively.

The ESA Venus Express mission made a breakthrough in our understanding of the clouds due to its powerful remote sensing payload, long duration of the mission and polar orbit of the spacecraft (Svedhem et al. 2007, 2009, 2011; Titov et al. 2006, 2009). The highly elliptical orbit of Venus Express with its apocentre above the Southern pole allowed the imaging instruments to zoom in on the equatorial and Northern latitudes putting high resolution images in global context. Mesoscale images taken by Venus Express from 10000$15000 \mathrm{~km}$ distance covered a significant portion of the planet with spatial resolution comparable to the best images from the earlier missions. They provided a close look at the sub-solar region (i.e. 10-14 hours local solar time). Venus Express was the first Venus orbiter to have an elliptical orbit with its pericentre at the North pole, providing ideal conditions for planetary scale observations of the Southern high latitudes from apocentre. Venus Express was also the first orbiter capable of observing the lower clouds of Venus, fully exploiting near-infrared spectral "windows" on the nightside; these revealed the morphology and motions of lower/middle clouds, as well as constrained their microphysical properties. The Visible and Infrared Thermal Imaging Spectrometer (VIRTIS) (Piccioni et al. 2011; Drossart et al. 2007) performed spectral imaging of the planet in a broad spectral range from near-UV $(0.4 \mu \mathrm{m})$ to thermal IR $(\sim 5 \mu \mathrm{m})$, including near-IR spectral transparency "windows" on the night side, thus enabling comprehensive study of the morphology, dynamics, total aerosol opacity and particle population in the deep cloud. The cloud top altitude and its variations were retrieved from the VIRTIS observations in the near-IR $\mathrm{CO}_{2}$ bands. This was complemented by assessment of the cloud top structure using the temperature field derived by the radio occultation experiment VeRa (Häusler et al. 2006). The VeRa sounding also provided indirect assessment of the cloud base altitude as well as mapped $\mathrm{H}_{2} \mathrm{SO}_{4}$ vapour abundance in the deep cloud (Oschlisniok et al. 2012).

The Venus Monitoring Camera (VMC) provided continuous monitoring of the cloud layer in four narrow-band filters from UV to near-IR with spatial resolution ranging from $50 \mathrm{~km}$ to few hundreds of meters (Markiewicz et al. 2007, 2011) resulting in detailed characterization of the cloud top morphology and wind pattern as well as optical and microphysical properties of the upper cloud.

The vertical structure and microphysical properties of the upper haze were studied in detail by the SPICAV-SOIR spectrometer onboard Venus Express (Bertaux et al. 2007). The experiment performed medium to high spectral resolution spectroscopy in the UV (118$320 \mathrm{~nm})$, visible and near IR $(0.7-1.7 \mu \mathrm{m})$ and IR $(2.2-4.3 \mu \mathrm{m})$ ranges in stellar and solar occultation geometry. The observations covered altitudes from $160 \mathrm{~km}$ to about $70 \mathrm{~km}$ that includes mesosphere and lower thermosphere. Due to large air mass factor the measurements were very sensitive to aerosol properties at these altitudes. The observations provided complete latitudinal coverage and characterized spatial and temporal variability of the upper haze.

The task of monitoring of the Venus atmosphere has been taken over from Venus Express by the JAXA Akatsuki spacecraft (Nakamura et al. 2007) inserted in orbit in December 2015. The orbiter carries a set of cameras imaging the planet in the broad spectral range from UV to thermal-IR to study cloud morphology and atmospheric dynamics at different levels within the cloud deck. The UVI camera (Yamazaki et al. 2018) and the IR1 (Iwagami et al. 
2011) and IR2 (Satoh et al. 2017) imagers continue investigations of the aerosol population at the cloud top and in the mesosphere. The thermal-IR camera (LIR) characterizes global cloud top temperature distribution (Fukuhara et al. 2017).

While many of the findings are still in development and so are too incomplete to include in this review, we do note that the early results from the mission have revealed new insights into the atmosphere of Venus. For example, the nearly planetary scale bow wave seen in the cloud tops by LIR suggests a direct coupling between the flow near the surface and that at $70 \mathrm{~km}$ altitude (Fukuhara et al. 2017). In addition, measurement of a persistent but intermittent zonal jet at $50 \mathrm{~km}$ altitude observed in IR2 data suggests that the Venus atmosphere exhibits changes of a magnitude, and on spatial and temporal scales that we would term as "weather" on Earth (Horinouchi et al. 2017). These findings and the promise of more to come show that there is still very much to learn about the workings of the Venus atmosphere and clouds.

Ground-based observations of Venus appeared to be an effective tool supplementing orbiter studies. Several ground-based observation campaigns were carried out in coordination with Venus Express investigations (see e.g. Lellouch and Witasse 2008). Tavenner et al. (2008) presented a multi-year sequence of nightside near-IR $(2.26 \mu \mathrm{m})$ images and derived global mean cloud pattern. Arney et al. (2014) provided spatially resolved measurements of minor species, cloud opacity and acid concentration in the near-IR "windows" on the Venus night side. Encrenaz et al. (2012) reported thermal mapping of Venus with high spectral resolution to determine spatial and temporal variations of $\mathrm{H}_{2} \mathrm{O}$ and $\mathrm{SO}_{2}$ at the cloud tops, while Marcq et al. (2006) and Chamberlain et al. (2013) mapped water abundance in the lower atmosphere.

\section{Vertical Structure of the Cloud}

Background Venus is completely shrouded by the clouds that form the largest aerosol system among the terrestrial planets. The basic knowledge about its vertical structure was established by Venera, Pioneer Venus, and Vega descent probes, the last of which conducted its mission in 1985 (Esposito et al. 1983; Ragent et al. 1985). There have been thirteen instrumented entry probes which have returned information about the vertical structure of the Venus clouds. There are some characteristics common to all the profiles, but there are also some significant differences. In particular, the Pioneer Venus Large (Sounder) probe (Knollenberg and Hunten 1980) and the Vega-1, -2 LSA aerosol particle size spectrometer (Zhulanov et al. 1986), all show a sharp increase in the cloud extinction just below $50 \mathrm{~km}$ suggesting an optically thick layer at $47-50 \mathrm{~km}$. Some descent probes did not see this feature, suggesting strong variability of the deep cloud structure. There is also considerable evidence for hazes below the main cloud layer. Both the Pioneer Venus Large Probe and Vega ISAV UV spectrometer showed discrete cloud layers near $46 \mathrm{~km}$ altitude, distinct from the lower cloud. The ISAV spectrometer found a second such layer at $43 \mathrm{~km}$ altitude (Knollenberg and Hunten 1980; Bertaux et al. 1996). Pioneer Venus and Vega probes also show evidence for further hazes extending down to $30 \mathrm{~km}$ altitude (Knollenberg and Hunten 1980; Moshkin et al. 1986; Gnedykh et al. 1987). These layers all exist at an altitude below that where one would expect to find liquid sulphuric acid at equilibrium. Finally, a reanalysis of the Venera-13, -14 spectrophotometer data by Grieger et al. (2004) tentatively suggested an evidence for a detached aerosol layer with extinction of $\sim 1.5 \mathrm{~km}^{-1}$ at visible wavelengths $1-2 \mathrm{~km}$ above the surface. 
Table 1 Parameters of the Venus cloud system (from Esposito et al. 1983). The modes of aerosol population are based on the data from Particle Size Spectrometer experiment on the PV Large Probe (Knollenberg and Hunten 1980). Note that this terminology should be used with caution in representing other data sets

\begin{tabular}{lllll}
\hline Region & Altitude range $(\mathrm{km})$ & $\begin{array}{l}\text { Optical depth, } \tau \\
(\text { at } 0.63 \mu \mathrm{m})\end{array}$ & Mean diameter $(\mu \mathrm{m})$ & $\begin{array}{l}\text { Average number density } \\
\left(\mathrm{N} \mathrm{cm}^{-3}\right)\end{array}$ \\
\hline Upper haze & $70-90$ & $0.2-1.0$ & 0.4 & 500 \\
Upper cloud & $56.5-70$ & $6.0-8.0$ & Mode 1: 0.4 & 1500 \\
Middle cloud & $50.5-56.5$ & $8.0-10.0$ & Mode 2: 2.0 & 50 \\
& & & Mode 1: 0.3 & 300 \\
Lower cloud & $47.5-50.5$ & Mode 2: 2.5 & 50 \\
& & $6.0-12.0$ & Mode 3: 7.0 & 10 \\
& & & Mode 1: 0.4 & 1200 \\
& & Mode 2: 2.0 & 50 \\
\end{tabular}

The atmospheric structure derived from the earlier missions is summarised in Fig. 1. This structure is typical for the low latitudes. The main cloud deck extends from about $48 \mathrm{~km}$ up to $\sim 70 \mathrm{~km}$. It can be subdivided in three layers according to the behaviour of extinction coefficient and particle population. The upper cloud $(57-70 \mathrm{~km})$ is populated by submicron $\left(r_{1} \sim 0.2 \mu \mathrm{m}\right)$ and micron size $\left(r_{2} \sim 1 \mu \mathrm{m}\right)$ particles (Table 1$)$, called mode 1 and 2 respectively. This is the altitude range where the photochemical "factory" producing sulphuric acid from $\mathrm{SO}_{2}$ and $\mathrm{H}_{2} \mathrm{O}$ is located. Another species present solely in the upper cloud is the mysterious UV-blue absorbers whose inhomogeneous vertical and spatial distribution creates well-known markings on the cloud top that are routinely used to study the cloud morphology and atmospheric dynamics (see Sect. 3). This species strongly absorbs at $0.3-0.5 \mu \mathrm{m}$ and is responsible for absorption of about half of the solar energy the planet receives from the Sun. The upper cloud is also the region of the strongest variability of the temperature structure. The tropopause is located approximately at the base of this region at about $60 \mathrm{~km}$ (Fig. 1) (Limaye et al. 2018a). Zonal wind speed reaches its maximum of 100-120 m/s in the upper cloud (Fig. 1) indicating that the cloud strongly affects atmospheric circulation (Sánchez-Lavega et al. 2017).

The upper and middle clouds are often separated by a 1-2 km gap with reduced extinction located at $\sim 56 \mathrm{~km}$. Below that level the cloud density gradually increases with depth reaching its maximum at $\sim 50 \mathrm{~km}$. The separation between the middle and the lower clouds is not very clear. This region is characterized by tri-modal particle distribution with typical radii of $0.15-0.2 \mu \mathrm{m}$ (mode 1 ), $1-1.25 \mu \mathrm{m}$ (mode 2 ) and 3.5-4.0 $\mu \mathrm{m}$ (mode 3 ). The existence of a separate mode 3 of large particles is still a controversy: the large particles might be just a "tail" of mode 2 rather than a separate mode (Toon et al. 1984). As in the upper layer sulphuric acid was found to be the major aerosol constituent in the middle and lower clouds, although significant elemental abundances of chlorine and phosphorous were also found at these altitudes (Andreichikov 1987) (Sect. 5). The temperature gradient here is close to adiabatic lapse rate and the stability parameter (difference between the measured temperature gradient and the adiabatic lapse rate) is close to zero (Seiff et al. 1985; Limaye et al. 2018a) suggesting that convection dominates the energy and material transport in this part of the cloud, in contrast to the convectively stable upper layer.

Extended layers of fine aerosols are observed both above and below the main cloud deck (Fig. 1). The upper haze fills the mesosphere up to $\sim 100 \mathrm{~km}$ altitude with evidences of 


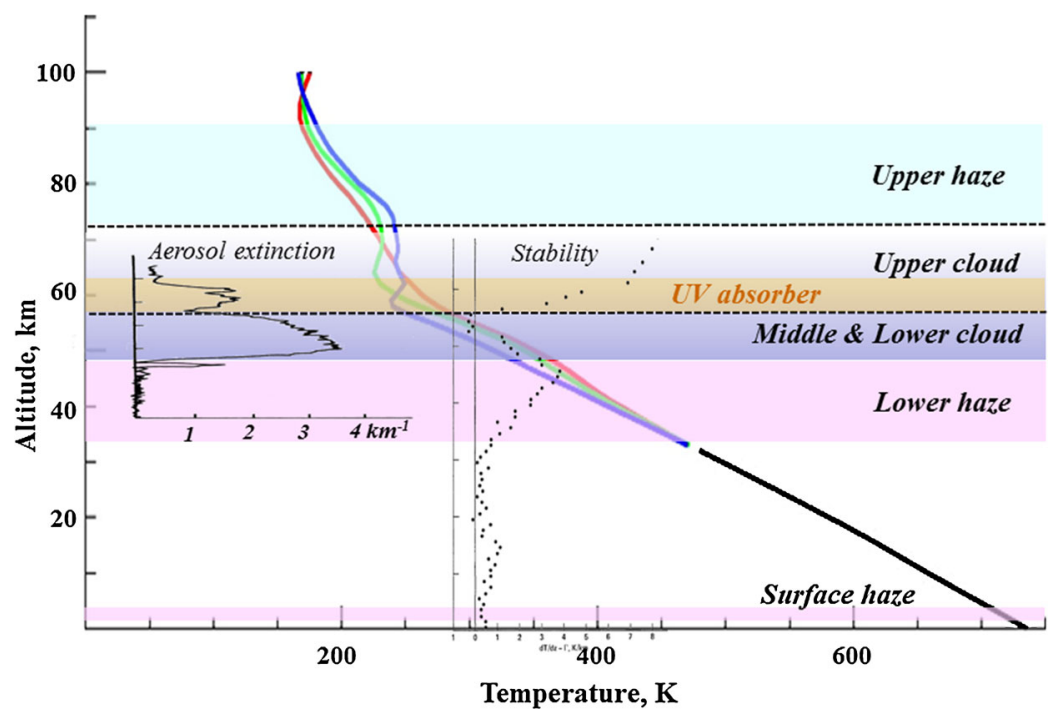

Fig. 1 Vertical structure of the Venus clouds as derived by the Venera and Pioneer Venus descent probes. The color lines show mean temperature profiles at low (red), middle (blue) and high (green) latitudes with a single black line representing the temperature structure below $30 \mathrm{~km}$. The typical vertical profile of aerosol extinction (Ragent et al. 1985) is shown on the left. The static stability profile from the VIRA model (Seiff et al. 1985) is shown in the middle

detached layers (Fig. 2). The haze is presumably composed of sulphuric acid. The lower haze extends down to $\sim 33 \mathrm{~km}$, far below the level of sulphuric acid thermal decomposition. Descent probes also provided some evidence for thin aerosol layers near the surface.

Later observations will be reviewed here in turn.

Upper Haze (70-90 km) FSE experiment onboard Venera-15, VIRTIS, VeRa, VMC and SPICAV-SOIR experiments onboard Venus Express, and Akatsuki cameras provided a more detailed view on the vertical structure of the Venus cloud system, in particular on its spatial and temporal variability.

Haze is ubiquitous in the mesosphere and extends from the cloud top ( $\sim 70 \mathrm{~km})$ up to $\sim 110 \mathrm{~km}$. Sulphuric acid particles make up most of the upper haze. The upper haze properties were probed through polarimetry (Kawabata et al. 1980; Esposito and Travis 1982; Braak et al. 2002) and dayside limb scans (Lane and Opstbaum 1983; Krasnopolsky 1983), all at relatively short wavelengths. Venus Express and Akatsuki missions provided significant progress in remote studies of the Venus upper haze and its variability in a wide spectral range. Solar and stellar occultation as well as observations in limb geometry enable detailed characterization of aerosol vertical distribution. The near-IR spectrometer SPICAV-SOIR sounded the Venus mesosphere between $0.22 \mu \mathrm{m}$ and $4 \mu \mathrm{m}$ in solar occultation geometry suggesting gradual increase of slant opacity and local extinction coefficient $\left(\beta, \mathrm{km}^{-1}\right)$ with decreasing altitude (Wilquet et al. 2009, 2012; Luginin et al. 2016). SPICAV-UV performed stellar occultations at $0.22-0.3 \mu \mathrm{m}$ on the night side (Wilquet et al. 2009). VIRTIS imaging spectrometer measured limb spectra in the IR range $(1.05-5.19 \mu \mathrm{m})$. Thermal radiation from the cloud top scattered by the mesospheric haze increased by a factor of $\sim 10$ between 90 and $82.5 \mathrm{~km}$ (de Kok et al. 2011). The infrared cameras onboard Akatsuki are delivering images of the full Venus disk (Satoh et al. 2015, 2017). 
Fig. 2 Typical profiles of aerosol extinction derived from SPICAV-SOIR observation on 19 August 2007 (6 am, 70 N) onboard Venus Express at different wavelengths (see colour legend) suggesting detached aerosol layer at $78-84 \mathrm{~km}$

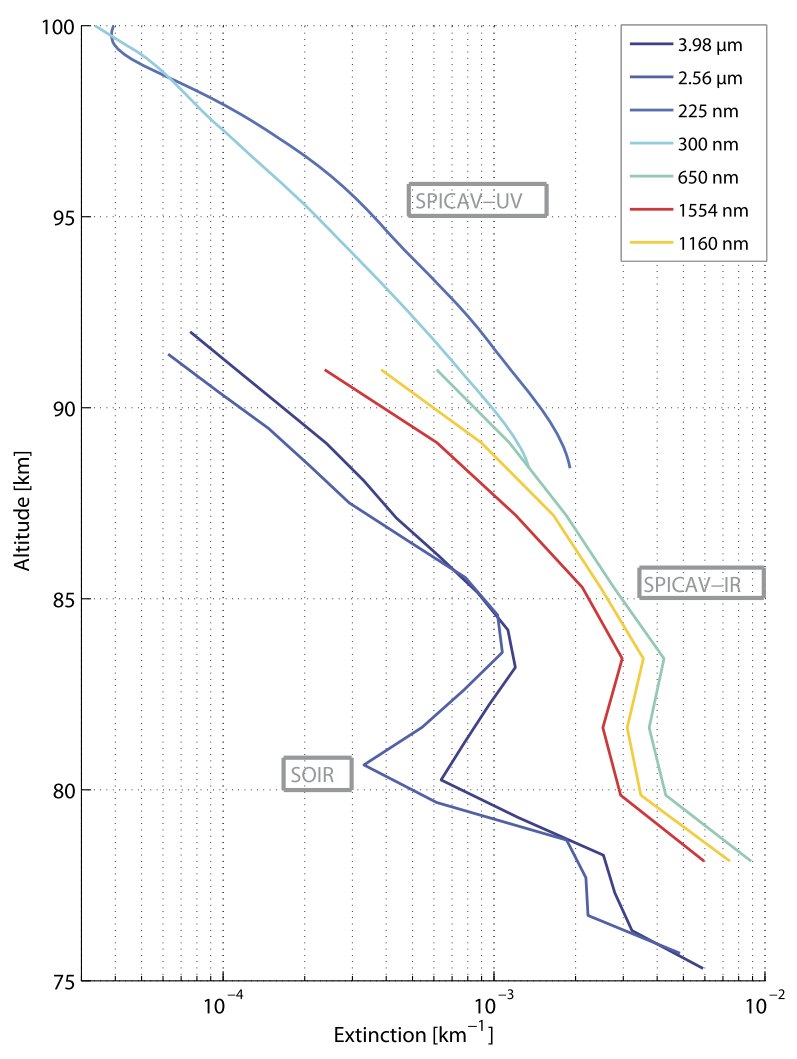

Figure 2 shows examples of aerosol extinction vertical profiles derived from the solar occultation sounding onboard Venus Express. Fine upper haze extends throughout the mesosphere up to $\sim 100 \mathrm{~km}$ with extinction coefficient decreasing by more than two orders of magnitude over $25 \mathrm{~km}$ altitude range. In some cases, observations with vertical resolution better than $2 \mathrm{~km}$ when the spacecraft was close to the planet allowed identification of detached aerosol layers (Wilquet et al. 2009). Optically thin haze layers were observed at $80-85 \mathrm{~km}$ in about $60 \%$ of high-resolution profiles (Luginin et al. 2016).

Figure 3 compares the aerosol scale height $H_{\mathrm{a}}$ derived from different experiments. The upper haze region $(75-90 \mathrm{~km})$ is rather uniform over the planet and is characterized by $H_{\mathrm{a}}=2.8 \pm 1.2 \mathrm{~km}$ for $20-80^{\circ} \mathrm{N}$ (de Kok et al. 2011; Luginin et al. 2016), with no evidence of morning-to-evening variability. At high polar latitudes $\left(>80^{\circ} \mathrm{N}\right)$, the scale height was found to be larger $\left(H_{\mathrm{a}}=4.4 \pm 1.0 \mathrm{~km}\right)$. Below $75 \mathrm{~km}$ at the cloud top the scale height increases to $4-5 \mathrm{~km}$ at low and middle latitudes, while in the "cold collar" and some polar regions the scale height can decrease to below $2 \mathrm{~km}$ indicating sharp upper boundary of the cloud. The sharp cloud top is usually associated with the regions of strong thermal inversions (Limaye et al. 2018a) suggesting physical relation between these two features (see Sect. 7). Comparison to the gaseous scale height $H_{\mathrm{g}} \sim 4.5 \mathrm{~km}$ shows that at least in low latitudes aerosol at the cloud top is well mixed with the gas. Decrease of the scale height of the upper haze above $75 \mathrm{~km}$ indicates that aerosol production occurs at the cloud top.

Understanding of the upper haze variability is of great importance for chemistry and radiative balance of the mesosphere. Early studies of spatial and temporal variations of Venus polarization by the Pioneer Venus Orbiter (PVO) between 1978 and 1990, revealed latitudi- 


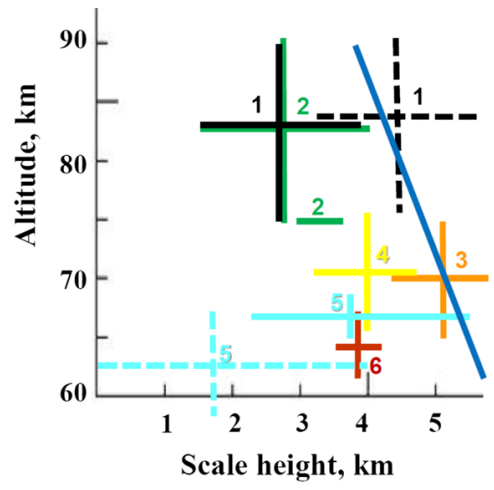

Fig. 3 Scale height of the mesospheric haze at low latitudes derived from observations: 1 (black) SPICAV-IR: solid/dashed correspond to latitude ranges $60^{\circ}-80^{\circ} \mathrm{N} />80^{\circ} \mathrm{N}$ (Luginin et al. 2016, 2018), 2 (green)_VIRTIS/VEX (de Kok et al. 2011), 3 (orange)—NIMS/Galileo (Roos-Serote et al. 1993), 4 (yellow)_ground-based observations (Roos-Serote et al. 1996), 5 (cyan)_VIRTIS\&VeRa/VEX: solid/dashed correspond to low-middle/high latitudes (Lee et al. 2012), 6 (red)_FSE/Venera-15 (Zasova et al. 1993). Blue line shows gaseous scale height according to the VIRA model (Seiff et al. 1985)

nal variations of an order of magnitude in haze opacity indicating that the haze is likely of photochemical origin. The observations also suggested temporal variations on the order of hundreds days and a long-term declining trend of the haze opacity over 11 years of the PVO mission (Kawabata et al. 1980; Braak et al. 2002).

SOIR and SPICAV-IR observations of aerosol extinction over 8 years of the Venus Express mission established climatology of the mesospheric haze (Fig. 4) (Wilquet et al. 2012; Luginin et al. 2016). The analysis confirmed latitudinal dependence of extinction, the extinction coefficient being at least one order of magnitude greater at the equator than that at poles. At $0-70^{\circ}$ latitude, the level of slant opacity $\tau \sim 1$ at $3 \mu \mathrm{m}$ is located 5-10 km lower on the morning side as compared to the evening side of the terminator. Thus the mesospheric haze demonstrates the latitudinal trend similar to that of the cloud top (see Figs. 7, 8). In the polar regions the morning-evening difference is negligibly small. Latitudinal variations of the altitude of $\tau \sim 1$ level between polar and equatorial latitudes reach about $12 \mathrm{~km}$ in the morning and almost $20 \mathrm{~km}$ in the evening. All this is consistent with photochemical production of the mesospheric haze on the day side.

Both short and long-term variability of the upper haze was revealed during the eight years of the Venus Express mission. The extinction variations can reach an order of magnitude on the time scale of a few Earth days (Wilquet et al. 2012). Observations of temporal variations of the Venus polarization during the Pioneer Venus Orbiter mission were revisited by Braak et al. (2002). The haze particle column density was confirmed to decrease gradually by a factor of $\sim 5$ during 12 years of the mission.

The haze extinction coefficient at low latitudes $\left(40^{\circ} \mathrm{S}-40^{\circ} \mathrm{N}\right)$ increased by more than one order of magnitude during the first 1000 orbits of the Venus Express (Fig. 5). The upper haze did not show any systematic or periodic variations between 2006 and 2014 except for strong increase of low latitude haze in the beginning of the mission. SPICAV-UV and SOIR observations suggested that $\mathrm{SO}_{2}$ mixing ratio at the cloud top decreased from equator to pole (Belyaev et al. 2012; Marcq et al. 2011). $\mathrm{SO}_{2}$ abundance increased in the beginning of the mission and then dropped. These temporal variations might be due to a multiple volcanic eruptions or to changes in the atmospheric circulation (Marcq et al. 2013). As a result, the 


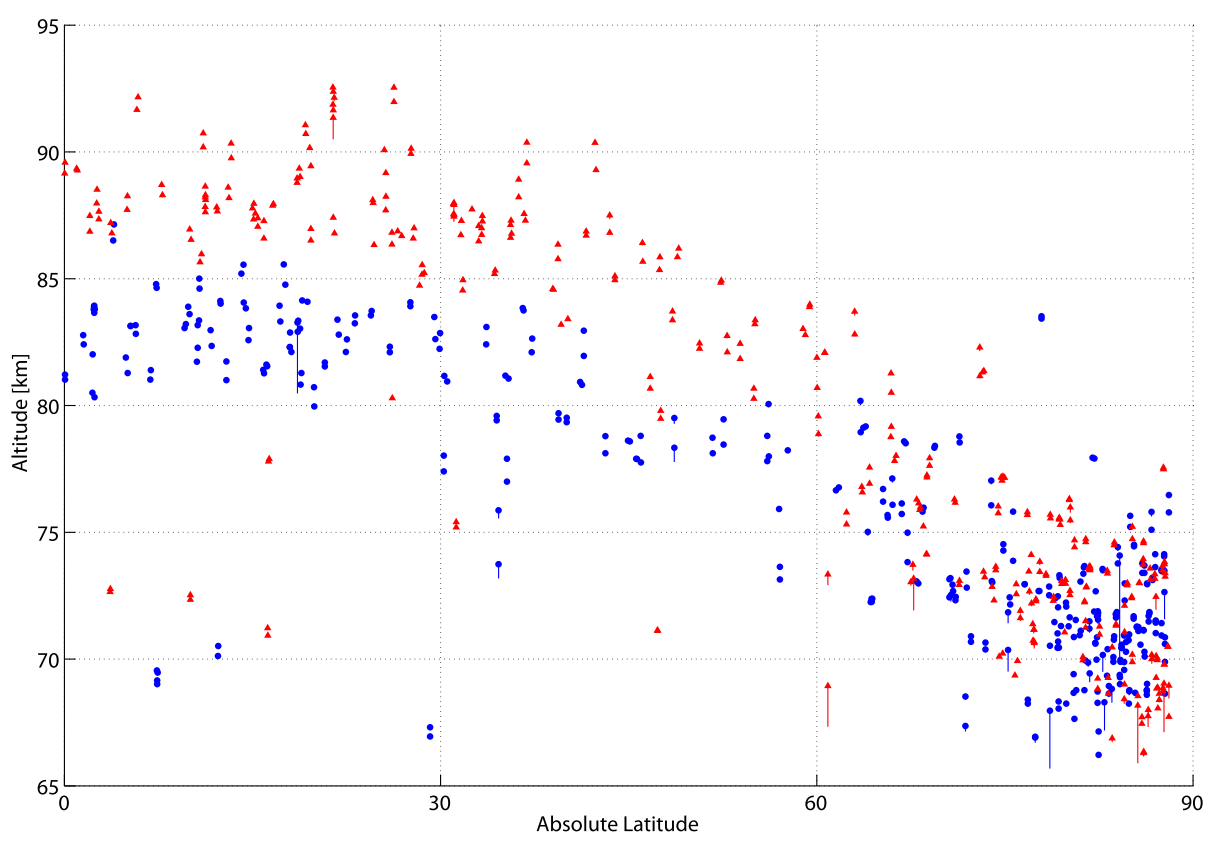

Fig. 4 Altitude of the reference slant optical depth $(\tau=1$ at $3 \mu \mathrm{m})$ as a function of absolute latitude for solar occultation observations at 6 am (blue) and $6 \mathrm{pm}$ (red) (updated from Wilquet et al. 2012)

$\mathrm{SO}_{2}$ concentration at cloud-top and the mesospheric haze opacity in the upper haze only partly correlate.

Upper Cloud (56.5-70 km) The cloud top can be observed from space in the broad spectral range from UV to thermal IR. The upper cloud boundary is rather diffuse in low and middle latitudes and becomes considerably sharper at high latitudes. The cloud top altitude varies with wavelength due to changing extinction properties of aerosols. Ragent et al. (1985) summarized that the altitude of the upper cloud boundary is located at 65 to $70 \mathrm{~km}$ and varies from equator to pole. It is depressed by about 3 to 4 kilometers near the "cold collar" from its lower latitude values, and then rises by 2 to 3 kilometers higher at about $80^{\circ} \mathrm{N}$, forming a lip into the polar region.

Venus Express observations allowed detailed characterization of the cloud top altitude. Spectroscopic observations by VIRTIS and SPICAV provided a reliable tool to monitor the location of the upper cloud boundary and its variability. Depth of the carbon dioxide absorption bands in the infrared range is proportional to the total number of $\mathrm{CO}_{2}$ molecules on the line of sight and, thus, depends on effective path of radiation in the atmosphere. This path is a function of the cloud top altitude, its vertical structure, aerosol optical properties, atmospheric temperature and pressure, and geometry of observations. The cloud top altitude is defined as the altitude of the unit optical depth ( $\tau=1$ level) and therefore is wavelength dependent (Fig. 6). However, in a wide spectral range from UV to $1.6 \mu \mathrm{m}$ the dependence is rather weak for $1 \mu \mathrm{m}$ sized particles that form the main part of the cloud particle population in the upper cloud in low and middle latitudes.

Ignatiev et al. (2009) used $1.6 \mu \mathrm{m} \mathrm{CO}$ band in the VIRTIS-M spectra to map the cloud top altitude from all available dayside observations. Later Cottini et al. $(2012,2015)$ used 


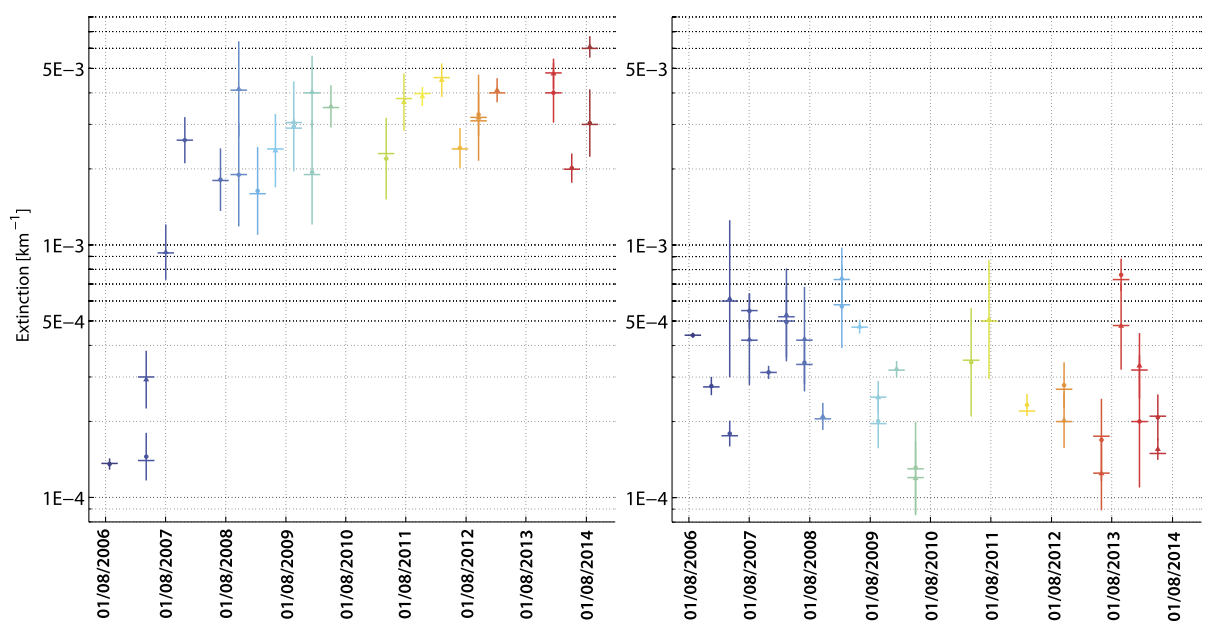

Fig. 5 Long-term variations of the upper haze volume extinction coefficient over the course of Venus Express mission for two different latitude bins. Mean of the local extinction at $3 \mu \mathrm{m}$ and altitude of $80 \mathrm{~km}$ for each season of solar occultation for $0^{\circ}-40^{\circ} \mathrm{N}$ (left) and $80^{\circ}-90^{\circ} \mathrm{N}$ (right) bin of absolute latitude (updated from Wilquet et al. 2012)

Fig. 6 Wavelength dependence of the cloud top altitude (i.e. $\tau=1$ level) calculated for several Venus cloud models (Ignatiev et al. 2009)

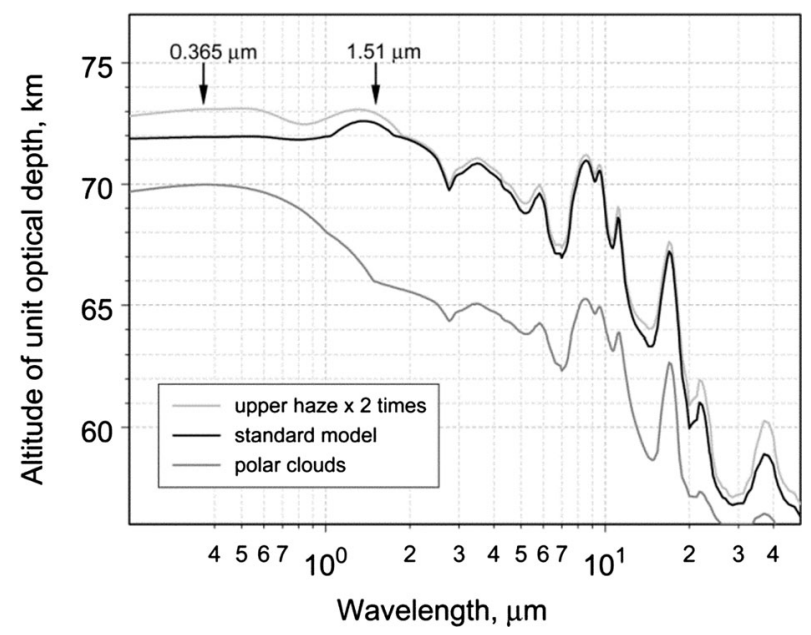

$2.5 \mu \mathrm{m} \mathrm{CO}_{2}$ band in the spectra measured by the high resolution channel of VIRTIS to derive the cloud top altitude. These results suggested that the cloud top altitude reported by Ignatiev et al. (2009) were affected by a systematic error and should be corrected by approximately $-2 \mathrm{~km}$. SPICAV measurements at $1.48 \mu \mathrm{m}$ also supported this suggestion (Fedorova et al. 2016). Summarizing these three sets of measurements we come to the following conclusions. In low and middle latitudes the cloud top at $1.5 \mu \mathrm{m}$ is located at $72 \pm 1 \mathrm{~km}$. It decreases poleward of $\pm 50^{\circ}$ and reaches $61-67 \mathrm{~km}$ in the polar regions (Fig. 7). No considerable local time variations were observed. The average latitudinal profile of the cloud top altitude is smooth, although instantaneous profiles have local maxima of several hundred meters over the average trend at $50^{\circ}-70^{\circ}$ latitudes with a typical size of $10^{\circ}$ along meridian (Ignatiev et al. 2009; Cottini et al. 2012, 2015). Fast variations at the scale of about $1 \mathrm{~km}$ 
Fig. 7 Mean cloud top altitude as a function of latitude and local time. Linear patterns are the traces of VIRTIS-M image frames (from Ignatiev et al. 2009 with systematic error corrected)

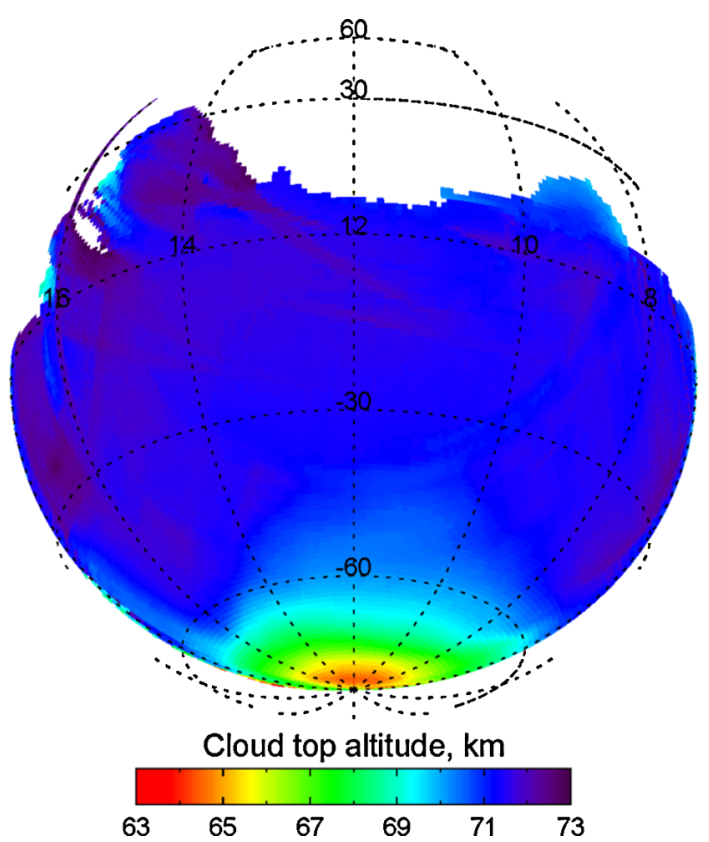

occur in tens of hours, while larger long-term variations of about several kilometers have been observed only at high latitudes. In low latitudes the cloud top altitude averaged over hundred day periods is remarkably stable.

Cottini et al. (2015) did not find any systematic correlations between the cloud top altitude, water vapor abundance and brightness at $0.375-0.385 \mu \mathrm{m}$. However, dark UV features, with characteristic size of a few degrees of latitude (i.e. several hundred kilometers), tend often to coincide with enhanced cloud density (or, equivalently, with higher cloud tops) and bright features with less dense (or deeper) clouds. This result seems to contradict the general understanding derived from global Pioneer-Venus and Venus Express imaging that the UV-dark material is located deeper in the upper cloud and is being brought to the cloud top by dynamical mixing (Esposito et al. 1983; Titov et al. 2008) although this conclusion was related to the global UV pattern and may not take into account local processes.

At longer wavelengths in the thermal IR range the cloud top $(\tau=1)$ level is located several kilometers deeper than in the near IR region, but demonstrates similar latitudinal trend (Zasova et al. 2007; Lee et al. 2012; Haus et al. 2013; Haus et al. 2014) (Fig. 8). The average latitudinal profile of the cloud top altitude is symmetric with respect to equator. In both hemispheres it starts decreasing at $\sim 30^{\circ}$. At $50^{\circ}-60^{\circ}$ its latitudinal gradient becomes larger and the cloud top altitude reaches its minimum at the pole. In the far IR range $(\sim 30 \mu \mathrm{m})$ the sulfuric acid absorption is much smaller than that at shorter wavelengths, and so the cloud top altitude is located considerably deeper (e.g. by about $10 \mathrm{~km}$ at low latitudes) than at shorter wavelengths (Fig. 8). Interestingly the cloud top strongly descends from equator to pole in the wavelengths range $1-8 \mu \mathrm{m}$ that sounds the upper cloud, while there is almost no decrease in cloud top altitude at $30 \mu \mathrm{m}$ (open circles in Fig. 8) that probes the middle cloud. This suggests that the upper cloud shrinks in vertical direction towards the pole while the middle cloud does not change its structure. The second peculiarity seen in Fig. 8 is that poleward from the "cold collar" the $8 \mu \mathrm{m}$ cloud top (filled circles) is located deeper than that at $5 \mu \mathrm{m}$ (diamonds) while the trend is opposite in low latitudes. Lee et al. (2012) argued that 


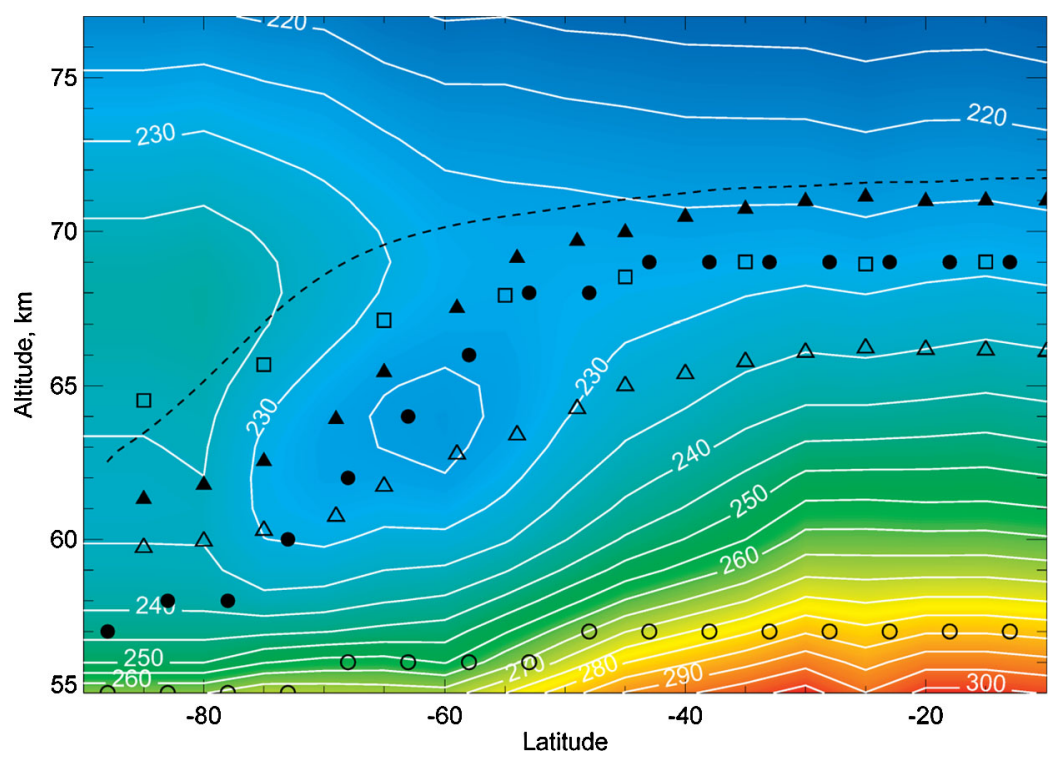

Fig. 8 Latitude dependence of the cloud top altitude overplotted on the latitude-altitude temperature field derived from analysis of VIRTIS-M dataset (Haus et al. 2014): dashed line-1.5 $\mu \mathrm{m} \mathrm{CO}_{2}$ band (Ignatiev et al. 2009) with systematic shift corrected (Cottini et al. 2012); squares-2.5 $\mu \mathrm{m} \mathrm{CO} 2$ band (Cottini et al. 2015); filled and empty triangles $-1 \mu \mathrm{m}$ and $5 \mu \mathrm{m}$, respectively, derived for the northern hemisphere and mapped to the southern hemisphere symmetrically with respect to equator (Haus et al. 2013); filled and empty circles-8.2 and $27.4 \mu \mathrm{m}$, respectively (Zasova et al. 2007)

this behaviour might indicate larger particle sizes in the polar regions than at low latitudes, since large particles $(r \sim 3-4 \mu \mathrm{m})$ have smaller extinction efficiency and thus deeper cloud top at $8 \mu \mathrm{m}$ than at $5 \mu \mathrm{m}$. A similar trend was found by Garate-Lopez et al. (2015).

Simultaneous observations by the VIRTIS and VMC instruments onboard Venus Express provide an opportunity to correlate the cloud top altitude pattern with the UV markings at global scale (Fig. 9). The UV bright and dark mesoscale features can be traced also in the cloud top altimetry maps as well as in the cloud top temperature fields. The UV dark spiral and circular features usually present at $-70^{\circ}$ are clearly seen in the cloud altimetry maps as variations of several hundred meters overlaid on the global descent to the pole (Fig. 9). Contrary to the analysis of the Pioneer Venus polarization measurements (Esposito and Travis 1982) and conclusions derived by Titov et al. (2008), the dark polar features are located higher or often correspond to the increasing latitudinal gradient of the cloud top altitude. The centre of the polar depression in the cloud top altitude always coincides with the "eye" of the polar vortex observed by VIRTIS at thermal IR wavelengths (Figs. 9, 10) (Piccioni et al. 2007). The "eye" that usually appears almost featureless at UV wavelengths has complex structure in the cloud altimetry map that perfectly correlates with the cloud top temperature. "Hot" spiral arms that have almost the same temperature as the core are located higher and characterized by strong gradient of the cloud top altitude, thereby being the boundary of the polar vortex. This feature will be discussed in more detail in Sect. 3 .

The sharpness of the cloud top boundary, characterized by aerosol scale height, is latitude dependent. In low latitudes the upper cloud is rather diffuse, while in the "cold collar" and polar regions the cloud top boundary can be very sharp. As well as the cloud top altitude, the scale height is wavelength dependent. However, although the cloud top altitude in the 

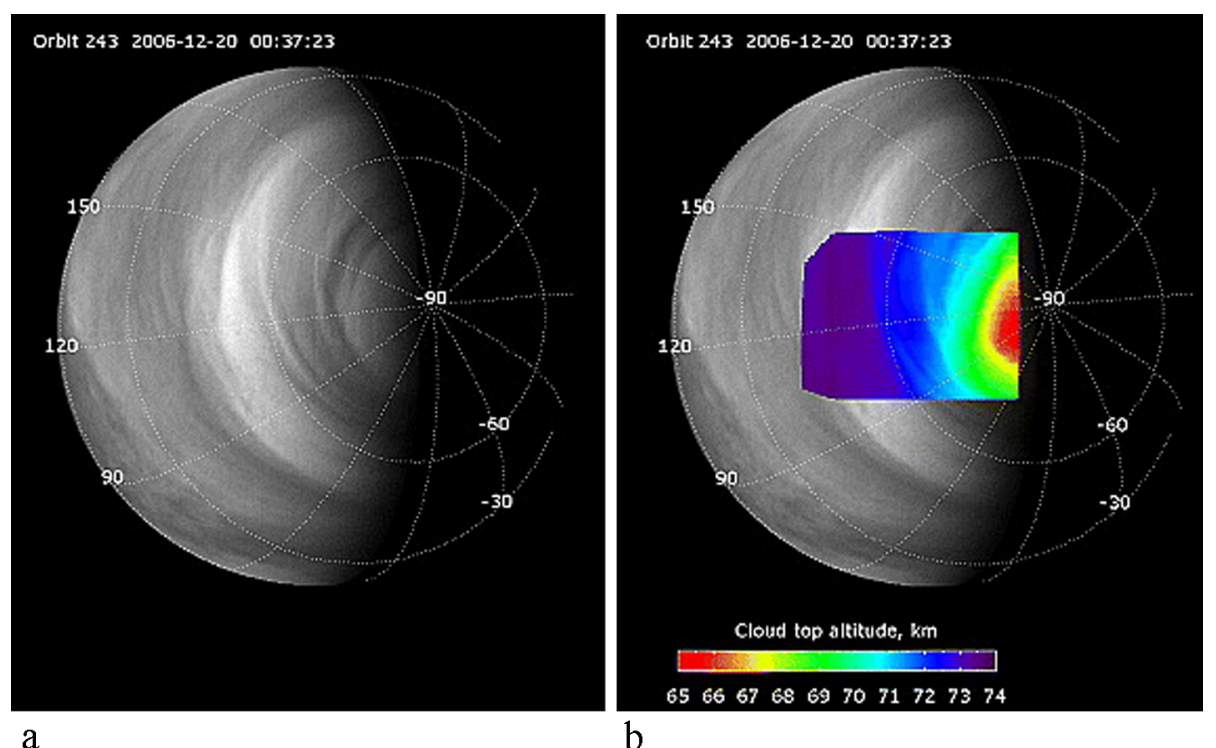

a

b
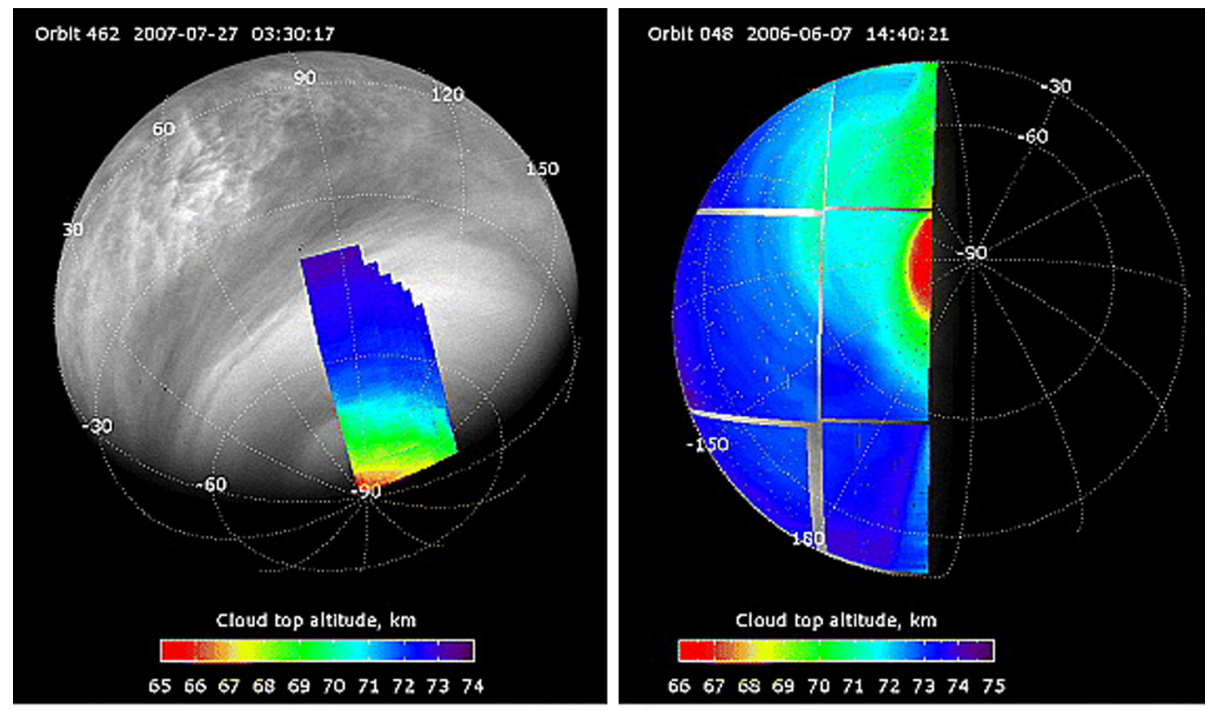

C

$\mathrm{d}$

Fig. 9 VMC UV images with overplotted cloud altimetry maps. Note correlation of the cloud altimetry and UV dark and bright features (Ignatiev et al. 2009)

UV and thermal IR differ by $15 \mathrm{~km}$, the cloud scale height evaluated from Pioneer Venus (Koukouli et al. 2005), Venera-15 (Zasova et al. 1993; Koukouli et al. 2005), Galileo (RoosSerote et al. 1993) and Venus Express (Lee et al. 2012) observations in nadir and solar occultation geometry are in good agreement and indicate the trend for the aerosol scale height to decrease with altitude in the mesosphere (Fig. 3). The observations also show a remarkable latitudinal trend (Fig. 11). The cloud top scale height strongly decreases from $\sim 4 \mathrm{~km}$ (that is similar to the gaseous scale height) at low-to-middle latitudes to $\leq 1 \mathrm{~km}$ 
Fig. 10 Correlation of the fine structure of the vortex eye (orange image, $5 \mu \mathrm{m}$ ) with the cloud top pattern (blue isolines). Altimetry data are absent in the nightside (upper part) and in a bright region of the dayside (lower part), where the signal is saturated. Contours are drawn every $0.2 \mathrm{~km}$ starting from $67.8 \mathrm{~km}$ in the center (Ignatiev et al. 2009)

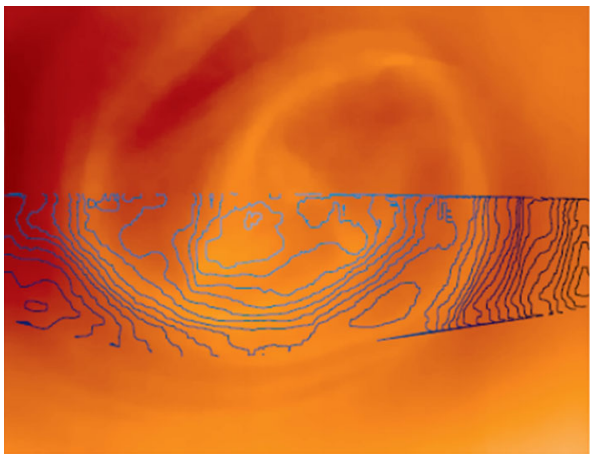

Thermal brightness, $\mathrm{K}$

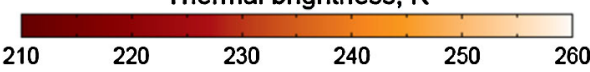

Cloud top altitude, $\mathrm{km}$

\begin{tabular}{|c|c|}
\hline 68 & 69 \\
\hline
\end{tabular}

Fig. 11 Latitude dependence of the cloud scale height from Zasova et al. (1993) and Lee et al. (2012)

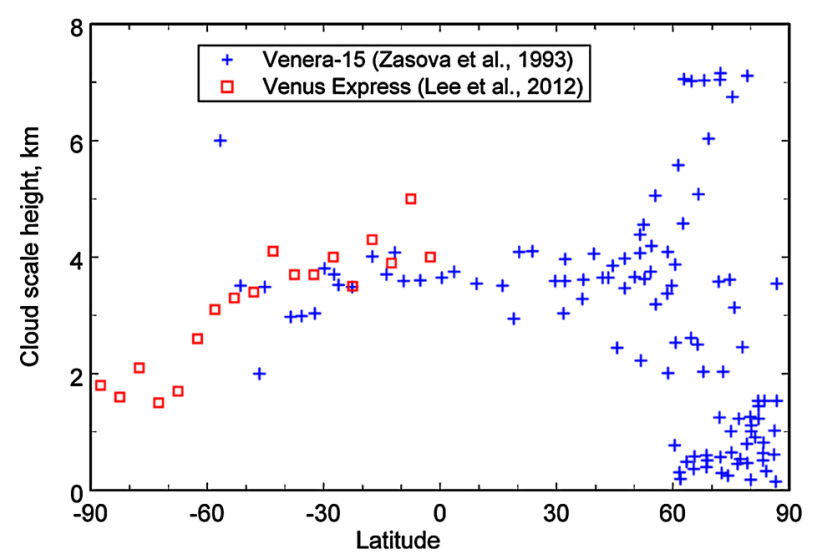

in the "cold collar". Further poleward the aerosol scale height varies from $1-1.5 \mathrm{~km}$ in the "hot dipole" and polar regions to $>4 \mathrm{~km}$ in the transition region (Fig. 11) suggesting strong spatial variability of the cloud top structure at high latitudes.

Middle and Lower Clouds (47.5-56.5 km) The Soviet Vega missions in 1985 had been the last so far to conduct in situ investigations of Venus by descent probes and balloons (Sagdeev et al. 1986). The measurements of aerosol properties by ISAV-A particle size spectrometer and nephelometer (Moshkin et al. 1986; Gnedykh et al. 1987) and LSA photoelectric aerosol counter (Zhulanov et al. 1986) on Vega descent probes in general confirmed the earlier results (Knollenberg and Hunten 1980), but also revealed substantial differences. Gnedykh et al. (1987) pointed out that above $55 \mathrm{~km}$ the ISAV-A measurements could have been compromised by smoke particles originated from the pyro-jettisoning of the probe's heat shield. Below this level, i.e. in the middle and lower cloud, the particle size distribution was characterized by two modes. Mode 1 can be approximated by the power law $\left(n \sim 1 / r^{\alpha}\right)$ in the particle radius range $0.25-2.5 \mu \mathrm{m}$ with an exponent of $5 \pm 1$ for Vega- 1 and $4 \pm 0.5$ for 
Vega-2. Mode 2 was composed of the particles with $r=1-2.5 \mu \mathrm{m}$. The particles with larger radii were rarely seen, and no separate mode of larger particles was detected. Both ISAV-A and LSA experiments detected much smaller number density in the middle and lower cloud layer as compared to Pioneer Venus. The mode 2 particles were about an order of magnitude $\left(N<10 \mathrm{~cm}^{-3}\right)$ less numerous. They were found to be spherical with refractive index of $1.4 \pm 0.05$. Two groups of particles were distinguished within mode 1 : about $80 \%$ of the population had refraction index $m=1.4 \pm 0.1$ while about $20 \%$ had much higher value of refractive index $(m=1.7 \pm 0.1)$. The measurements also suggested non-sphericity of small particles.

Gnedykh et al. (1987) used the aerosol properties derived from the particle size spectrometer to model the backscattering nephelometer signal and vertical profile of thermal radiation leaking from the surface - the quantities measured by the same instrument. The analysis suggested a presence of large number of small particles with size below ISAV-A detection limit $(r<0.25 \mu \mathrm{m})$. The results indicated that the haze with high refractive index $m=2$ and number density of $5 \cdot 10^{4}-5 \cdot 10^{5} \mathrm{~cm}^{-3}$ extends down to $\sim 35 \mathrm{~km}$. The estimated mass density of the haze was in the range of $0.1-2 \mathrm{mg} / \mathrm{m}^{3}$. The authors mentioned that similarly dense lower haze was observed during Venera-8 descent in 1972. Since Vega and Venera- 8 probes landed on the night side that might indicate development of dense subcloud haze at night. On the other hand, the nephelometric profiles recorder by two PV night probes did not support this finding. We note that analysis of VMC/Venus Express observations of glory also led Petrova et al. (2015) and Shalygina et al. (2015) to the conclusion about presence of the particles with high refractive index at the cloud top.

Aerosol properties in the middle cloud were sounded in situ by the nephelometer experiment onboard Vega-1 balloon that floated at 53.5-55 km altitude for about 46 hours having covered the distance of $\sim 11000 \mathrm{~km}$ (about $105^{\circ}$ longitude) driven by zonal winds (Sagdeev et al. 1986; Lorenz et al. 2018). For most of the flight duration Sagdeev et al. (1986), Ragent et al. (1987) and Crisp et al. (1990) reported unbroken clouds with scattering properties in agreement with the other descent probes. Over the range of altitudes traversed by the Vega-1 balloon during the course of the flight the measured backscattering coefficient varied from $0.8 \cdot 10^{-4} \mathrm{~m}^{-1} \mathrm{sr}^{-1}$ to $1.8 \cdot 10^{-4} \mathrm{~m}^{-1} \mathrm{sr}^{-1}$ with general trend to decrease with altitude suggesting the particle scale height of about $3 \mathrm{~km}$. In some regions a lack of anti-correlation with altitude indicated small scale variability in the cloud structure. During the period of greatest convective activity the measurements suggested about a factor of two greater backscattering. Ragent et al. (1987) tentatively attributed these events to moderate increase of number density of large particles admixed from lower regions by convective motions. During periods of minor convective activity the observations indicated much small-scale backscatter fluctuations with time scale of about $5 \mathrm{~min}$.

While Venus Express has brought a wealth of information on the upper hazes and cloud top structure, it has provided only indirect constraints on the vertical structure of the deep cloud from the measurements of the wings of the nightside infrared spectral "windows". Assuming sulphuric acid composition of the clouds and particles size distribution from Knollenberg and Hunten (1980), Barstow et al. (2011) found that the observed spectral variations of the nightside emissions can be explained by changes in the altitude of the cloud base from $46 \mathrm{~km}$ at $50^{\circ} \mathrm{S}$ to $42 \mathrm{~km}$ at $75^{\circ} \mathrm{S}$. However, these results should be taken with caution since the nightside emission is sensitive to several parameters of the cloud and distinguishing between them can be ambiguous. For instance, Haus et al. (2013) did not report a need for variable cloud base to fit VIRTIS/Venus Express spectra. Little variation in the cloud structure was observed as a function of local solar time and longitude. The total opacity of the clouds was derived from the radiance measured in the near-IR transparency "windows". The opacity at $1 \mu \mathrm{m}$ averaged over the globe is 34.7 (Haus et al. 2013). According to 
NIMS/Galileo observations the total opacity at 1.7 and $2.3 \mu \mathrm{m}$ ranges from 25 to 40 (Grinspoon et al. 1993). Satoh et al. (2009) used a small subset of VIRTIS/Venus Express data in the $1.74 \mu \mathrm{m}$ "window" to assess properties of the lower haze at $30-40 \mathrm{~km}$. They tentatively suggested that the lower haze has total opacity of $0.5-3$ and consists of very small particles. The total aerosol opacity is $30-50$.

Further indirect evidence that the cloud base descends by several kilometers towards the pole can be found in VeRa/Venus Express measurements of static stability (Tellmann et al. 2009; Limaye et al. 2018a). This parameter is quite sensitive to the presence of infrared opacity sources such as clouds. Zero stability is likely to indicate presence of dense clouds. VeRa radio occultation sounding suggested zero stability atmosphere extending down to $50 \pm 2 \mathrm{~km}$ at low and middle latitudes and about $5 \mathrm{~km}$ deeper at polar latitudes $\left(>70^{\circ}\right)$ thus indicating presence of dense clouds down to $\sim 45 \mathrm{~km}$ in the polar regions. Similarly, mapping the nightside near-IR emissions also indicated greater total cloud opacity in the polar region (see Fig. 20 in Sect. 3). More direct constraints on the cloud base altitude may eventually be obtained from the measurements of sulphuric acid vapour abundance at 40$60 \mathrm{~km}$ altitude by the radio occultation experiment VeRa/Venus Express (Oschlisniok et al. 2012).

\section{Cloud Morphology in 3-D}

Since extinction of the Venus atmosphere is strongly spectrally dependent, imaging of the planet at different wavelengths is a powerful tool to sound different altitudes and properties of the cloud layer. At visible wavelengths Venus appears as a bright featureless white disc due to high albedo uniformly across visible wavelength (Fig. 12, upper left). The cloud morphology is well pronounced if observed at a specific wavelength of the unknown UV absorber $(365 \mathrm{~nm})$ of which inhomogeneous distribution at the cloud top $(\sim 60 \mathrm{~km})$ is responsible for the pattern (Fig. 12, upper right). Thermal IR imaging gives access to the cloud top temperature and its variations that can reach 40-50 K (Fig. 12, lower right). Imaging in the narrow spectral transparency "windows" in the near-infrared range on the night side provides back illuminated view of the clouds (Fig. 12, lower left). This adds vertical dimension to the cloud morphology, since the patchy pattern observed at these wavelengths is created by opacity inhomogeneities in the deep cloud $(\sim 50 \mathrm{~km})$.

Venus Express observations from UV (Markiewicz et al. 2007, 2011) to thermal IR (Drossart et al. 2007; Piccioni et al. 2011) provided remarkable progress in understanding of the cloud morphology. The broad spectral coverage enabled sounding of the Venusian clouds from their tops to deep layers. The images revealed a great variety of features at different spatial and temporal scales, strong variability of the cloud patterns and unexpected correlations between the features seen at different altitudes. They also provided excellent material to characterize general circulation and dynamical properties of the Venus atmosphere within the cloud deck (Sánchez-Lavega et al. 2017). This section describes in detail the cloud morphology observed by Venus Express and reveals morphological relations between the images observed at different wavelengths.

Near-UV brightness contrasts that reach $20-30 \%$ are produced by inhomogeneous distribution of an unknown absorber mixed within the sulphuric acid aerosol in the upper cloud layer. Radiative transfer modelling by Haus et al. (2016) suggests that apparent changes in the near-UV albedo of $\sim 10 \%$ require more that $25 \%$ changes in total abundance of the absorber. The UV markings have been routinely used to study the cloud top morphology. Rossow et al. (1980) described basic types of the cloud features seen in the Pioneer Venus 
Fig. 12 Examples of Venus views at different wavelength: equatorial view from

MESSENGER flyby (upper left); mosaic composed of UV $(365 \mathrm{~nm})$ (gray) and near-IR $(1.7 \mu \mathrm{m})$ (red-black) images simultaneously taken by Venus Express in the middle and high latitudes of the Southern hemisphere (upper right); false colour equatorial view in the $2.3 \mu \mathrm{m}$ spectral transparency "window" by Galileo (lower left); false colour thermal IR $(11.5 \mu \mathrm{m})$ image of the Southern hemisphere by Pioneer Venus (lower right). (Credits NASA and ESA)

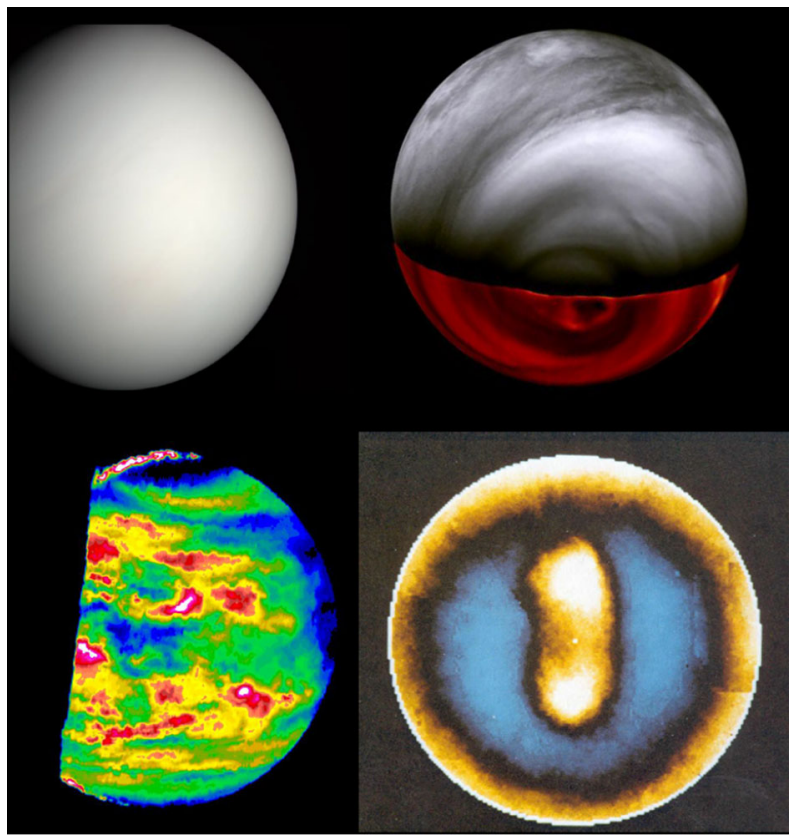

Orbiter Cloud Photopolarimeter (OCPP) images. Here we follow the earlier classification and introduce several new types of features documented by Venus Express.

Figure 13 shows examples of the Venus global views captured by the Venus Monitoring Camera (VMC)/Venus Express (Titov et al. 2012) and UVI/Akatsuki camera (Yamazaki et al. 2018). The VMC filter was centred at $0.365 \mu \mathrm{m}$, in the spectral band of the unknown UV absorber. The Akatsuki camera took images at both $0.365 \mu \mathrm{m}$ and $0.283 \mu \mathrm{m}$, the latter centred on the absorption features of $\mathrm{SO}_{2}$. Despite the large-scale similarity of morphology patterns in two filters, there are certain differences in details (Limaye et al. 2018b). The radiance at $0.283 \mu \mathrm{m}$ is about ten times smaller than that measured at $0.365 \mu \mathrm{m}$. The $0.365 \mu \mathrm{m}$ image shows more contrast and a bright area in the equatorial region near the image centre. This trend is the opposite to what was observed by OCPP/Pioneer Venus. Small-scale details in $0.283 \mu \mathrm{m}$ images are muted or absent. Quantitative analysis of colocated $0.283 \mu \mathrm{m}$ and $0.365 \mu \mathrm{m}$ (near) simultaneous images shows the correlation of brightness values at the two wavelengths to be variable and part of the variation appears to be latitude dependent, similar to what was found with Galileo and MESSENGER data at other wavelengths. The UVI/Akatsuki show many features previously observed with contrasts decreasing near the terminators.

Preliminary analysis of the IR $(0.9 \mu \mathrm{m})$ images of the day side revealed low-contrast features whose appearance is quite different from that seen in UV (Limaye et al. 2018b) that indicate variations of opacity on the deep cloud. The IR2 camera images taken at $2.02 \mu \mathrm{m}$, the wavelength at which $\mathrm{CO}_{2}$ absorption becomes significant, indicated brightness decrease towards the poles that can be explained by deeper cloud top (Fig. 7, Ignatiev et al. 2009).

Figure 13 (lower panel) and Fig. 14 show equatorial views of the planet that clearly reveals the global "V" dark feature frequently observed by ground-based telescopes, Pioneer Venus (Rossow et al. 1980) as well as during Galileo flyby. The figure emphasizes the relation of the cloud pattern to latitude and local solar time. The morning sector is usually covered with bright haze even in low latitudes. At the equator it takes zonal wind one Earth 

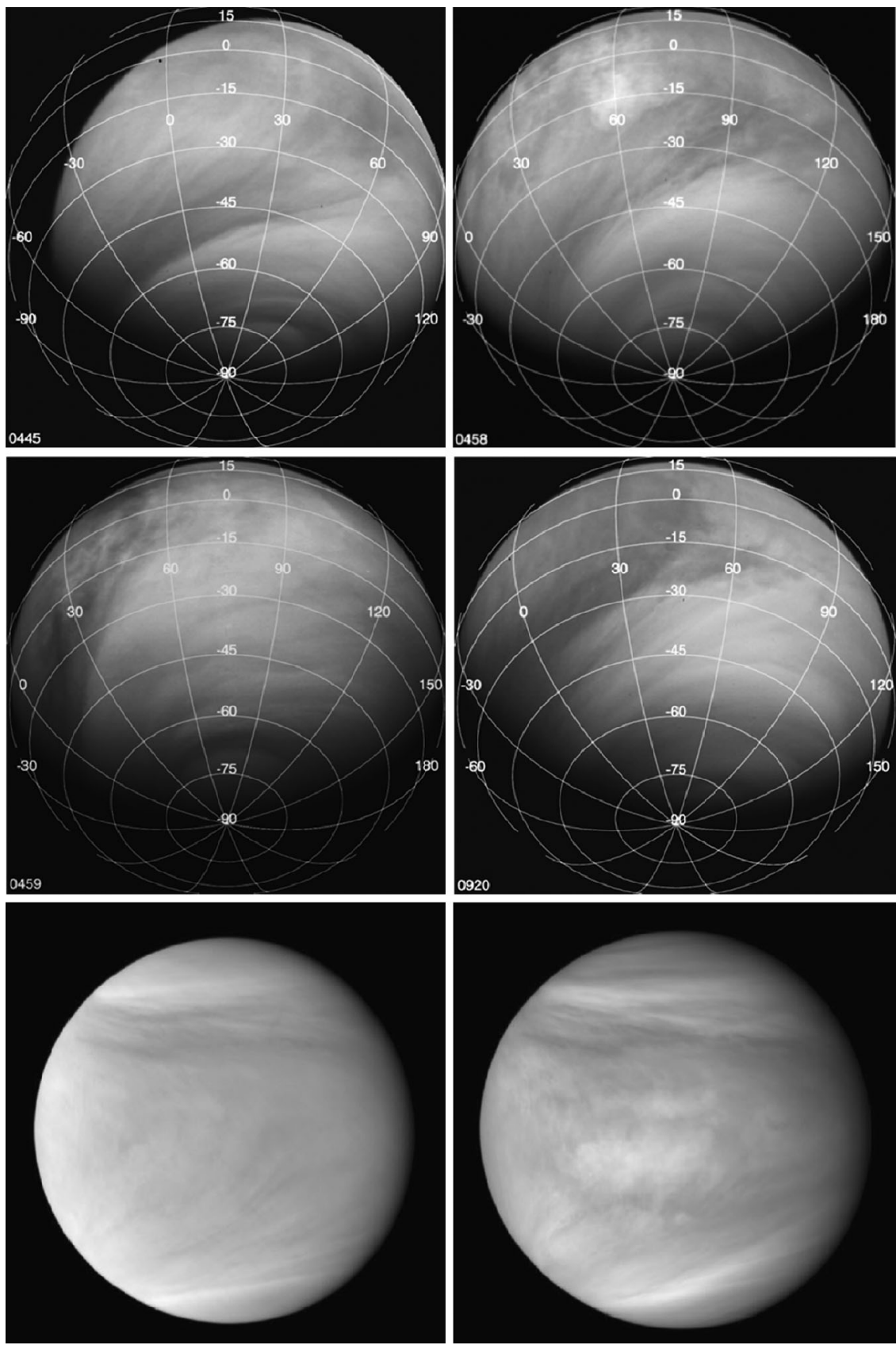

Fig. 13 Global views of Venus. Upper and middle panels: VMC UV (365 nm) images taken from a distance of about 30,000 km with the sub-spacecraft point approximately in the middle latitudes of the Southern hemisphere (Titov et al. 2012). The spatial resolution is about $25 \mathrm{~km} / \mathrm{px}$. The Southern pole is on the bottom of the images. The atmosphere superrotates in the counter-clockwise direction (from right to left). Orbit numbers are given at the bottom left of each image. The Venus Express orbital period was one Earth day. Lower panel: examples of UVI/Akatsuki images in $0.283 \mu \mathrm{m}$ (left) and $0.365 \mu \mathrm{m}$ (right) filters (Yamazaki et al. 2018). North is at the top of the images 


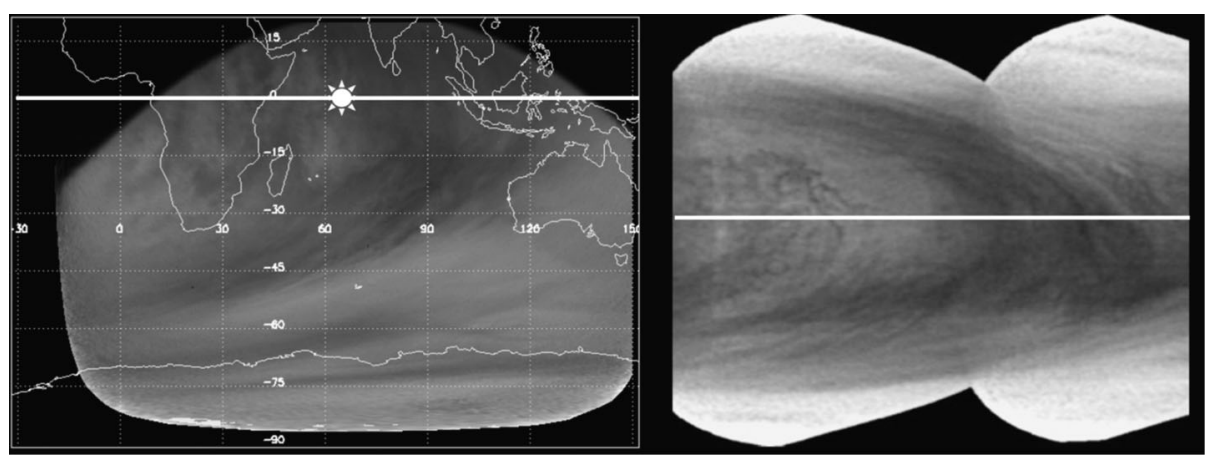

Fig. 14 Dark "V" feature in the Venus UV images in a simple cylindrical projection: VMC/Venus Express (left) (Titov et al. 2012) and SSI/Galileo (right) (Belton et al. 1991). The "sun" symbol in the left image marks the sub-solar point. The atmosphere super-rotates from right (morning) to left (evening). Thick white line shows the equator. Contours of the Earth's continents are overplotted on the left image to illustrate location and scale of the Venus global cloud features

day to bring air parcels to the sub-solar point. In the late morning the cloud tops become darker suggesting that either dark material is brought from the depths of the cloud layer or that the upper haze is destroyed (evaporated) by solar heating. Global streaks that extend from the equator in the south-east direction usually form a sharp boundary between bright high-latitudes and dark tropics. This boundary frames the afternoon convective region filled with patchy clouds. The global cloud pattern suggests that the sub-solar point is some sort of an "obstacle" for the flow deviating from purely zonal motion, the analogy also noticed by Belton et al. (1976).

Venus low and middle latitudes $\left(<50^{\circ} \mathrm{S}\right)$ are generally darker than the high latitudes (Figs. 13, 14). The dark equatorial band is often present in the Venus tropics. Sometimes the brightness minimum is displaced to the middle latitudes forming dark mid-latitude bands separating slightly brighter equatorial region (circum-equatorial belt) and very bright high latitudes. Mottled and patchy cloud patterns ubiquitously present at low latitudes suggest significant role of convection and turbulence here (Titov et al. 2008), as prominently observed by Mariner-10 (Belton et al. 1976), Pioneer Venus (Rossow et al. 1980) and Galileo (Hueso and Sánchez-Lavega 2007). In the middle latitudes, the mottled clouds give way to streaky features (bright streamers), indicating a transition to quasi-laminar flow at $\sim 50^{\circ} \mathrm{S}$.

The high latitudes are dominated by bright almost featureless cloud (bright polar band), suggesting presence of a large amount of conservatively scattering aerosol that masks the UV absorbers hidden in the cloud depth. Sometimes the boundary between the dark and the bright regions is displaced to as low as $30^{\circ} \mathrm{S}$. The regions poleward from $70^{\circ} \mathrm{S}$ are generally slightly darker than the middle latitudes. They form a "polar cap" earlier observed by Pioneer Venus at slant angles. Very often a narrow (few hundreds of kilometres) dark circle appears at about $70^{\circ} \mathrm{S}$ (Figs. 13, 17). All aspects of the planet's appearance, including its brightness, contrasts, and morphological pattern show strong variability on the time scale of few days.

Figure 15 provides examples of a closer look at Venus low latitudes and shows the cloud morphology in the Southern "tropics". They cover low and middle latitudes from about equator to the edge of the mid-latitude bright band $\left(\sim 50^{\circ} \mathrm{S}\right)$. The bright "lace" veil on top of a darker cloud that extends to $\sim 30^{\circ} \mathrm{S}$ is frequently present here. The images also show bow shape waves in much more detail than documented by Pioneer-Venus (Rossow et al. 1980). The image taken in orbit 722 (Fig. 15) shows a pronounced afternoon convective 

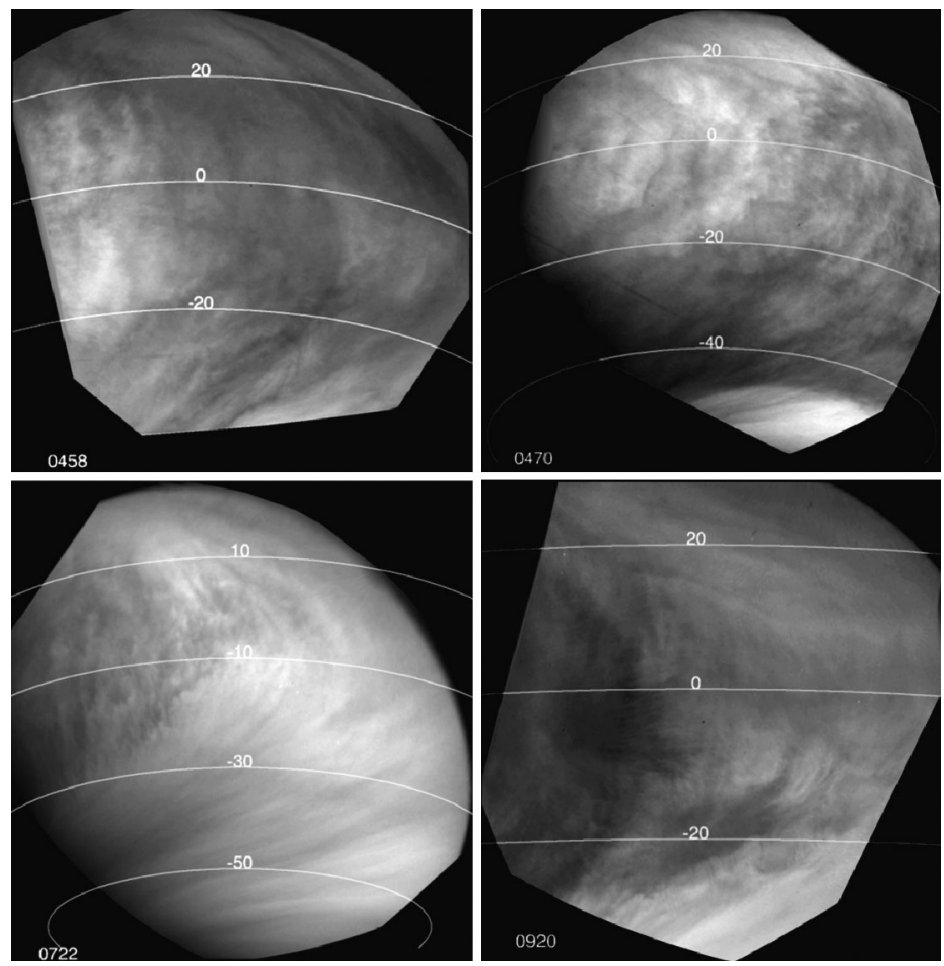

Fig. 15 UV images of the Venus "tropics" captured by VMC/VEX from a distance of 10000-15000 km with spatial resolution of $10-15 \mathrm{~km} / \mathrm{px}$ (Titov et al. 2012). Lines and numbers mark latitudes. Image centres are close to the local noon. Orbit numbers are given in the bottom left

wake featuring well-developed turbulence downstream of the sub-solar point. The image from orbit 920 shows the sub-solar point dominated by dark clouds with small wind streaks suggesting flow diverging from the sub-solar point.

Mesoscale images in Fig. 16 zoom in on the transition to the bright mid-latitude band. The remarkable change usually occurs at $50^{\circ}-60^{\circ} \mathrm{S}$ (Fig. 13) and occupies about $1000 \mathrm{~km}$ $\left(\sim 10^{\circ}\right.$ latitude). The region is characterised by drastic change from mottled to streaky cloud morphology. This trend in the global cloud pattern implies that convection vanishes poleward of $\sim 50^{\circ} \mathrm{S}$ that is consistent with the convectively stable temperature structure in the "cold collar" region (Limaye et al. 2018a). Thin cloud streaks, thousands of kilometres long, are typical for this zone, implying that quasi-laminar flow completely dominates over turbulent mixing. The streaks are tilted with respect to the latitude circles (see also Fig. 14) indicating a relation between zonal and meridional wind components. As pointed out by Schinder et al. (1990) they could be formed by a dominant zonal motion combined with a poleward advection and shearing of the clouds by the winds with possible action of a superimposed wave. The ratio of the mean meridional and zonal wind components can be assessed from the streaks' slope (Fig. 14) and is in agreement with zonal and meridional wind velocities of approximately $100 \mathrm{~m} / \mathrm{s}$ and $15 \mathrm{~m} / \mathrm{s}$ derived from the cloud tracking (Sánchez-Lavega et al. 2017).

The long streaks with sharp brightness contrasts in the transition region suggest a strong jet stream flowing along the equatorward edge of the bright mid-latitude band. The position 

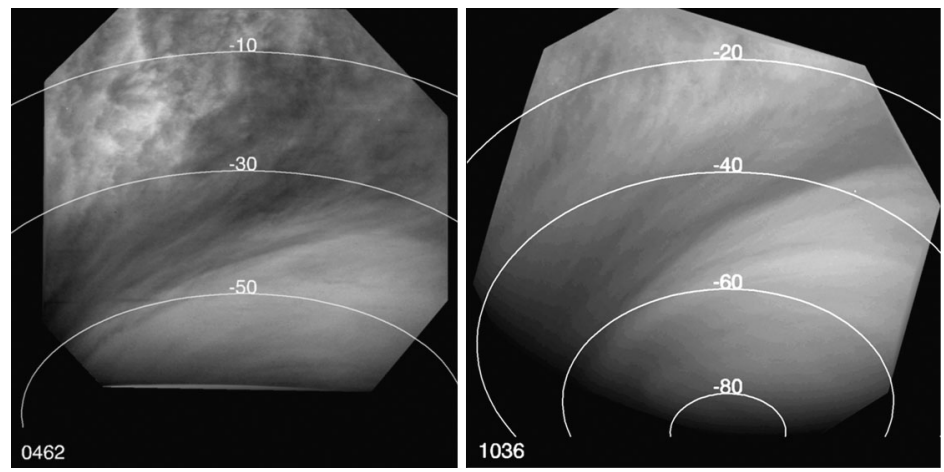

Fig. $16 \mathrm{UV}$ images of the mid-latitude transition region taken by VMC/VEX from a distance of $10000-15000 \mathrm{~km}$ with resolution of 10-15 km/px (Titov et al. 2012). The South pole is on the bottom. Orbit numbers are given in the lower left of each image
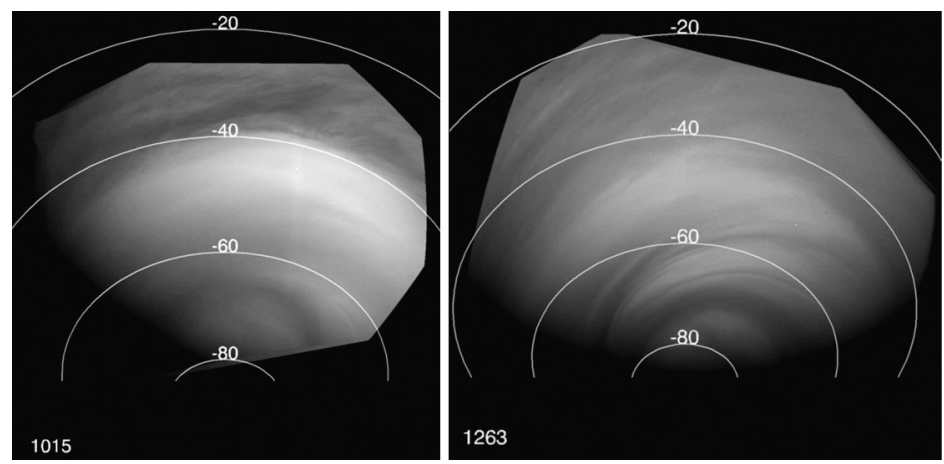

Fig. 17 UV images of the Southern polar region from a distance of about $15000 \mathrm{~km}$ and spatial resolution of $\sim 10 \mathrm{~km} / \mathrm{px}$ (Titov et al. 2012). The pole is in the bottom. Orbit numbers are given in the bottom left of each image

of this morphological feature is roughly consistent with the mid-latitude jet observed in the zonal wind field derived from the cloud tracking (Khatuntsev et al. 2013) and calculated from the temperature field in cyclostrophic approximation (Piccialli et al. 2011). The jet roughly follows the equatorial edge of the "cold collar" region (Limaye et al. 2018a).

Figure 17 shows examples of polar images. Poleward of $50-60^{\circ} \mathrm{S}$ the clouds become very bright and uniform, suggesting that the UV absorbers are either absent here or more likely hidden deep below the cloud top overlaid by a thick sulphuric acid hood. This may be due to suppression of the convection that brings absorbers from the deep cloud (Titov et al. 2008). In the periods of reduced polar hood the polar region is often crossed by thin dark circular or spiral "grooves" that are a few hundred kilometres wide and are likely created by local jets. The most frequently observed feature is the dark polar oval located at $\sim 70^{\circ} \mathrm{S}$ (Fig. 17). This almost axisymmetric structure sometimes disappears and dark features in the "polar cap" are distributed chaotically (see Titov et al. 2012). Appearance of the "polar cap" strongly varies. For instance, in orbit 1015 (Fig. 17) the polar hood was very thick, uniform and extended to $40^{\circ} \mathrm{S}$, while in orbit 1259 the darker main cloud deck is clearly visible.

Close-up images of the Northern hemisphere reveal many features indicating convective activity, turbulence and waves at the cloud tops (Fig. 18). At a spatial resolution of few kilo- 
Fig. 18 Small scale features at the Venus cloud top: UV images of the low latitudes (upper panel and lower left image) and near IR image (lower right) taken from a distance of 3000-5000 km with spatial resolution of few kilometres per pixel (Titov et al. 2012). White bars in the lower right of each image show the scale distance of $200 \mathrm{~km}$. Orbit numbers are given at the bottom left of each image

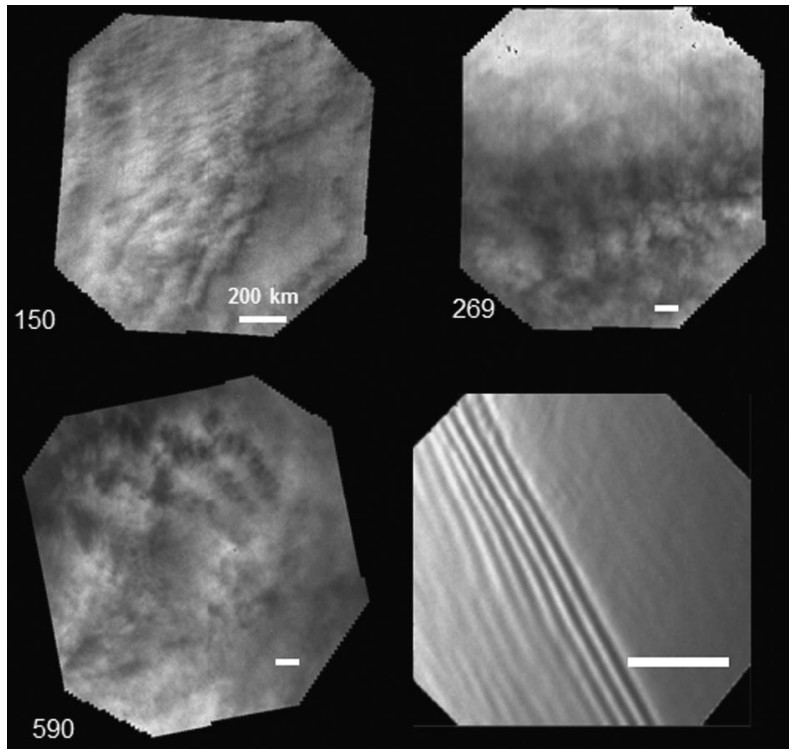

metres the cloud top has patchy morphology with dark spots and "valleys" a few tens of kilometres in size (orbits 269, 590). The dark material appears to be hidden in the depths of the cloud and becomes visible through openings in the upper cloud. The mottled clouds form convective cells with typical size of 100-200 km and "wave trains" with similar wavelength (orbit 269). In some cases they resemble Earth cumulus cloud columns a few tens of kilometres across (orbits 150, 590). These clouds show signs of lateral advection indicating strong wind shear at the visible cloud tops (orbit 150) as originally suggested by Crisp and Young (1978).

At high latitudes $\left(>60^{\circ} \mathrm{N}\right)$ three types of waves: long straight features, short wave trains, and irregular wave fields - are often observed. The long waves (bottom right in Fig. 18) have wavelengths of a few tens of kilometres and extend for a few hundred kilometres. Short waves form compact "trains" several tens of kilometres wide with typical wavelengths of 3-7 km. The trains often originate at the fronts of long features and seem to be genetically related to them. Irregular wave fields consist of chaotically distributed features with a size of several kilometres. Such irregular wave fields often overlap with short regular waves. Interestingly, the waves are seen in all VMC channels, suggesting that their origin is not related to inhomogeneities in the near-UV absorbers distribution, but they are rather produced by variations in haze opacity or, more likely, changes in the solar illumination angle across the wave (Piccialli et al. 2014; Sánchez-Lavega et al. 2017). We note that the cloud tops in the VMC images at $0.965 \mu \mathrm{m}$ is located at $61-67 \mathrm{~km}$ close to that in UV and near-IR $(1.5 \mu \mathrm{m})$ (see Sect. 2 and Fig. 6).

The observed global cloud pattern strongly supports the idea of a planet scale vortex circulation first discovered by UV imaging (Suomi and Limaye 1978).

VIRTIS/Venus Express observations in the thermal IR range $(3-5 \mu \mathrm{m})$ (Piccioni et al. 2007) significantly contributed to our understanding of the polar cloud morphology and dynamics by providing details that complement the Pioneer Venus observations (Taylor et al. 1980). The most remarkable feature observed by Venus Express "in action" is the polar eye of the planetary vortex. Figure 19 shows examples of its view at $5 \mu \mathrm{m}$. 

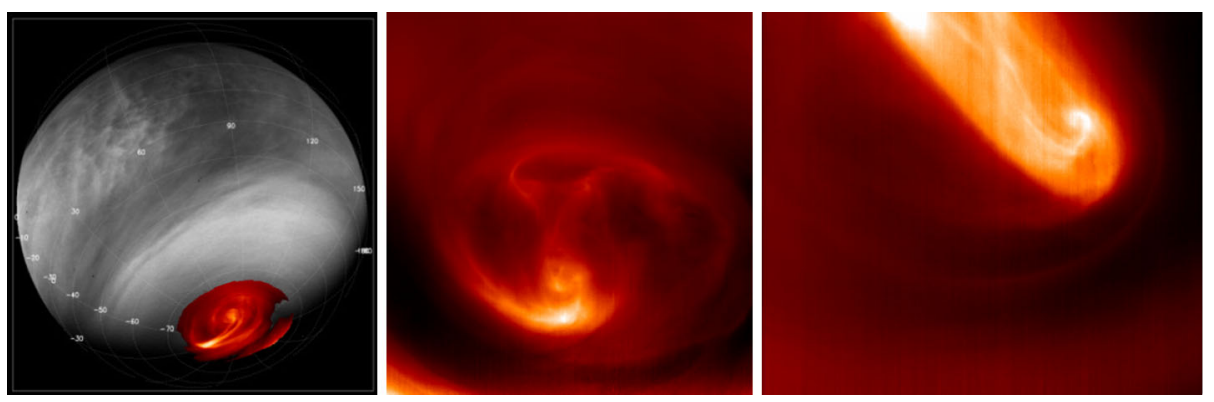

Fig. 19 Morphology of the "eye" of the planetary vortex: left—sketch of the vortex "eye" (red) overplotted on top of a VMC UV image (grey), middle and right—original images of the polar "eye" taken at $5 \mu \mathrm{m}$. The colour approximately represents the cloud top temperature

The brightness pattern at thermal IR wavelengths reveals spatial variations of the cloud top temperature. The polar "eye" is usually confined within $\sim 70^{\circ} \mathrm{S}$ latitude circle thus having the size of few thousands of kilometres. It is located within the dark polar oval in the UV images (Figs. 12, 17; Titov et al. 2008). The spiral arms of the IR features are often connected to the dark oval. In some cases the vortex eye or its spiral arms have counterparts in the simultaneously captured UV images. All of this suggests that the UV and thermal IR features observed at the pole are both manifestation of the same dynamical processes in the polar atmosphere and that the global UV pattern is likely to be created by the temperature and dynamical conditions at the cloud tops (Titov et al. 2008). The polar "eye" has a very variable appearance spanning from a simple oval to complex multi-pole structures (Fig. 19). It has remarkable morphological similarities to Earth's tropical cyclones and hurricanes, with vivid dynamics. Limaye et al. (2009) succeeded to simulate the "eye" morphology with an idealized nonlinear and non-divergent barotropic model and found similar structures in the modelled vorticity field. Luz et al. (2011) showed that the centre of rotation of the polar "eye" is displaced from the South pole by typically $\sim 3$ degrees of latitude and drifts around the pole.

One of the first major results from the LIR/Akatsuki camera was discovery of a bright band aligned almost north-south with a slight curvature which has been interpreted as a standing gravity wave triggered by surface topography (Fukuhara et al. 2017; Navarro et al. 2018; Limaye et al. 2018b). The feature had brightness temperature contrast of $\sim 5 \mathrm{~K}$ and lasted as long as $2-3$ weeks. Surprisingly, the signature of the standing wave can also be detected in UVI and IR2 $(2.02 \mu \mathrm{m})$ dayside images (Satoh et al. 2017). The detection at $2.02 \mu \mathrm{m}$ suggests that cloud-top variations likely occur due to the wave. However the stationary wave has not yet been detected either in $0.9-\mu \mathrm{m}$ daytime IR1/Akatsuki images, or MDIS/MESSENGER images or VIRTIS/Venus Express data that could probably indicate transient nature of the wave. Observations in the near-IR transparency "windows" on the night side enabled sounding of the deep cloud morphology that is not visible from orbit at other wavelengths. In this case the cloud layer is illuminated from below by thermal emission from the hot surface and the lower atmosphere. The features revealed by these images are produced by the cloud opacity variations occurring mainly in the middle and lower cloud layers $(50-60 \mathrm{~km})$. Figure 12 (lower left) shows equatorial view of Venus in the $2.3 \mu \mathrm{m}$ "window" captured by NIMS/Galileo (Carlson et al. 1993). This image reveals patchy morphology of the deep cloud at low latitudes. Recently IR2 camera onboard the Akatsuki spacecraft (Satoh et al. 2017) captured views of the planet night side in the nearIR spectral "windows" revealing morphology of the deep cloud (Fig. 20) (Limaye et al. 

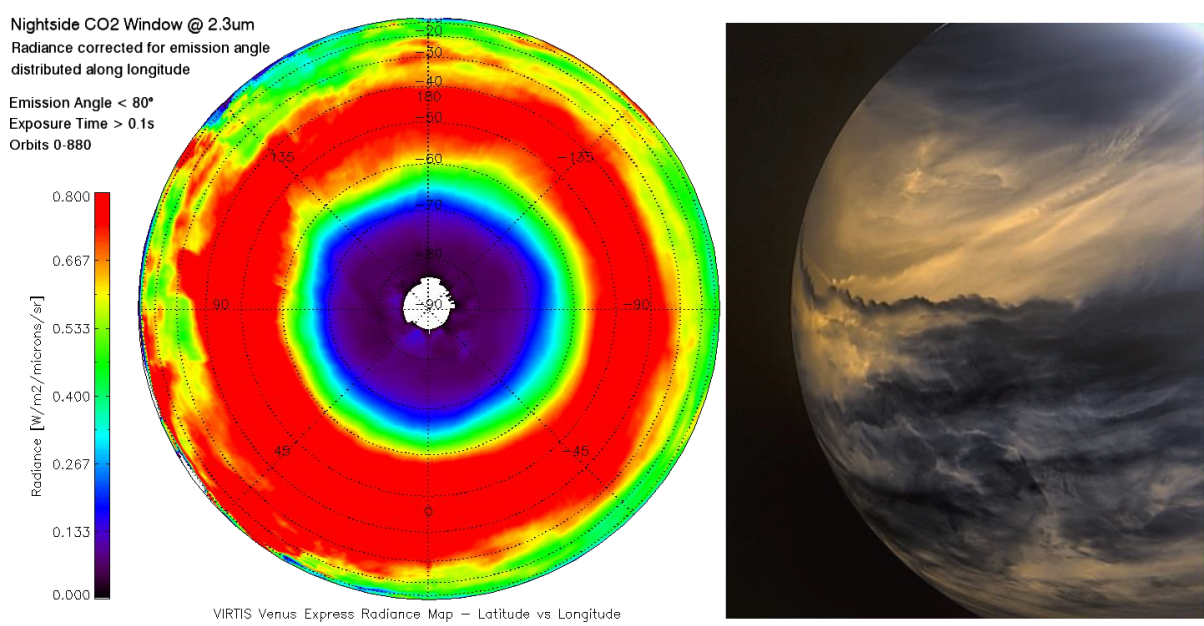

Fig. 20 Observations of the deep cloud morphology in the $2.3 \mu \mathrm{m}$ "window on the night side: left-averaged radiation field from VIRTIS/VEX (Cardesín-Moinelo et al. 2010). South pole is in the middle; right-false colour equatorial view by IR2/Akatsuki camera (credit JAXA/ISAS/DARTS/Damia Bouic)

2018b). The low latitudes are full of small- and large-scale features: waves, mushroomshaped mesoscale vortices, long linear streaks, sharp-contrast fronts etc. Some images show high-contrast sharp linear boundaries running roughly north-south that can be explained by strong opacity variations in adjacent air masses echoing the results Vega balloon (Lorenz et al. 2018). However, the origin of different air masses is still an open question. The cloud morphology in high latitudes is smoother and streaky resembling that of the cloud tops seen in UV (Figs. 13-17). The nightside images suggest that dynamics plays significant role in their formation. Moreover, they might indicate a mixture of unknown dynamics as well as compositional differences that must be responsible for the differences in the appearance of the features.

The polar view of the planet (Fig. 20) at the same wavelength indicates that the emission reaching space from the lower atmosphere reaches its maximum in the middle latitudes $\left(40-60^{\circ} \mathrm{S}\right)$. The emission slightly decreases towards the equator that could be due to higher observation angle. The emission abruptly drops poleward of $\sim 60^{\circ}$ latitude (CardesínMoinelo et al. 2010). This feature can be explained either by supposing that the cloud opacity at $1 \mu \mathrm{m}$ increases by a factor of 2-3 reaching values of 60-90 in the polar regions or that the cloud composition in the polar region differs from sulphuric acid. There are also evidences of anomalously large particles present in the deep cloud in the polar regions (Wilson et al. 2008; Barstow et al. 2011).

The latitude of the emission abrupt drop coincides with the "cold collar" region with the coldest temperature at the cloud top (Limaye et al. 2018a) and is located at the poleward side of the midlatitude jet (Sánchez-Lavega et al. 2017). Figure 20 suggests that the cloud properties in the polar and middle latitudes are quite different with a sharp separation at $60^{\circ} \mathrm{S}$ and suppressed material exchange between the regions. Analogous transport "barriers" were observed on other planets resulting in strong composition gradients in the stratospheres of Titan (Teanby et al. 2008) and Earth (polar ozone "hole"). Such mixing "barriers" are associated with regions of maximum gradient of potential vorticity that seems to be true also for Venus (Sánchez-Lavega et al. 2017). 

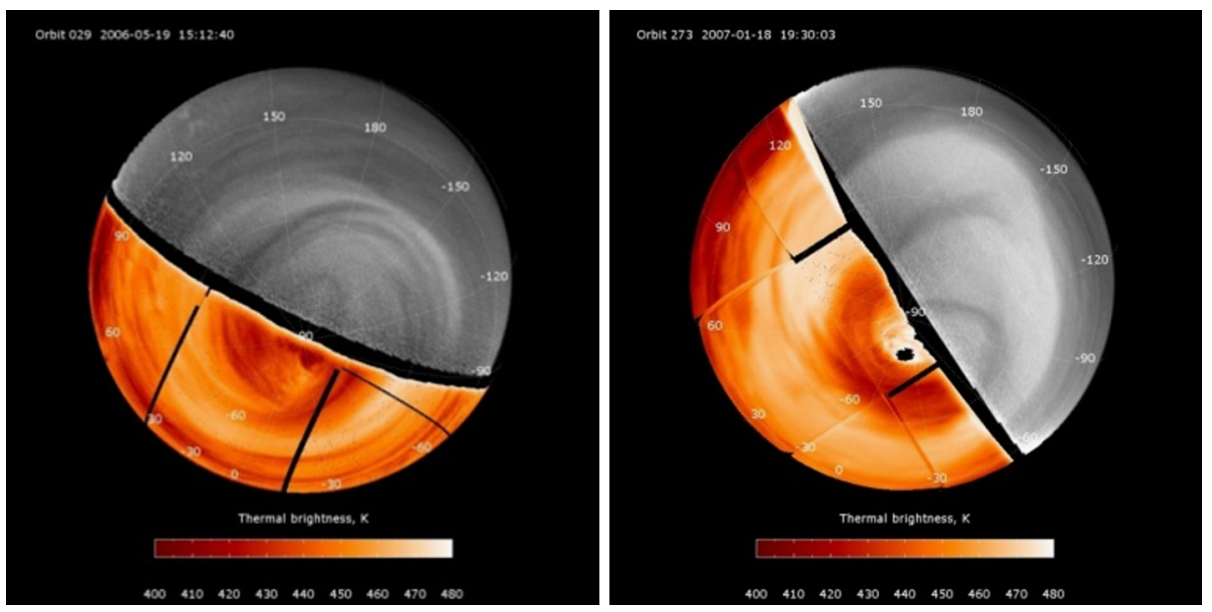

Fig. 21 Correlation of the global morphology patterns in the upper cloud (grey UV images) and in the deep cloud (red-orange images at $1.7 \mu \mathrm{m}$ on the night side)

Simultaneous Venus Express observations in UV and near-IR transparency "window" on the night side (Fig. 21) show remarkable correlation of the global cloud morphology at the cloud tops and in the middle cloud.

\section{Microphysical Properties of the Cloud Population}

The upper haze was known to be composed of submicron aerosol particles with an effective radius of about $0.25-0.29 \mu \mathrm{m}$, also present within the clouds. The refractive index of $1.435-1.45$ at $0.55 \mu \mathrm{m}$ is in agreement with sulphuric acid composition of the haze particles (Hansen and Hovenier 1974; Kawabata et al. 1980; Krasnopolsky 1983; Sato et al. 1996; Braak et al. 2002). The progress in this field achieved after publication of the Venus and Venus-II books (Esposito et al. 1983, 1997) is mainly due to remote sensing observations. Properties of the upper haze and upper cloud were revealed by solar occultation. Deep atmospheric sounding in the near-IR transparency "windows" provided important insights in the microphysics of the middle and lower cloud.

Microphysical properties of the mesospheric haze were inferred from the solar occultation in UV through the near-IR spectral range performed by SPICAV-SOIR onboard Venus Express. Wilquet et al. (2009) derived the wavelength dependence of aerosol extinction related to the effective radius and composition of the particles (Fig. 22). Comparison of the spectral dependence of extinction coefficient derived from the measurements to that calculated for mode 1 aerosol distribution (Table 1) suggests that either the assumption on the upper haze sulphuric acid composition or size distribution need to be revisited. The study demonstrated for the first time existence in some cases of at least two types of particles: submicron haze with $r=0.1-0.3 \mu \mathrm{m}$ and larger particles with $r=0.4-1 \mu \mathrm{m}$. Therefore, the model describing the upper haze on Venus should include a bimodal population (Wilquet et al. 2009).

Luginin et al. (2016) analysed about 200 solar occultations obtained by SPICAV-IR onboard Venus Express. A bimodal distribution was found to be typical for 75-85 km altitude range while unimodal particle population dominates at 70-75 km and above $85 \mathrm{~km}$. Table 2 
Fig. 22 Spectral dependence of aerosol extinction derived from SPICAV-SOIR spectra (brown line and circles) and normalized extinction calculated from the Mie theory assuming $75 \%$ $\mathrm{H}_{2} \mathrm{SO}_{4}$ aerosols and a unimodal log-normal size distribution with $r_{\text {eff }}=0.3 \mu \mathrm{m}$ and $\nu_{\text {eff }}=0.18$ (cyan solid line)

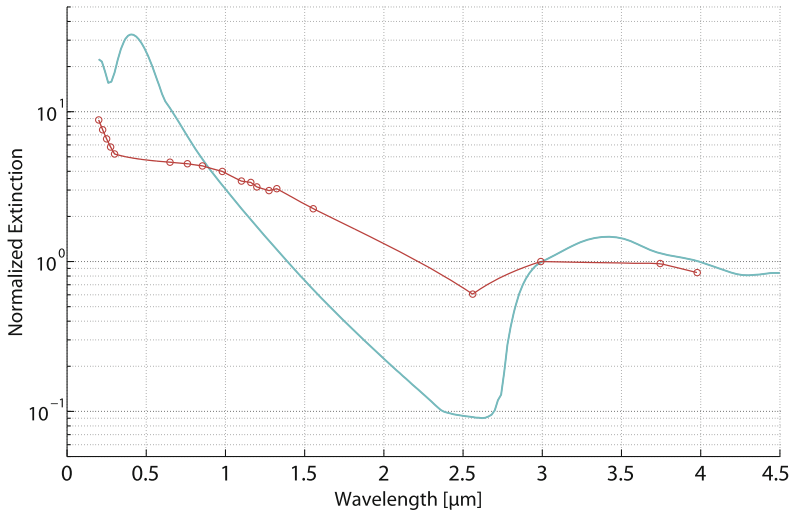

Table 2 Latitudinal variation of the mean effective radius. $R_{\text {eff }}$ corresponds to the unimodal distribution; $r_{\text {eff } 1}$ and $r_{\text {eff } 2}$ correspond to modes 1 and 2 of the bimodal case

\begin{tabular}{|c|c|c|c|c|c|c|}
\hline \multirow[t]{2}{*}{ Altitude, $\mathrm{km}$} & \multicolumn{3}{|l|}{$60^{\circ} \mathrm{S}-60^{\circ} \mathrm{N}$} & \multicolumn{3}{|l|}{$60^{\circ} \mathrm{N}-90^{\circ} \mathrm{N}$} \\
\hline & $R_{\mathrm{eff}}, \mu \mathrm{m}$ & $r_{\mathrm{eff} 1}, \mu \mathrm{m}$ & $r_{\mathrm{eff} 2}, \mu \mathrm{m}$ & $R_{\mathrm{eff}}, \mu \mathrm{m}$ & $r_{\mathrm{eff} 1}, \mu \mathrm{m}$ & $r_{\mathrm{eff} 2}, \mu \mathrm{m}$ \\
\hline$>85$ & $0.42 \pm 0.14$ & $0.12 \pm 0.02$ & $0.78 \pm 0.12$ & $0.30 \pm 0.14$ & $0.12 \pm 0.05$ & $0.81 \pm 0.08$ \\
\hline $80-85$ & $0.75 \pm 0.09$ & $0.12 \pm 0.02$ & $0.82 \pm 0.07$ & $0.32 \pm 0.15$ & $0.13 \pm 0.03$ & $0.81 \pm 0.11$ \\
\hline $75-80$ & $0.79 \pm 0.06$ & $0.11 \pm 0.03$ & $0.89 \pm 0.08$ & $0.47 \pm 0.20$ & $0.12 \pm 0.04$ & $0.82 \pm 0.12$ \\
\hline $70-75$ & $0.77 \pm 0.07$ & $0.13 \pm 0.03$ & $0.97 \pm 0.17$ & $0.59 \pm 0.18$ & $0.11 \pm 0.07$ & $0.82 \pm 0.12$ \\
\hline
\end{tabular}

summarises the results. For the unimodal size distribution, the effective radius is larger in the middle and equatorial latitudes than that observed near the North Pole. No statistically significant differences were found in the size distribution between morning and evening. Figure 23 shows variability of the retrieved size distribution over the mission. When a unimodal size distribution is sufficient to reproduce the aerosol extinction, the effective radius $\left(r_{\text {eff }}\right)$ varies greatly between $0.2 \mu \mathrm{m}$ and $1.0 \mu \mathrm{m}$, while for the bimodal distribution the ranges of values for $r_{\mathrm{eff} 1}$ and $r_{\mathrm{eff} 2}$ are much smaller.

Luginin et al. (2016) derived particle number density profiles for modes 1 and 2 as shown in Fig. 24. The population of both modes gradually decreases with altitude from $\sim 500 \mathrm{~cm}^{-3}$ at $75 \mathrm{~km}$ to $\sim 50 \mathrm{~cm}^{-3}$ at $90 \mathrm{~km}$ for mode 1 , and from $\sim 1 \mathrm{~cm}^{-3}$ at $75 \mathrm{~km}$ to $\sim 0.1 \mathrm{~cm}^{-3}$ at $90 \mathrm{~km}$ for mode 2 . The ratio between mode 1 and 2 number densities is $\sim 500$ and does not change with altitude. The mean parameters of mode 1 agree with the haze properties summarized in the first edition of the Venus book (Esposito et al. 1983) wherein the number density at $70-90 \mathrm{~km}$ is $\sim 500 \mathrm{~cm}^{-3}$. The most significant difference with earlier investigations is detection of larger particles $(r>0.2 \mu \mathrm{m})$ ubiquitously present at $80-90 \mathrm{~km}$.

Limb imaging in thermal IR range by VIRTIS/VEX confirmed the presence of micron size sulphuric acid particles in the upper haze. de Kok et al. (2011) analysed nightside spectra at 4.5-5.0 $\mu \mathrm{m}$ of the Venus limb. Assuming log-normal size distribution and $75 \% \mathrm{H}_{2} \mathrm{SO}_{4}$ particle composition the authors retrieved vertical profiles of $1 \mu \mathrm{m}$-sized mode 2 particles. The number density monotonically decreased with height demonstrating higher variability at middle latitudes than at low latitudes. These results are in general agreement with those derived from the solar occultation by SPICAV-IR and SOIR at high northern latitudes (Wilquet et al. 2009). These works are therefore complementary in terms of local solar time 

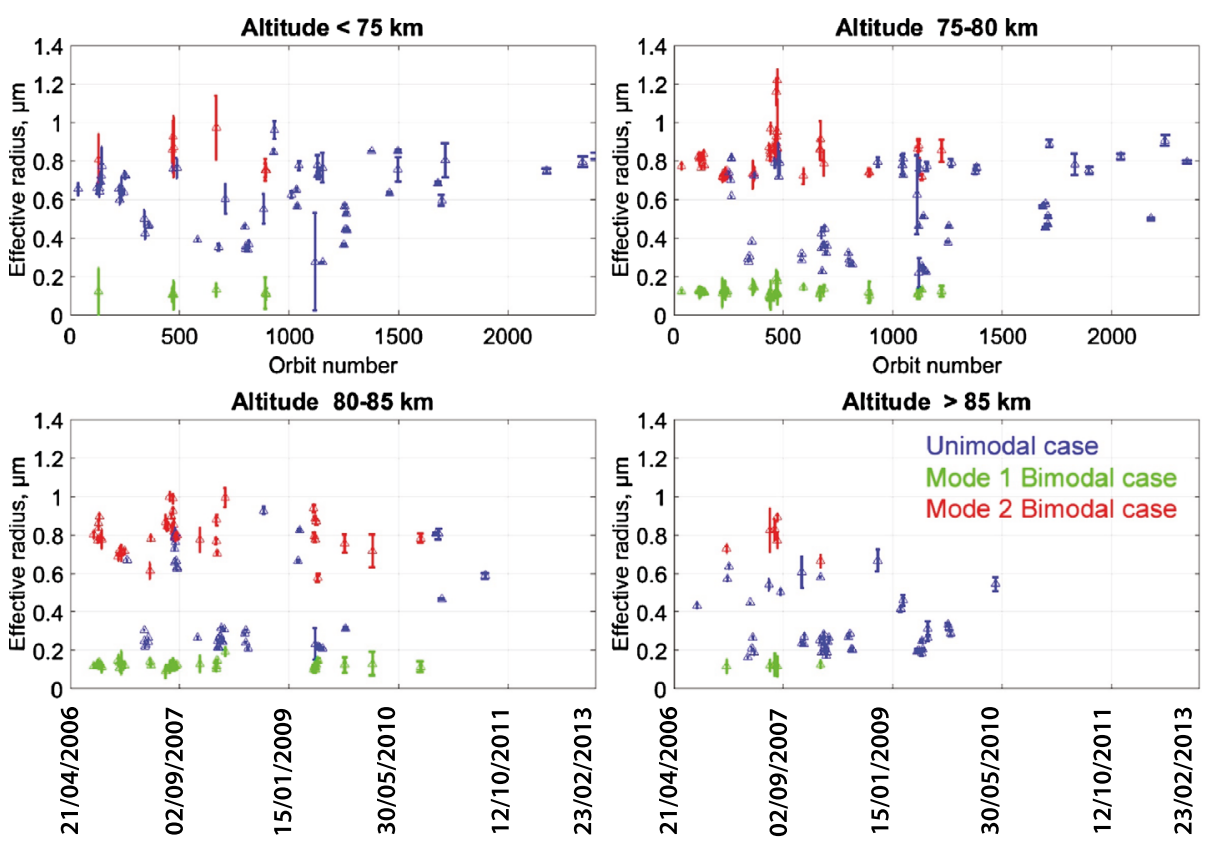

Fig. 23 The retrieved mean effective radius for four altitude ranges over the mission. Each occultation measurement is averaged within the altitude bin. Green and red symbols correspond to mode 1 and mode 2 of the bimodal distribution. The blue symbols represent unimodal distribution. Big crosses show mean values. The $x$-axis is the orbit number for the upper panels and the corresponding date for the bottom panels of the figure (Luginin et al. 2016)

(nightside vs terminator) and latitudes (equatorial and middle vs. polar latitudes). They also suggest that the transition between the upper cloud and overlaying haze is less abrupt than was previously thought.

Imaging at varying phase angle enabled sounding of both mesospheric haze and the cloud top properties. Markiewicz et al. (2014) discovered a glory in the VMC/VEX observations of the planet at small phase angles in three wavelengths of $0.365 \mu \mathrm{m}, 0.513 \mu \mathrm{m}$ and $0.965 \mu \mathrm{m}$. Glory is an optical phenomenon that poses stringent constraints on the cloud properties. The very fact that the glory was observed implies that the scattering medium is rather homogeneous and consists of spherical particles with narrow size distribution. From the angular position of the glory features Petrova et al. (2015) and Markiewicz et al. (2018) estimated particle effective radius $r_{\text {eff }}=1.0-1.4 \mu \mathrm{m}$ for different regions of the cloud deck that corresponds to the mode 2 of the particle size distribution. Interestingly, some features of the glory implied a real part of the refractive index higher than that of concentrated sulphuric acid. The authors suggested this material to be ferric chloride or sulphur, both of which are candidates for the unknown UV-blue absorber in the upper cloud layer of Venus. The change of the glory maximum position in the UV phase curve indicated decrease of the particle size from $1.05 \mu \mathrm{m}$ to $0.8-0.9 \mu \mathrm{m}$ with latitude $\left(40^{\circ} \mathrm{S}-60^{\circ} \mathrm{S}\right)$ before local noon. Shalygina et al. (2015) analysed the full set of VMC observation at $965 \mathrm{~nm}$. The results showed temporal and spatial variations of the cloud properties. In general, the particles at low latitudes were larger than those in the southern polar regions $\left(r_{\text {eff }}=1.2-1.4 \mu \mathrm{m} v s .0 .9-1.05 \mu \mathrm{m}\right)$. At $40^{\circ} \mathrm{S}-60^{\circ} \mathrm{S}$ the refractive index was usually smaller than that in the other regions (1.44-1.45 vs. $1.45-1.47)$. Small submicron $\left(r_{\text {eff }} \sim 0.23 \mu \mathrm{m}\right)$ particles are detected mostly in the morn- 
Fig. 24 Mean profiles of the particle number density based on the analysis of SPICAV-IR/VEX solar occultation (Luginin et al. 2016) for mode 1 (green) and mode 2 (red)

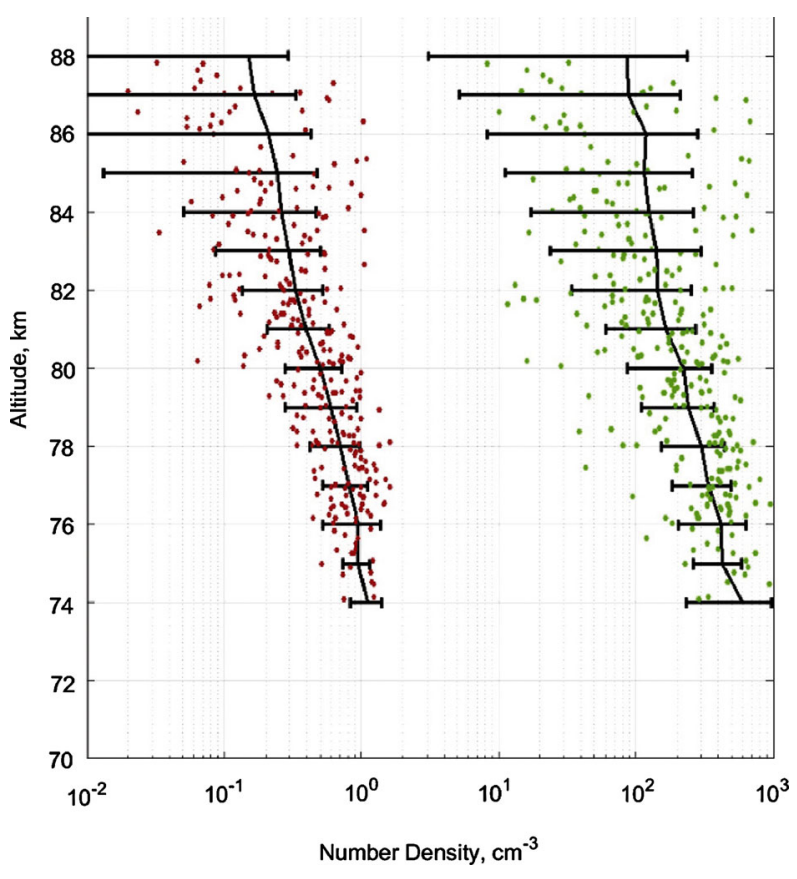

ing. Rossi et al. (2015) analysed degree of polarization at low phase angles measured by SPICAV in the $0.65-1.7 \mu \mathrm{m}$ range. The results are consistent with mean values of effective radius $r_{\text {eff }} \sim 1 \mu \mathrm{m}$ and its variance $\nu_{\text {eff }} \sim 0.07$ and a refractive index $n_{\mathrm{r}}=1.42 \pm 0.02$ at $\lambda=1.1 \mu \mathrm{m}$ in good agreement with previous determinations.

In 2016 JAXA's Akatsuki spacecraft had started regular orbital observations. Analysis of the phase curves acquired by IR1 $(\sim 1 \mu \mathrm{m})$ and IR2 $(\sim 2 \mu \mathrm{m})$ cameras on board Akatsuki during the first attempt of orbit insertion in 2010 already suggested existence of $1 \mu \mathrm{m}$ particles at the cloud top. Satoh et al. (2015) had to modify the standard cloud model (Esposito et al. 1983) that fits both Pioneer Venus and recent ground based observations (Mallama et al. 2006; García Muñoz et al. 2014) extending population of micron-size particles to higher altitudes (up to $75 \mathrm{~km}$ ) and adding large mode 3 particles in the upper cloud to reproduce the observed phase curve at low phase angles. Lee et al. (2017) derived $r_{\text {eff }}=1.26 \mu \mathrm{m}$ and variance $v_{\text {eff }}=0.076$ from the phase angle dependence of the planet global albedo derived from the images captured by Akatsuki UVI camera at $0.283 \mu \mathrm{m}$ and $0.365 \mu \mathrm{m}$ in agreement with the earlier results on mode 2 particles in the upper cloud.

Spectroscopy in the near-IR transparency "windows" on the night side provided new information about global distribution of the microphysical properties of the deep cloud. The method exploits correlation between the radiances measured at $1.74 \mu \mathrm{m}$ and $2.3 \mu \mathrm{m}$ which are sensitive to the aerosol properties, in particular, proportion between mode 2' and mode 3 (Table 1) and concentration of sulphuric acid in the deep cloud particles. Analysing the NIMS/Galileo data Carlson et al. (1993) favoured the conclusion about significant spatial variability of particle population in the deep cloud with a tendency for larger particles in the Northern hemisphere. The analysis by Grinspoon et al. (1993) indicated that opacity at $1 \mu \mathrm{m}$ ranged from 25 to 40, reinforcing the conclusion that the "typical" cloud properties measured by Pioneer Venus (Table 1) should be adopted with caution. 
A similar analysis of near-infrared emissions on the nightside of Venus observed by VIRTIS/Venus Express revealed anomalous cloud particles in the polar regions (Wilson et al. 2008). These particles were found close to the centers of the polar vortices at both poles and are either larger or differ in composition from those elsewhere in the planet. This result was confirmed by Barstow et al. (2011) who also found that the acid concentration increases with opacity resulting in $90-100 \%$ concentration in the polar regions. A comprehensive analysis by Haus et al. (2013) showed that the cloud particle size and total opacity exhibit a minimum at $50^{\circ} \mathrm{N}$ and increase towards the equator and the North pole.

\section{Cloud Composition}

The composition and chemistry of Venus clouds was reviewed in both Venus and Venus-2 books (Esposito et al. 1983, 1997). The Venus clouds are composed primarily of liquid sulphuric acid mixed with water. However, there must be other constituents as well. It is also not clear whether cloud condensation nuclei play an important role on Venus, and if so what their composition is. Particulates have been detected at altitudes below the main cloud base at $48 \mathrm{~km}$, where temperatures are too high to allow sulphuric acid droplets to exist. And finally, the unknown UV-blue absorbers responsible for absorption at $0.3-0.5 \mu \mathrm{m}$ in the upper cloud are likely to be particulate species. In this section we will first review the evidence for sulphuric acid and then we will discuss evidence for particulates of other composition. Gaseous chemical cycles relevant to the formation of aerosols are reviewed in a dedicated chapter of this Book (Marcq et al. 2017).

Sulphuric Acid The first indications that the clouds of Venus were composed of sulphuric acid droplets came from ground-based observations. Polarimetric observations of Venus were shown to be consistent with scattering from spherical droplets with a narrow size distribution with a mean radius $\sim 1 \mu \mathrm{m}$ and a refractive index of $1.44 \pm 0.02$ at $\lambda=0.55 \mu \mathrm{m}$ (Hansen and Hovenier 1974) that was attributed to $\sim 75 \%$ by weight sulphuric acid. Spectral absorption features near $3 \mu \mathrm{m}, 11.2 \mu \mathrm{m}$ and $25 \mu \mathrm{m}$ seen in Venus thermal infrared emission spectra were found to match the spectrum of sulphuric acid (Young and Young 1973; Zasova et al. 2007). Finally, the altitude of the cloud-base, as revealed by descent probes, was found to lie at around $48 \mathrm{~km}$, at a temperature consistent with that expected for thermal decomposition of sulphuric acid.

In situ measurements of particle composition confirmed that the clouds are composed primarily of sulphuric acid mixed with water. The Pioneer Venus mass spectrometer did not have a dedicated aerosol sampling inlet, but it did experience blockages attributed to aerosol droplets getting stuck in its inlet. When the droplets evaporated, the evolved gases were consistent with those which would be expected from a droplet composed of $85 \% \mathrm{H}_{2} \mathrm{SO}_{4}$ and $15 \% \mathrm{H}_{2} \mathrm{O}$ (Hoffman et al. 1980). The most direct evidence of sulphuric acid composition of cloud droplets was finally provided by the Vega probes. Atmosphere was pumped through aerosol collecting filters, so that the composition of the aerosol droplets could be determined separately from that of the gaseous species. Cloud droplets were collected on carbon fibres while the probe descended from $63 \mathrm{~km}$ to $48 \mathrm{~km}$, and then the sample was sealed off and heated. The evolved gases were analysed by gas chromatography and mass spectrometry and were found to consist of $\mathrm{SO}_{2}, \mathrm{H}_{2} \mathrm{O}$, and $\mathrm{CO}_{2}$ as expected from sulphuric acid droplets heated on a carbon fibre substrate (Gel'man et al. 1986). In addition to sulphuric acid the Vega-1 $\mathrm{X}$-ray fluorescent spectrometer revealed significant amounts of chlorine and phosphorus in the cloud droplets, as will be discussed below. 
It is from scattered light sensors (particle size spectrometers and nephelometers) on Pioneer Venus, Venera and Vega probes that the cloud vertical structure and particle size distributions were determined (Fig. 1). Nephelometry does not provide a strong constraint on the refractive index (and thus on the composition) of small particles (mode 0/mode 1), because their phase function is close to that of Rayleigh scatterers. The modes 2 and 2' particles were found to have refractive indices of $1.35-1.50$ as summarised in Knollenberg and Hunten (1980) and Ragent et al. (1985). This range includes the value of 1.42-1.47 expected for sulphuric acid solution at visible wavelengths at temperatures of 200-350 K. Initial analyses of LCPS data showed a population of large non-spherical mode 3 particles (Knollenberg and Hunten 1979), but subsequent studies suggested that the mode 3 could in fact be simply a large "tail" of the liquid mode 2' distribution, once calibration errors are taken into account (Toon et al. 1984). The presence of mode 3 and in general particles with $r>5 \mu \mathrm{m}$ also was not confirmed by the particle size spectrometers onboard Vega descent probes (Zasova et al. 1996).

There have not been further in situ measurements in the Venus clouds since the Vega probes in 1985. However, a large number of remote sensing observations have been provided by Venus Express, Galileo and ground-based telescopes. The most spectacular new observations, perhaps, are those of 'glories'—rainbow-like circular patterns imaged from Venus Express's VMC camera on the cloud tops. Analysis of these features finds cloud top refractive index to vary widely over the range 1.44-1.53 (Petrova et al. 2015; Markiewicz et al. 2018). The higher end of this refractive index range is too high to be explained by sulphuric acid/water mixtures. No consistent correlations of the refractive index with UV-blue albedo have been reported to date, but analyses are ongoing. Initial analyses of polarimetric observations by SPICAV suggests lower refractive indices of $1.42 \pm 0.01$ at $\lambda=1.101 \mu \mathrm{m}$ (Rossi et al. 2015) but these results are somewhat preliminary and may be sensitive to aerosol at altitudes different from those probed by the glories.

Further indirect constraints on particle composition in the lower and middle clouds can also be obtained from observations in the near-infrared spectral "windows" at $1.7 \mu \mathrm{m}$ and $2.3 \mu \mathrm{m}$ on the nightside. As has been discussed, the emission in these spectral domains is sensitive to cloud thickness, and the relative brightness in the different spectral bands within the transparency "windows" depends on cloud particle size and refractive index. If the clouds are modelled solely as combinations of modes 1, 2, 2' and 3 of sulphuric acid droplet populations, then the band ratios can be best matched by having particles of $80 \%$ $\mathrm{H}_{2} \mathrm{SO}_{4}: 20 \% \mathrm{H}_{2} \mathrm{O}$ in optically thin clouds, rising to $95 \% \mathrm{H}_{2} \mathrm{SO}_{4}: 5 \% \mathrm{H}_{2} \mathrm{O}$ in regions of thick cloud (Barstow et al. 2011). The same analysis also found a slight increase of $\mathrm{H}_{2} \mathrm{SO}_{4}$ concentration from $\sim 84 \% \mathrm{H}_{2} \mathrm{SO}_{4}$ at low latitudes to $\sim 90 \%$ at high latitudes. It must be emphasized, though, that there are many other parameters to which these band ratios are sensitive, in particular the size distributions of the cloud particles. A marked change in the brightness ratio of the $1.7 / 2.3 \mu \mathrm{m}$ "windows" at the core of the polar vortex is seen, which may be associated with changing particle sizes, but could equally signal a change in particle composition (Wilson et al. 2008).

Recent ground-based observations supported space missions in the study of Venus clouds and their relation to the minor species. Arney et al. (2014) mapped emissions in the nearIR spectral "windows" on the Venus night side using the Apache Point Observatory $3.5 \mathrm{~m}$ telescope TripleSpec spectrograph. They produced the first simultaneous maps of water vapor, $\mathrm{CO}, \mathrm{HCl}, \mathrm{OCS}, \mathrm{SO}_{2}$ below the clouds and sulphuric acid concentration and total cloud opacity and established some trends between the cloud properties and gaseous species. The retrieved mean cloud opacity at $\sim 2.0 \mu \mathrm{m}$ was found to be about 20 , i.e. by a factor of $1.7-$ 1.8 higher than that in the post-Pioneer Venus model by Crisp (1986). The cloud opacity 
is highly variable but the features with the most opaque clouds tend to be near the equator. The average value of sulphuric acid concentration was $79 \pm 4 \%$-slightly higher than in the earlier models (75\%) - with a trend to higher concentrations in the Northern hemisphere. The authors also tentatively confirmed the conclusion by Barstow et al. (2011) that the acid percentage correlates with the total opacity.

Analysis of the VIRTIS/Venus Express observations (Tsang et al. 2010; Barstow et al. 2011) suggested an anticorrelation between the cloud opacity and water vapor mixing ratio at 30-45 km. This may be due to breakdown of cloud particles below the cloud deck (Krasnopolsky 2007). In this case, optically thin clouds indicate cloud dissolution and therefore enhanced water. The correlations between the cloud opacity and abundance of minor species observed by Arney et al. (2014) were less pronounced. The authors reported evidence of correlations between the cloud deck and several gases, suggesting active processes in the Venus lower atmosphere. They also observed a marked hemispherical dichotomy in sulfuric acid, water vapor, and sulfur dioxide. All three parameters were enhanced in the Northern hemisphere. Sulfuric acid virga, the rain that evaporates before reaching the ground (Gao et al. 2014), was suggested as a possible mechanism for the water vapor dichotomy. Alternatively the dichotomy can be related to peculiarities of the atmospheric dynamics. We note however that ground-based observations in the $2.3 \mu \mathrm{m}$ "window" by Marcq et al. (2006) did not indicate significant latitudinal variability of the subcloud water abundance.

Unknown UV-Blue Absorbers The unknown UV-blue absorbers responsible for the striking contrasts seen in the images such as Figs. 13-18 cannot be explained by clouds composed solely of sulphuric acid. Some absorption below $0.3 \mu \mathrm{m}$ is due to gaseous $\mathrm{SO}_{2}$. Spectral behaviour of the planet albedo particularly in the $0.3-0.4 \mu \mathrm{m}$ region requires presence of an additional absorber. The absence of sharp spectral features in its spectrum, as well as results from Venera and Pioneer Venus photometers, indicate that the unknown absorption is due to a particulate rather than a gaseous species (Ekonomov et al. 1984; Tomasko et al. 1980) and occurs mainly above $57 \mathrm{~km}$. A vast number of candidates for this UV absorber have been proposed, from sulphur and chlorine species to organic compounds and mineral dusts. Recent reviews of atmospheric composition and chemistry as well as candidate materials can be found in Mills et al. (2007), Zhang et al. (2012) and Marcq et al. (2017).

Elemental sulphur was proposed as a candidate for the unknown absorber by Hapke and Nelson (1975). However elemental sulphur and its $S_{3}$ and $S_{4}$ allotropes fail to fit the observed near-UV absorption. Recently Carlson et al. (2016) found that some of sulphur allotropes could form aerosols at cloud level on Venus producing a good spectral match to the Venus albedo. However, concerns have been raised over whether the vertical distribution of polyatomic sulphur would match that of the unknown UV absorber. All photochemical models since Yung and DeMore (1982) predicted negligible abundances of aerosol sulphur in the upper cloud layer. According to the chemical kinetic model (Krasnopolsky 2013), significant abundances of gaseous sulphur are produced in the lower atmosphere below the clouds. This sulphur should condense near $48 \mathrm{~km}$ and form an aerosol layer (Krasnopolsky 2016) with mass loading of $\approx 10 \%$ of that in the lower cloud layer observed by the Pioneer Venus particle size spectrometer. This proportion is similar to the sulphur-to-sulphuric acid aerosol mass loading ratios of 1:10 observed by the Vega nephelometer and particle size spectrometer (Gnedykh et al. 1987) and of 1:7 observed by the Vega gas chromatograph (Porshnev et al. 1987). Furthermore, microphysical models of the Venus clouds suggest that soluble condensation nuclei are required for realistic cloud formation, but polyatomic sulphur is not soluble in sulphuric acid and so other species would be needed. 
There have been several attempts to constrain the composition of the UV-blue absorbers by finding correlations between observed cloud morphology in UV images and atmospheric composition, but to date these have been largely inconclusive. Water vapour above the clouds was mapped by Venus Express using both the SPICAV and VIRTIS spectrometers (Fedorova et al. 2016; Cottini et al. 2012, 2015). No consistent correlations were found for small-scale variations between UV features and abundances of water vapour or sulphur dioxide. On a larger scale, both works show that water concentrations are elevated at latitudes of $\pm 60-80^{\circ}$, that is likely related to the several kilometres lower position of the cloud top.

Analysis of the photometrically corrected VMC/VEX UV images by Lee et al. (2015) revealed a decline of the mean albedo at $0.365 \mu \mathrm{m}$ by $25-40 \%$ over 2000 orbits in 2006 through 2011 that could be partly due to slow decrease of the UV channel sensitivity. The relative brightness contrast between high and low latitudes was also observed to change and this cannot be due to detector degradation. Lee et al. (2015) identified short-term contrast variations of up to $40 \%$ correlated with mesospheric $\mathrm{SO}_{2}$ abundance. Since the global contrast variability was mainly due to albedo changes at high latitudes, the authors explained the correlation by intensive formation of sulphuric acid haze in the periods of mesospheric $\mathrm{SO}_{2}$ enhancement. Lee et al. (2015) also found that the UV contrast slowly decreased over almost 6 years of Venus Express observations, apparently correlated with the long-term decrease of mesospheric $\mathrm{SO}_{2}$ abundance. The observed increase of the contrasts phase angle dependence possibly implies variations of the vertical motions at the cloud top level on meso- or global scale.

The images recently taken by Akatsuki UVI camera at $0.283 \mu \mathrm{m}$ and $0.365 \mu \mathrm{m}$ showed morphological differences suggesting that the spatial distributions of $\mathrm{SO}_{2}$ and unknown UVblue absorbers sounded respectively at these wavelengths are governed by, at least partly, different chemical and/or dynamical processes (Yamazaki et al. 2018).

Observations at UV-blue wavelengths by VMC and VIRTIS onboard Venus Express provided the best opportunity to study spatial and temporal distribution of the unknown absorbers since the Pioneer Venus mission. Molaverdikhani et al. (2012) found two models of the UV absorber vertical distribution that match the VMC data set. One model is a wellmixed absorber above $\sim 63 \mathrm{~km}$ that is consistent with the altitude of photochemical formation of sulphuric acid. The second model suggests a thin layer of pure absorber placed roughly around $71 \mathrm{~km}$, the altitude consistent with the cloud top. This echoed previous work by Braak et al. (2002) using Pioneer Venus OCPP data, which similarly found that a wide range of vertical distribution models could satisfactorily fit the observations. Molaverdikhani et al. (2012) concluded that the average optical depth of the absorber at $0.365 \mu \mathrm{m}$ in the equatorial region is $0.21 \pm 0.04$ decreasing to $\tau=0.08 \pm 0.05$ towards the pole.

Petrova et al. (2015) examined the phase function of dark and bright regions at both UV and near-IR wavelengths at low phase angles in VMC/VEX images. The authors noted that the contrasts occurred usually in the UV channel only, implying that the UV absorber is present only in small $(\sim 0.3 \mu \mathrm{m})$ particles. The contrasts are sometimes observed also in the near-IR wavelengths; this would be consistent with UV absorber being present also in $1 \mu \mathrm{m}$ particles which are the dominant population in the upper cloud. They suggested that the UV absorber could be present in $0.3 \mu \mathrm{m}$ aerosol mode, which acts as a condensation nucleus for larger cloud particles.

Titov et al. (2008) found correlation of UV-dark areas with the regions of enhanced convective mixing in the upper cloud inferred from the global cloud morphology pattern and dynamical properties. Similarly, Bertaux et al. (2016) concluded that regions near Aphrodite Terra were on average UV-dark and exhibited high water vapour concentrations. Both absence of correlation between the UV absorber and mesospheric water vapour abundance 
and morphological evidences support the hypothesis that the UV-blue absorbers are brought to the cloud tops from depth, along with tropospheric water vapour, with no evidence that water vapour constrains formation of the UV absorber. Simultaneous VMC imaging in the $\mathrm{UV}$ and visible filters tentatively indicated that the absorption is likely to extend to visible wavelengths (Titov et al. 2012).

Most of the researchers associate the unknown UV-blue absorption with cloud particles. However, there are recent attempts to suggest gaseous species as candidates. Frandsen et al. (2016) studied chemistry and optical properties of $\mathrm{S}_{2} \mathrm{O}_{2}$ and found that this species can form in a sulphur cycle at the cloud tops and that its spectral properties match those of the unknown near-UV absorber reasonably well. The problem of this identification is that the photochemical lifetime of $\mathrm{S}_{2} \mathrm{O}_{2}$ is very short (few seconds in sunlight) that precludes its existence on the day side of the planet. Krasnopolsky (2018) included the $\mathrm{S}_{2} \mathrm{O}_{2}$ formation rate and absorption cross sections from Frandsen et al. (2016) in his photochemical model. The predicted $\mathrm{S}_{2} \mathrm{O}_{2}$ absorption was found to be about two orders of magnitude weaker than that observed.

Iron was detected in cloud droplets by the Venera-14 X-ray fluorescent spectrometer (Petryanov et al. 1981). Zasova et al. (1981) proposed $\sim 1 \% \mathrm{FeCl}_{3}$ solution in sulphuric acid mode 2 particles as the near-UV absorber. Recently this idea was elaborated in detail by Krasnopolsky (2017) summarising chemical, dynamical and spectroscopic arguments in favour of this species being additional constituent in the Venus clouds responsible for the UV-blue absorption. The analyses confirmed that $\mathrm{FeCl}_{3}$ vertical distribution matches that measured by descent probes, and that it is soluble in sulphuric acid so could act as a condensation nuclei. The resulting solution would not only have a refractive index higher than that of sulphuric acid, as required to match the glory observations (Petrova et al. 2015; Markiewicz et al. 2018), but also would absorb light at 0.32-0.5 $\mu \mathrm{m}$ explaining the UV-blue absorption in the Venus spectrum. If iron chloride is present in the rocks with abundance of $19 \mathrm{ppb}$, its vapor would condense at $47.5 \mathrm{~km}$ and form mode 1 aerosol in the lower and middle cloud layers. These particles can become condensation nuclei in the upper cloud layer, and mode 1/mode 2 mass ratio and vertical flux would be in agreement with the required concentration of $1 \%$. The solution is rather stable at low temperatures and converts to colorless iron sulphate at room temperature $(<58 \mathrm{~km})$ that explains vanishing of absorption detected by Venera-14 photometer (Ekonomov et al. 1984).

Pérez-Hoyos et al. (2018) analysed the spectra from $0.3 \mu \mathrm{m}$ through $1.49 \mu \mathrm{m}$ taken by the MASCS spectrometer during MESSENGER second Venus flyby on 5 June 2007. The analysis included radiative transfer modelling to fit the observed spectra using vertical distribution of aerosols and spectral properties of the UV absorber as free parameters. The imaginary part of refractive index of the UV absorber was found to be centred at $0.34 \pm 0.03 \mu \mathrm{m}$ with a full width at half maximum of $0.14 \pm 0.01 \mu \mathrm{m}$ assuming Gaussian shape of the absorption band, thus suggesting the absorption a bit blue shifted with respect to the previous works. Figure 25 compares the UV-blue absorption derived from the MASCS/MESSENGER observations to that of several species which spectral properties closely match the measurements. Several candidates could account for the core absorption around $0.35 \mu \mathrm{m}$, but the main problem is fitting the spectral slope at $0.4-0.5 \mu \mathrm{m}$. The best agreement was found for an irradiated version of $\mathrm{S}_{2} \mathrm{O}$ (Lo et al. 2003) and $\mathrm{S}_{2} \mathrm{O}_{2}$ or OSSO (Frandsen et al. 2016) if a single absorber is assumed. Other species including iron chloride have too narrow absorption to be in agreement with the MASCS spectra. We note, however, that the analysis by Pérez-Hoyos et al. (2018) did not include sulphur allotropes recently suggested by Carlson et al. (2016).

Recently, a possibility of microorganisms contributing to absorption of sunlight and contrasts in the clouds has been discussed by Limaye et al. (2018c). This hypothesis was based 
Fig. 25 Comparison of the relative absorption in arbitrary units (colour lines) of the candidates for the near-UV absorber proposed so far with the absorption spectrum derived from MASCS/MESSENGER observations (grey area). The black dashed line shows the best fitting values (from Pérez-Hoyos et al. 2018)

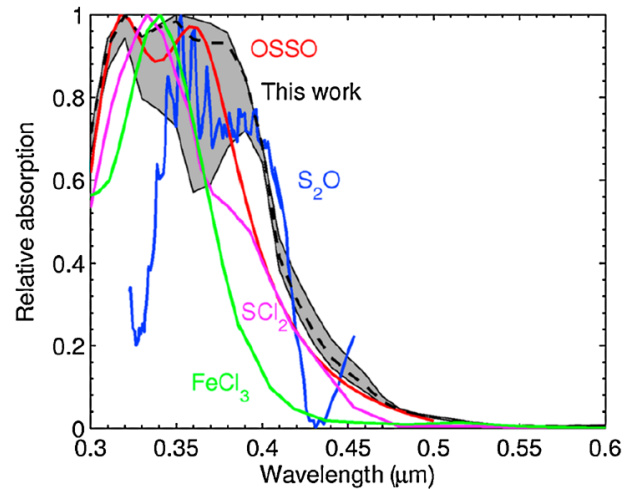

on the consideration that terrestrial-type biology may have evolved and could survive within Venus clouds. The authors showed that the observed physical, chemical and spectral properties of the Venus cloud population can be matched by terrestrial microorganisms. Earth clouds harbour many microorganisms, so a similar existence in the clouds of Venus cannot be excluded.

In summary, identification of the UV-blue absorber (or absorbers) in the Venus atmosphere is a problem far from being solved. Several single candidates provide good match to the observed properties but none of them can fully and consistently explain the phenomenon, including spectral properties, chemistry and dynamics. For instance, iron chloride $\left(\mathrm{FeCl}_{3}\right)$ whose presence in the Venus clouds agrees with chemical models (Krasnopolsky 2018) does not seem to fit well the observed spectral behaviour (Fig. 25). On the other hand, the abundance of disulphur dioxide $\left(\mathrm{S}_{2} \mathrm{O}_{2}\right)$ that provides the best spectral fit deviates from the profiles computed by Frandsen et al. (2016). Krasnopolsky (2018) also showed that the required $\mathrm{S}_{2} \mathrm{O}_{2}$ abundance is in contradiction with state-of-the-art photochemical models. As most of single candidates do not match the MASCS observations at $0.4-0.5 \mu \mathrm{m}$ (Fig. 25) Pérez-Hoyos et al. (2018) argued in favor of a second absorber that could complement the species absorbing at shorter wavelength, such as $\mathrm{S}_{4}$, for instance. This echoes the tentative conclusion by Titov et al. (2012) about likely presence of an additional species whose absorption extends to visible wavelengths to explain the cloud features seen by VMC/VEX at $0.513 \mu \mathrm{m}$. Other constituents. There are hints of further non-sulphur cloud particle constituents from several sources. As mentioned above, analysis of the cloud material acquired by the aerosol collector/pyrolyser on the Vega probes by the mass-spectrometer suggested presence of chlorine and sulphur. Inferred abundance in particulates in the cloud region were $0.3 \mathrm{mg} / \mathrm{m}^{3}$ for chlorine, compared to $2 \mathrm{mg} / \mathrm{m}^{3}$ for sulphur (Surkov et al. 1986). Even more intriguing are the results from Soviet X-ray radiometer experiments. Analysis of aerosols on Venera-13 and -14 indicated presence of sulphur, chlorine and iron (Petryanov et al. 1981), while similar experiments on Vega 1 and 2 found little iron but strong signatures of sulphur, chlorine and phosphorus in the lower cloud (Fig. 26) (Andreichikov 1987). This could plausibly exist in the form of phosphoric acid droplets $\left(\mathrm{H}_{3} \mathrm{PO}_{4}\right)$ with $\mathrm{P}_{4} \mathrm{O}_{6}$ as a possible gaseous species acting as a reservoir for phosphoric acid formation (Krasnopolsky 1989). The sub-cloud hazes found at altitudes of 33-48 km at temperatures too elevated for sulphuric acid droplets to exist, so might be explained by phosphoric acid droplets. The lack of detection of any phosphorus-containing species from any other investigations makes it difficult to proceed further with evaluation of the possibility of the phosphoric acid in the clouds, but it is clear that this is an intriguing area for future investigation. 
Fig. 26 Accumulation of chlorine, sulphur, and phosphorus on the filter of Vega-2 X-ray radiometer as a function of altitude (from Andreichikov 1987)

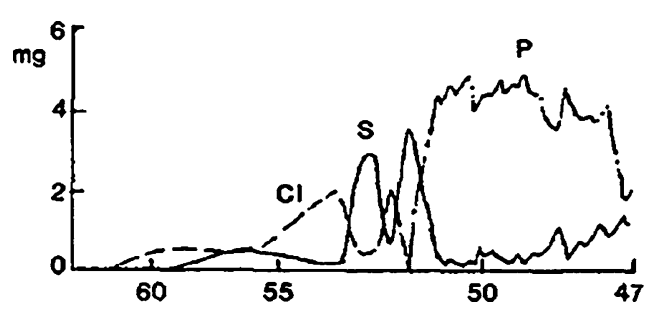

Finally, we should mention also the possibility of near-surface hazes. A recent reanalysis of Venera-13, -14 descent probe spectrophotometer data found a sharp decrease of light levels at 1-2 km altitude, interpreted as indicating a detached layer of aerosols of unknown nature at this level (Grieger et al. 2004) The authors point out that its altitude is similar to that at which radar-bright deposits attributed to metallic condensate on the mountain tops have been found (e.g. Schaefer and Fegley 2004). The aerosol layer could also be associated with volcanic ash or dust lifted by wind. Further investigation of such low-altitude hazes may be possible by radar investigations or near-infrared spectroscopy on the nightside.

\section{Modelling Chemistry and Microphysics of the Clouds}

The vertical structure and makeup of the system of Venus clouds and aerosols has been described in the preceding sections. Here, we focus on modelling investigations of the processes that operate within the clouds and aerosols of Venus. To facilitate that discussion, we include a schematic figure that shows the interaction between the chemical, microphysical, dynamical, and radiative processes that occur in the Venus clouds and lead to their longterm stability, and their short-term variation (Fig. 27). The goal of microphysical modelling of the Venus clouds is to characterize the physical properties of the aerosols in the Venus atmosphere, through simulation and comparison with observations, so that we can better elucidate these coupled drivers of cloud formation and dissipation. Hence, we will be able to better leverage observations of changes in cloud morphology to measurements of atmospheric circulation, chemistry, and radiative balance. However, the cloud system of Venus is a highly coupled system, with many forcings, few of which are well-characterized.

\subsection{Microphysical and Chemical Processes in the Clouds}

Photochemical reactions involving water vapour and sulphur species shown schematically as " $\mathrm{H}_{2} \mathrm{O}+\mathrm{SO}_{2}+$ sunlight" in Fig. 26, potentially including hundreds of possible reactions (Krasnopolsky 2012; Zhang et al. 2012), produce sulphuric acid vapour in the middle atmosphere of Venus. Peak production is modelled to occur at about $62 \mathrm{~km}$ (Esposito et al. 1979), but even this is dependent upon the modelled pathway from vapour to cloud, since direct measurement is very difficult because the concentrations of sulphuric acid number density at these altitudes are so slight due to its very low vapour pressure.

At sufficient supersaturations, this sulphuric acid vapour will condense into cloud droplets; this process can either occur homogeneously or heterogeneously (Seinfeld and Pandis 1998). Homogeneous nucleation is conceptually simpler-the only requirement being sufficiently large concentrations of sulphuric acid molecules that collisions between molecules are frequent enough that a cluster of nucleated acid molecules (sometimes called 


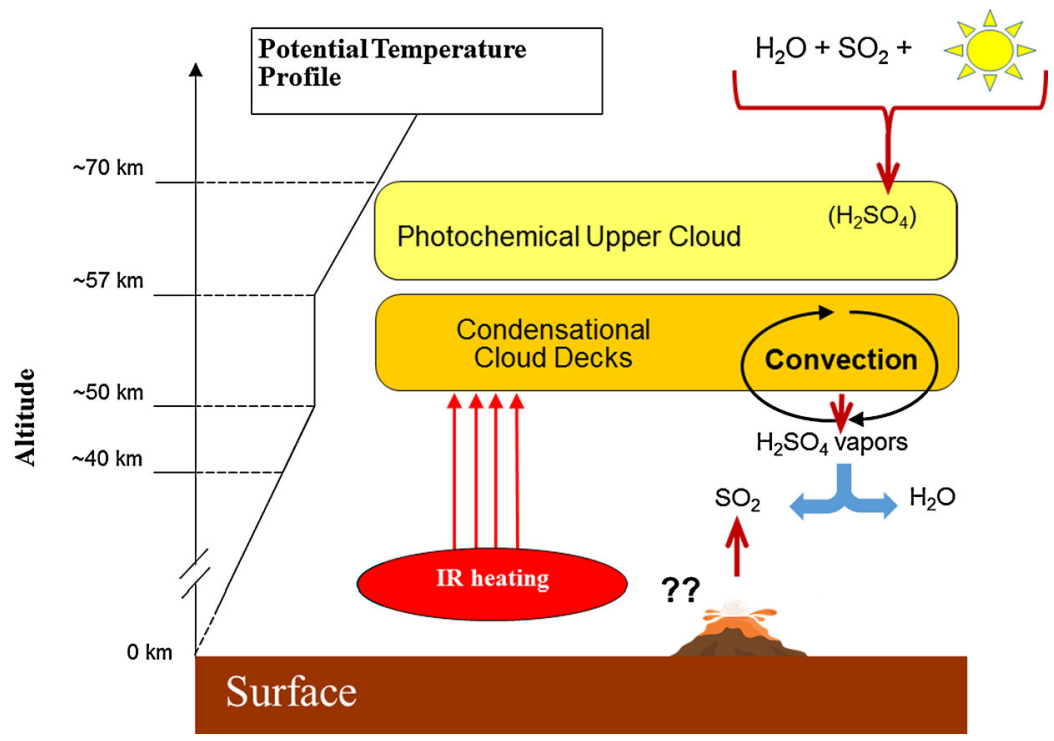

Fig. 27 A schematic figure of the Venus atmospheric clouds and hazes, provided as a guide to the discussion in the text

a germ and having a radius on the order of nanometres), will remain intact long enough for diffusional growth processes to begin to take over. This generally requires rather large supersaturations. Heterogeneous activation of droplets, on the other hand, generally (but not of necessity) requires a soluble condensation nucleus in order for the activated particle to overcome the Kelvin barrier (below which radius, a very small droplet will evaporate more quickly than it can grow, because the small radius of curvature increases the equilibrium vapour pressure; the addition of a solute reduces this effect, allowing smaller radius particles to persist and then grow condensationally). This activation process will proceed at lower supersaturation rates, but does require a condensation nucleus that is soluble in order to do so. This is possible in the Venus clouds, especially in the lower and middle condensational clouds, because we have observational evidence for a population of submicron sized particles below the main cloud deck that cannot be sulphuric acid, and likely are involatile (Knollenberg and Hunten 1980). But since we do not have a firm understanding of the composition of the particles that can serve as potential cloud condensation nuclei in the Venus atmosphere, simulations of this physical process necessarily involves the addition of a relatively unconstrained knob in a microphysical model. Furthermore, the most likely candidates for these cloud condensation nuclei are polyatomic sulphur species-which are necessary products of the aforementioned photochemistry (e.g., Yung et al. 2009) and for which there is some observational evidence (e.g. Toon et al. 1984)—which have been shown to be incapable of serving as condensation nuclei, since they are completely insoluble in sulphuric acid (Young 1983).

These photochemically produced sulphuric acid cloud droplets tend to form a several kilometres thick cloud deck above about $57 \mathrm{~km}$, which Fig. 26 labels the photochemical cloud. These upper cloud droplets were determined to be spherical droplets with effective radius of about 1 micron, composed of sulphuric acid by polarimetry measurements in the 1970s (Hansen and Hovenier 1974). Above this is a haze of particles that appears to be composed of sulphuric acid and appears to be at least at times, bimodal (Kawabata et al. 1980; 
Wilquet et al. 2012; Luginin et al. 2016). The upper haze extends to about $100 \mathrm{~km}$. Above the region of photochemical production the haze vertical structure is governed by dynamical processes such as eddy diffusion and Stokes settling of the particles. Historically, the definition of this upper haze has varied, and this has led to some confusion and misunderstandings in the community. In one sense it refers to the population of particles located above the main cloud deck defined by the photochemistry and condensational processes occurring between about $45 \mathrm{~km}$ and $65 \mathrm{~km}$. At the same time, Kawabata et al. (1980) referred to haze particles and cloud particles that existed in the top optical depth of the clouds accessible by polarimetry. In this description, the micron sized "cloud" particles and the submicron sized "haze" particles sometimes co-existed in the uppermost optical depth, and sometimes the population was dominated by the submicron sized particles. The point of this tangent is to draw the reader's attention to the inconsistencies in the definitions in use in the literature, and to take the time to state here that in this paper, "upper haze" refers not to a size of particle but rather to the population of particles in the topmost optical depth that can be sensed by polarimetry.

The characteristics of the upper haze are discussed in Sects. 3 and 4 above. When two modes of particles are seen in the upper clouds and hazes, they tend to have typical radii of around one micron - consistent with the particles first characterized by Hansen and Hovenier (1974) — and a submicron mode. At about $57 \mathrm{~km}$, a transition region is observed in most descent probe data (Knollenberg and Hunten 1980). Perhaps coincidentally, this altitude is consistent with the altitude below which the ambient temperature warms to a point at which frozen particles of sulphuric acid can no longer be supported (see Sect. 8.1). Also at this altitude, the tops of the middle clouds can cool sufficiently during the Venusian night to drive convection in the middle and lower cloud decks (Baker et al. 2000; McGouldrick and Toon 2008; Imamura et al. 2014). Furthermore, this vertical mixing, driven both by this cooling at $57 \mathrm{~km}$ and heating at cloud base due to absorption of upwelling IR, draws large quantities of sulphuric acid vapour upward in to the cloud from a reservoir below. Thus, in Fig. 27 the cloud deck below $57 \mathrm{~km}$ is called the condensational cloud that corresponds to the middle and lower clouds in the earlier terminology. Particle sizes in this region of the cloud tend to be somewhat larger than those in the upper clouds and hazes. A possibly trimodal distribution of cloud particles was observed in the condensational cloud by the Large Probe Cloud Particle Size Spectrometer (LCPS) of Pioneer Venus (Knollenberg and Hunten 1980). Furthermore, the typical radius of the 1-micron size mode of particles was observed to increase with depth, both in the aforementioned in situ measurements, as well as in subsequent remote sensing analysis of the near-infrared spectral "windows" by Carlson et al. (1993) and Grinspoon et al. (1993).

Total opacity variations in this condensational cloud are largely responsible for the inhomogeneities seen in the emitted near infrared (Crisp et al. 1989). Descent probes from Venera and Pioneer Venus indicated large spatial variations in the vertical profile of mass loading of these clouds, especially in the lower cloud between about $48-50 \mathrm{~km}$ (Ragent and Blamont 1980; Marov et al. 1980). And analysis of Galileo NIMS observations of the NIR spectral "windows" that had been discovered by Allen and Crawford (1984) suggest that these variations can be attributed to both changes in total mass of the clouds as well as changes in the particle size distributions (Grinspoon et al. 1993; Carlson et al. 1993). Since the vapour pressure of sulphuric acid is so low and so sensitive to temperature and concentration, subtle changes in microphysical properties, or in temperature or in local winds can all potentially drive these changes in cloud characteristics (McGouldrick and Toon 2007).

At altitudes below about $40 \mathrm{~km}$, the sulphuric acid vapour is thermally decomposed, ultimately back into $\mathrm{SO}_{2}$ and $\mathrm{H}_{2} \mathrm{O}$ (and likely other sulphur, oxygen, and hydrogen bearing 
species (Krasnopolsky 2013). Although this is many kilometres below the clouds, it is a process that is highly dependent upon temperature and local stoichiometric composition. Thus, under the right conditions, this decomposition can have a feedback on the physical properties of the cloud particles above $48 \mathrm{~km}$. Thus, in order to fully understand the condensational clouds of Venus, we need to understand the chemical drivers, as well as microphysical; just as we do for the photochemical cloud.

Alternate compositions of the Venus clouds are possible at some altitudes (see previous section), including possibilities for rather exotic possibilities in the deep atmosphere of Venus. However, to date, nearly all in situ and remote sensing measurements (with the most notable exception being the largest size mode of particles observed by LCPS) are consistent with sulphuric acid having a weight percent between $75 \%$ and $90 \%$, so this remains the preferred identification of the composition of both the photochemical and condensational cloud decks of Venus.

\subsection{Modelling the Venus Clouds}

Modelling of aerosol microphysical properties and processes involves the simultaneous solution of several differential equations that govern the growth and transport of the aerosol particles. Namely, nucleation of particles $(P)$, condensational growth and evaporation of the aerosols $(G)$ must be considered including total evaporation $(L)$, as well as coagulation (and coalescence) between particles (integrals involving $\left.K_{\text {coag }}\right)$, and transport by diffusion $\left(K_{\text {diff }}\right)$, winds $(w)$ and gravitational sedimentation $\left(v_{\text {fall }}\right)$ :

$$
\begin{aligned}
& \frac{\partial N(m, z, t)}{\partial t}+\frac{\partial}{\partial z}\left\{N(m, z, t)\left\{w(z)-v_{\text {fall }}(m, z, t)\right\}\right\}-\frac{\partial}{\partial z}\left\{\rho(z) K_{\text {diff }}(z) \frac{\partial}{\partial z}\left\{\frac{N(m, z, t)}{\rho(z)}\right\}\right\} \\
& =P(m, z, t)-L(m, z, t) N(m, z, t) \\
& \quad+\int_{0}^{m} K_{\text {coag }}\left(m_{1}, m-m_{1}\right) N\left(m_{1}, z, t\right) N\left(m-m_{1}, z, t\right) d m_{1} \\
& \quad-N(m, z, t) \int_{0}^{\infty} K_{\text {coag }}\left(m_{1}, m\right) N\left(m_{1}, z, t\right) d m_{1}-\frac{\partial}{\partial m}\{N(m, z, t) G(m, z, t)\}
\end{aligned}
$$

Here, the particle concentrations $(N)$ are functions of mass $(M)$, altitude $(z)$ - or, more generally, spatial location $(x, y, z)$-and time $(t)$.

Thus, the growth of individual aerosol particles and the evolution of aerosol populations are dependent upon temperature, the concentrations of the condensing species, the concentrations of solutes within the aerosols, the diffusional processes of the dry atmosphere, and the number density of the particles themselves (more correctly, the size distributions). In addition, transport processes can change the environment in which the particles exist, hence changing their growth rates. Three-dimensional winds may advect particles and gasses and thermal energy, while the particles themselves, if large enough, may fall relative to the ambient air. And, as discussed above, varying aerosol particle size distributions and trace atmospheric species can alter the local radiative properties, leading to significant changes in heating and cooling rates. Since the system can be so heavily coupled, previous researchers have endeavoured to understand the cloud system by making various assumptions about one or more of the atmospheric or microphysical properties in order to reduce the complexity of the problem to a manageable level. Next, we shall describe some of the microphysical modelling efforts that have transpired since the publication of the Venus II book in 1997. 
Fig. 28 Size distribution of Venus aerosols (both volatile and involatile) at $50 \mathrm{~km}$ for several of the simulations by James et al. (1997). This figure shows the emergence of a third mode in the size distribution when solute effects are taken into account (increasing the efficiency of condensational growth by vapor diffusion), and when the efficiency of condensational growth is reduced artificially by altering the diffusional flux of molecules to an existing droplet

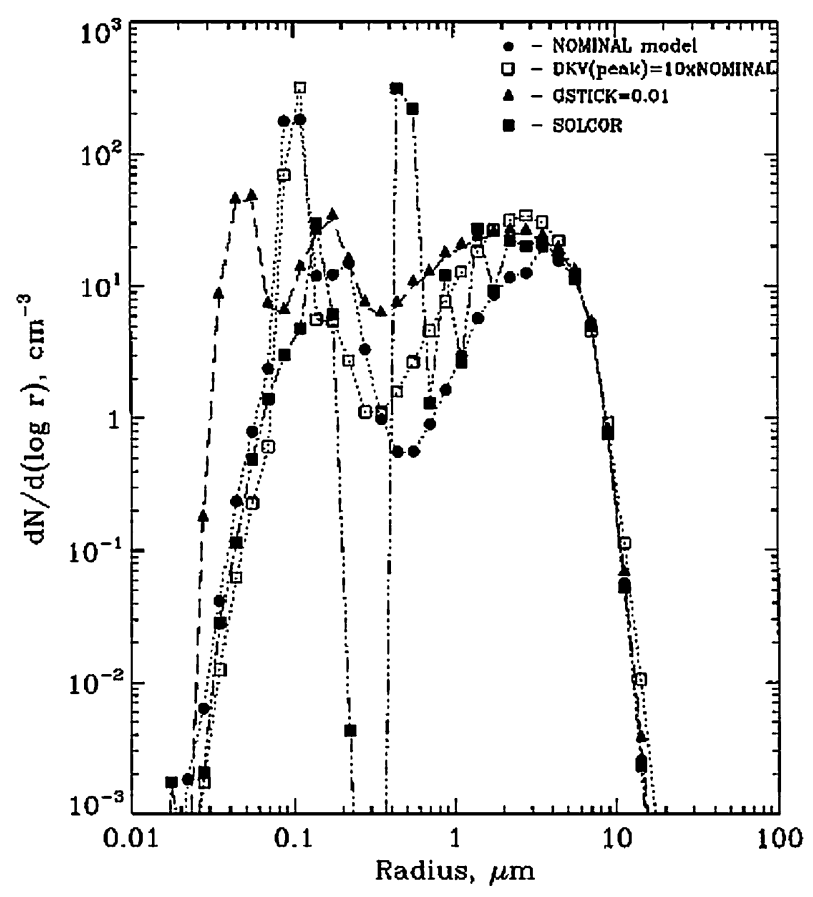

James et al. (1997) developed a one-dimensional model of the condensational clouds of Venus in which the upper cloud was a boundary condition flux of particles into the model domain, determined from in situ measurements of the downward mass flux of upper cloud particles at $57 \mathrm{~km}$. They also stipulated a profile of eddy diffusion coefficient that was constant with time, and that was based on existing understanding of convective vertical motions in the middle and lower cloud decks. They were able to reproduce the vertical profiles mass loading of the condensational cloud (as compared with in situ measurements by Pioneer Venus descent probes). However, they could only reproduce the trimodal structure of the size distribution in the lower clouds by invoking solubility in the activation of cloud particles in the condensational cloud (Fig. 28). As mentioned above, however, since the composition of the involatile particles in the lowest part of the Venus cloud system is unknown, their modelled solubility properties were necessarily arbitrary.

Imamura and Hashimoto (1998) sought to understand connections between large-scale dynamical transport and observable aerosol properties and distribution. They explored the consequences of a putative near-global Hadley-like meridional circulation on the latitudinal distribution of aerosol opacity. Unlike James et al. (1997), they included photochemical production of sulphuric acid vapours in order to adequately model the formation of the upper photochemical clouds as well as the deeper condensational clouds. However, they did not attempt to simulate evolution in the size distributions of the particles, instead treating the particles as comprised of two monodisperse populations, having radii of $1.15 \mu \mathrm{m}$ and $3.65 \mu \mathrm{m}$, consistent with the in situ observations of modes 2 and 3 . They found that their combination of simplified chemistry, meridional transport, and simplified aerosol microphysics was able to largely reproduce the observed latitudinal distribution of aerosol mass loading (Fig. 29), aerosol vapour mixing ratios, and average radiance that is seen in the nightside NIR emission. They perceived a build-up of mass in the upper cloud at high latitude, arising from the accumulation of photochemical cloud particles as the sulphuric acid 


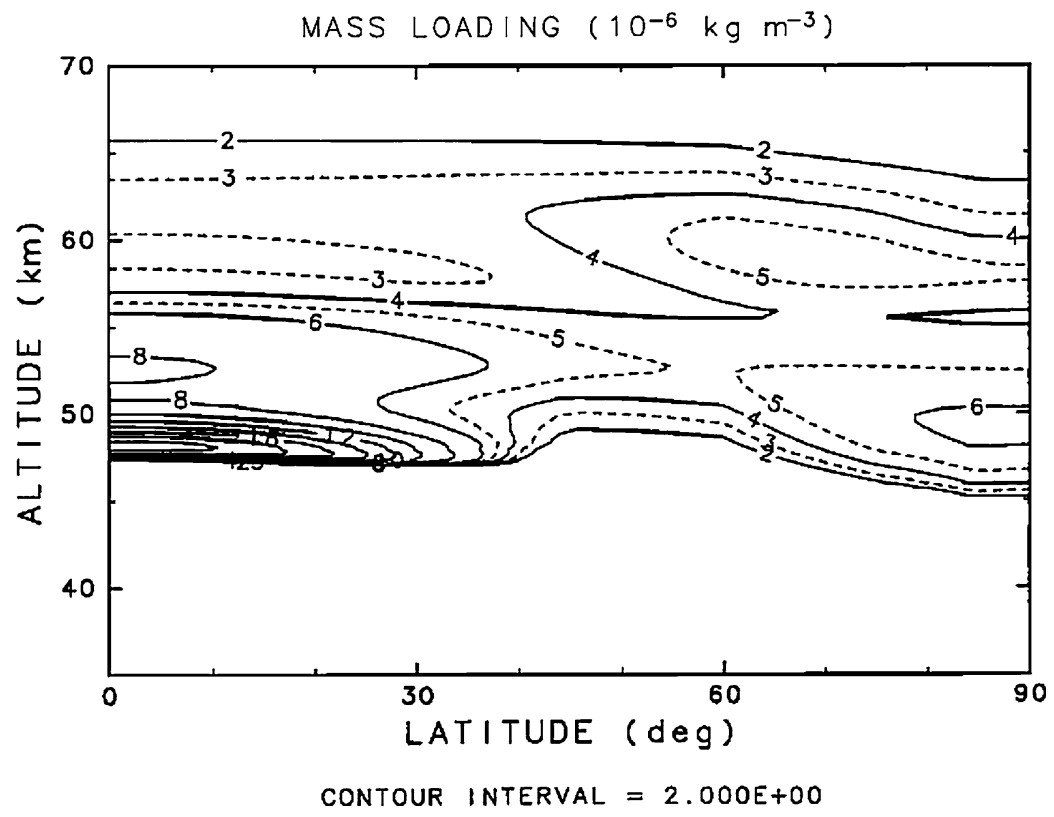

Fig. 29 The mass loading of the sulphuric acid water solution droplets in the nominal model of Imamura and Hashimoto (1998) which shows condensational cloud mass enhancements at equatorial latitudes, and upper cloud mass enhancements at polar latitudes

is exposed to sunlight during its trek from equatorial latitudes toward the poles. They also found an enhancement of cloud thickness near the equator, which they attributed to the upwelling branch of the Venusian meridional circulation. However, since their simulations did not account for changes in microphysical properties (such as fall velocities, growth rates, and coalescence rates) that are functions of particle size, the application of their results to more localized events is not yet possible.

Imamura and Hashimoto (2001) later developed a bin-resolved microphysical model, similar to that of James et al. (1997), that they used to demonstrate that the trimodal size distribution observed in the condensational cloud can be obtained by mixing a column experiencing upwelling with another experiencing downwelling, and allowing the merged column to evolve with time (Fig. 30). This simulation showed that the size distribution existing in the condensational cloud at any time is as much dependent upon the current conditions as it is on the history of local eddy activity.

McGouldrick and Toon (2007) reproduced the work of James et al. (1997) with an updated version of the same model; but then went on to demonstrate the role of the radiativedynamical feedback in the evolution and sustenance of the Venusian condensational clouds. Rather than employ an eddy diffusion profile that was constant in time as had been done previously, they calculated an eddy diffusion coefficient that was based on the static stability of the local atmosphere, parameterized according to the Richardson number, which represents the ratio of Brunt-Vaisala frequency to the vertical shear of the horizontal winds. Their model incorporating this radiative dynamical feedback was able to reproduce the aerosol mass loading and backscatter cross section observed by the Pioneer Venus LCPS (Fig. 31). They also showed that waves propagating through the clouds, and vertical winds consistent with those observed by the in situ Vega balloons were capable of producing the observed 


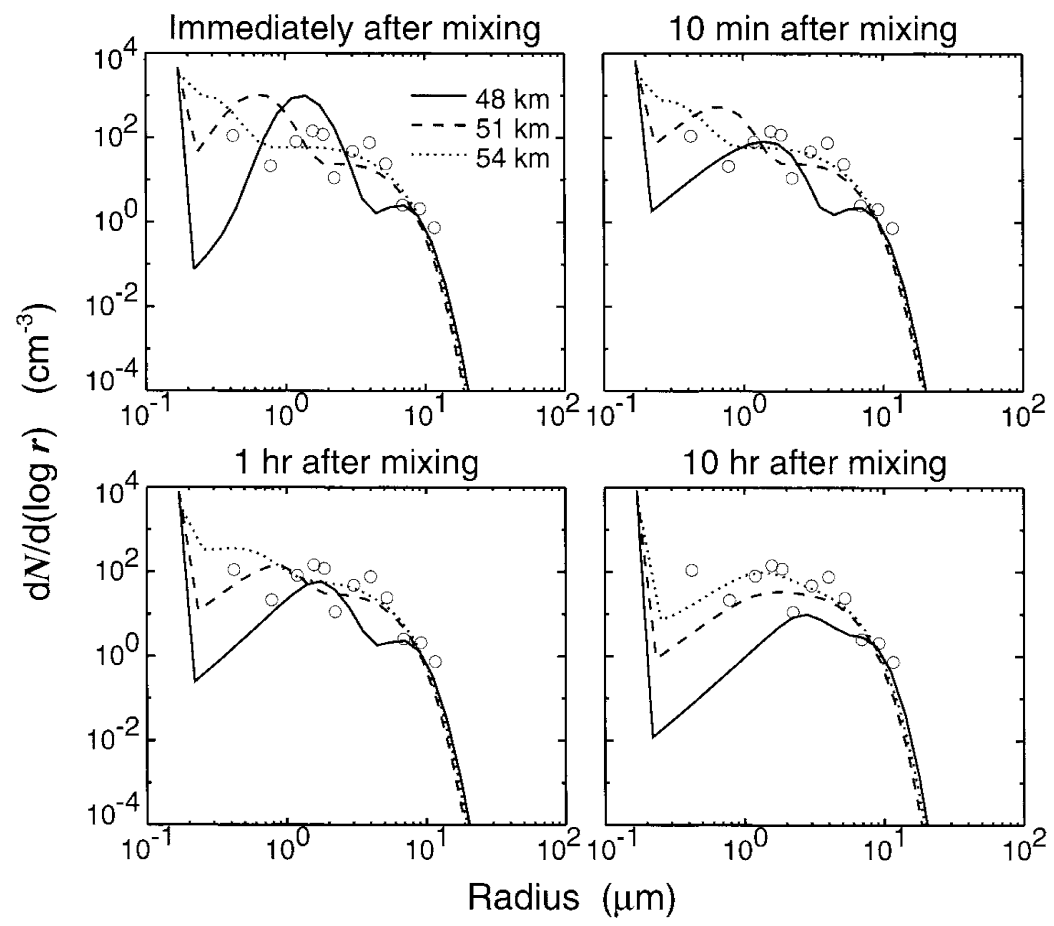

Fig. 30 The evolution of the size distribution of cloud particles simulated by the model of Imamura and Hashimoto (2001), at three altitudes over a time span of ten hours after the initial mixing of a column that had experienced upwelling with another that had experienced downwelling

(a)

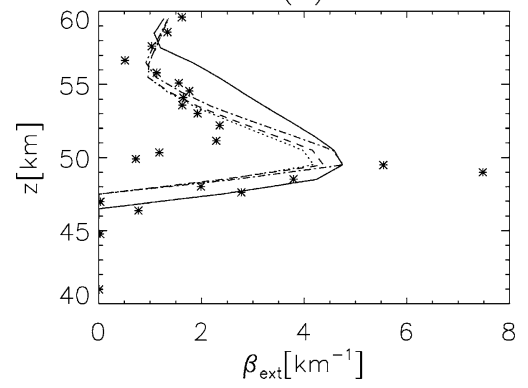

(b)

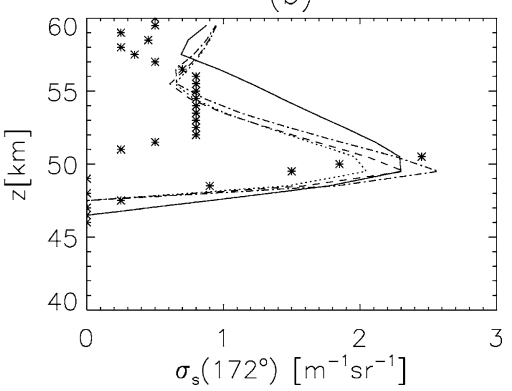

Fig. 31 Vertical profiles of the extinction coefficient and the backscattering cross section at $0.56 \mu \mathrm{m}$ calculated from the simulations of McGouldrick and Toon (2007). The solid line represents the results using a static eddy diffusion profile; the broken lines are the results from simulations incorporating the radiative-dynamical feedback

clearings in the clouds in timescales consistent with the observed changes. McGouldrick and Toon (2008) simulated small scale convective overturning by applying a very simple convectively overturning wind field that was not responsive to the local temperature structure. The simulation was valid only a for a few hours of modelled time, but showed that while convective cells were capable of generating NIR nightside emitted radiance contrasts 
comparable to those observed between clouds and holes in timescales of as small as hours, they also demonstrated that the radiative-dynamical feedback applied in McGouldrick and Toon (2007) needed to be employed in three-dimensional models in order to adequately simulate the evolution of the condensational clouds of Venus on longer timescales. In each of these simulations, McGouldrick and Toon included the upper clouds (and hazes) as a boundary condition to their models, since they were focused primarily on the microphysics of the condensational clouds. Thus any potential feedbacks caused by interaction between the photochemical and condensational clouds were absent.

Vertical transport of $\mathrm{H}_{2} \mathrm{O}$ and $\mathrm{H}_{2} \mathrm{SO}_{4}$ in both gas and condensed phases was calculated by Krasnopolsky $(2011,2015)$ for the conditions of the main clouds $(45-75 \mathrm{~km})$ and the haze $(70-110 \mathrm{~km})$, respectively. The model explains the observed reduction of the $\mathrm{H}_{2} \mathrm{O}$ mixing ratio from the cloud bottom to the top by an order of magnitude and formation of a layer of gaseous sulfuric acid centered at the lower cloud boundary. The models were calculated for low, middle latitudes and $60^{\circ}$. Formation of the lower cloud layer is stimulated by a strong vertical gradient of gaseous sulfuric acid near the boundary (Krasnopolsky and Pollack 1994). Concentration of sulfuric acid decreases from $98 \%$ at the cloud bottom near $48 \mathrm{~km}$ to $80 \%$ in the upper cloud layer, then reaches a minimum of $70 \%$ at $90 \mathrm{~km}$ and increases to $\approx 100 \%$ at $100-110 \mathrm{~km}$.

Observations of occultation data by SPICAV on Venus Express indicated an "inversion" of the $\mathrm{SO}_{2}$ profile whereby significantly larger concentrations of the gas were observed than would be expected if the concentration of $\mathrm{SO}_{2}$ decreased with altitude as a consequence of diminishing atmospheric density and photochemical destruction of $\mathrm{SO}_{2}$. Zhang et al. (2012) suggested that the vertical transport of sulphuric acid aerosols to altitudes $>90 \mathrm{~km}$ where they would evaporate and then the resultant sulphuric acid vapour could be photolyzed to produce the observed $\mathrm{SO}_{2}$ enhancement. Others have shown that the role of available water in the vibrational overtone initiated chemistry that would drive this photolysis of sulphuric acid is a significant factor in its ultimate atmospheric fate (Vaida and Donaldson 2014). This demonstrated the need to consider both microphysical processes as well as chemistry in order to adequately simulate the behaviour of the upper clouds and hazes of Venus.

Gao et al. (2014) and Parkinson et al. (2015) found a bimodal size distribution of aerosols in the upper hazes of Venus and a trimodal distribution in the lower cloud by considering activation of sulphuric acid droplets onto meteoritic dust and a monodisperse distribution of polyatomic sulphur species that are products of the same photochemical process (Fig. 32). However, this latter microphysical behaviour is inconsistent with the physical properties of polysulphur and sulphuric acid (Young 1973). Gao et al. (2014) and Parkinson et al. (2015) see a correlation between the production rate of polysulphur and the presence of larger "rain" droplets of sulphuric acid deeper in the cloud. When the typical polysulphur particle produced is small (and numerous), oscillations in the size distribution of the deeper sulphuric acid droplets that occasionally produce rain; they do not see these oscillations when the production rate is smaller. Parkinson et al. (2015), using a very similar model to Gao et al. (2014), finds that this effect only occurs equatorward of about 60 degrees latitude. However, unlike James et al. (1997) and McGouldrick and Toon (2007, 2008), Gao et al. (2014) and Parkinson et al. (2015) fix the vertical profile of water vapour in their models.

Imamura et al. (2014) showed that, perhaps counter-intuitively, a consequence of varying insolation due to the atmospheric super-rotation was to enhance vertical mixing (i.e., unforced convection) during the night relative to the day. Since the peak of absorption of the incident solar radiance occurs in the vicinity of the cloud tops, and since the clouds and atmosphere are so optically thick in the infrared that the radiative cooling to space is relatively insignificant at most infrared wavelengths below an altitude of about $57-60 \mathrm{~km}$ 
Fig. 32 The size distribution as a function of altitude from the nominal model of Gao et al. (2014). Note the existence of a trimodal size distribution in the deep cloud, and suggestions of a bimodal cloud structure above $60 \mathrm{~km}$
Fig. 33 Time series of root-mean-square vertical velocity and convective heat flux from the dynamical models of Imamura et al. (2014), showing the significant reduction in convection to be expected at midday in lower latitudes in the Venus atmosphere and the more consistent levels of convective flux that occur at higher latitudes
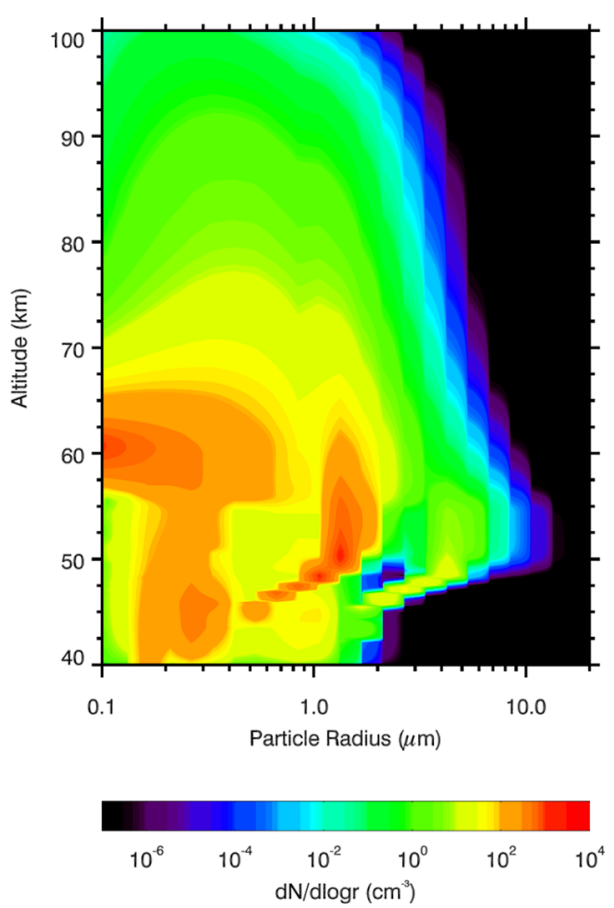
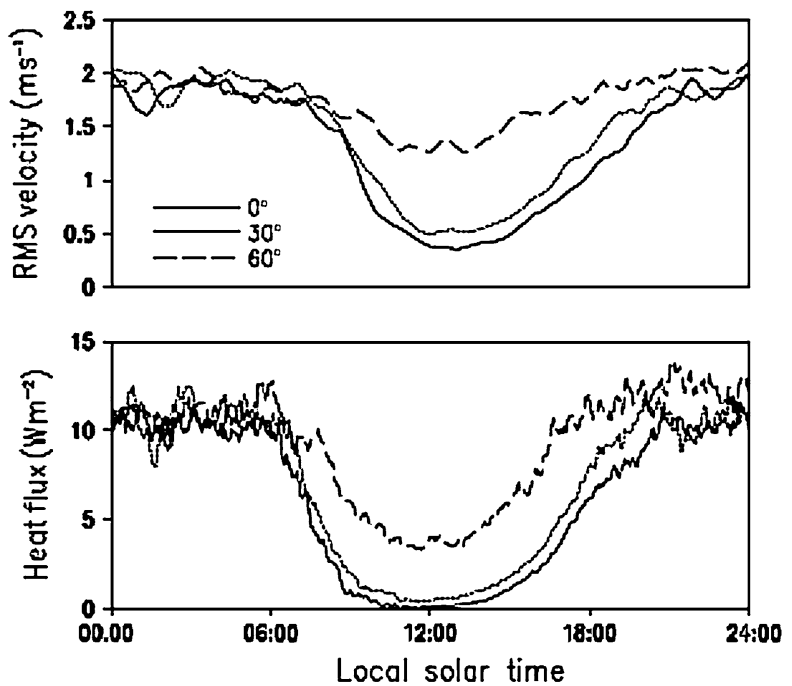

(near the upper cloud to middle cloud transition), the primary effect of insolation is to suppress cooling from the top of the condensational cloud deck, hence suppressing the build-up of the thermal gradient necessary to drive free convection in the middle clouds (Fig. 33). Since the altitude range of the upper clouds is so stable to overturning, the variations in insolation there are still too small to drive convection above $60 \mathrm{~km}$. Imamura et al. (2014) did not directly consider the effects of these variations in vertical mixing would have on 
the cloud structure by coupling their dynamical model to a microphysical cloud model; but previous work by McGouldrick and Toon $(2007,2008)$ suggested that these subtle changes in the radiative-dynamical feedback could produce small but significant effects on the cloud particle distribution.

To date, very little modelling of the Venusian clouds has considered compositions other than sulphuric acid. However, as mentioned in the previous section, there is observational evidence that the aerosol could include additional compositions. Chlorine was detected in the aerosols by the Vega probe. Recent work by Krasnopolsky (2017) suggests that iron chlorides could represent a significant fraction of the mode 1 aerosol mass, and could be responsible for the near ultraviolet absorption. Further supporting this hypothesis is the recent work by Sandor and Clancy (2012) who found that concentrations of hydrochloric acid above the cloud tops are somewhat less than would be expected from current photochemical models. Furthermore, Sandor and Clancy (2017) find that these $\mathrm{HCl}$ concentrations do not vary diurnally. One possibility is that Vega collected at least some sulphuric acid droplets that also contained ferric chloride.

\section{Radiative Effects of the Clouds}

Clouds are one of the main factors forming the Venus climate due to complete coverage of the planet, large total opacity and specific optical properties (Crisp and Titov 1997; Titov et al. 2007, 2013). Sulfuric acid aerosols almost conservatively scatter the solar light in the range from UV to near-IR $(\sim 2.5 \mu \mathrm{m})$. As a result, more than $75 \%$ of the incoming solar flux is returned back to space and, on average, only $\sim 3 \%$ of the solar flux incident at the top of the atmosphere reaches the surface. This results in a surprising fact: even though Venus is $30 \%$ closer to the sun, it receives less solar energy than the Earth due to the bright cloud "blanket" shrouding the planet. On the other hand, strong absorption at longer wavelengths makes sulfuric acid clouds a powerful greenhouse agent responsible for trapping thermal radiation at $\lambda>2.5 \mu \mathrm{m}$ in the lower atmosphere. The unknown near-UV absorbers plays significant role in deposition of the solar energy due to that its absorption band is located in the UV-blue range in which the solar radiation is the most intensive. Figure 34 shows the mean spectrum of Venus as seen from space. It has three components: the reflected solar light dominating at $\lambda<4 \mu \mathrm{m}$, thermal radiation emitted to space by the cloud tops and the mesosphere that prevails at $\lambda>4 \mu \mathrm{m}$, and emissions leaking from the lower atmosphere through the so-called spectral transparency "windows" in the near-IR $(0.6-2.5 \mu \mathrm{m})$. This section reviews the effects that Venus clouds have on the radiative energy budget and complements more general and comprehensive discussion of this topic by Limaye et al. (2018a).

Inhomogeneous distribution of the unknown near-UV absorbers at the cloud tops that produces famous contrast markings (Fig. 13) strongly affects the radiative energy deposition. The observed global latitudinal variations of the UV-blue albedo imply that the UV-dark tropics receive by a factor of 3-4 greater amount of solar energy than the UV-bright high latitudes. This contrast in energy deposition between the low and high latitudes is further enhanced by gradual equator-to-pole decrease of sun elevation angle. Latitudinal, spatial and temporal changes of the planetary albedo affect the radiative energy deposition pattern and thus have an impact on the atmospheric dynamics. The unknown UV-blue absorber was found to be confined to the upper cloud (57-65 km) (Ekonomov et al. 1984). This results in absorption of about half of radiative energy that the planet receives from the sun at the cloud tops, thus creating energy deposition pattern remarkably different from the other terrestrial 
Fig. 34 General view of the Venus spectrum at a resolving power $\lambda / \Delta \lambda \sim 200$ as seen from space: the reflected solar light (dashed line), the thermal emission from the cloud tops and mesosphere (dotted line), and the night side emission escaping from the lower atmosphere (solid line). Positions of strong gaseous and aerosol absorption bands are marked (from Titov et al. 2007)

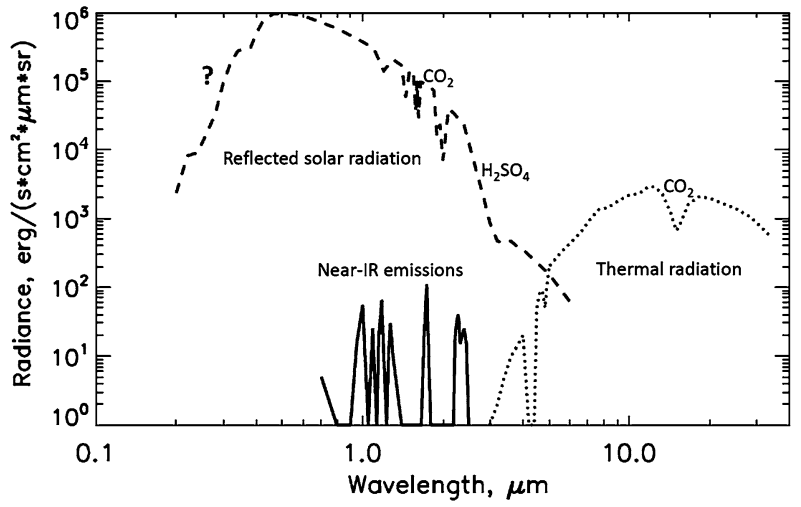

planets (Crisp and Titov 1997). This drives an unusual global circulation in the form of retrograde zonal superrotation.

Venus returns energy to space mainly through thermal emission from the cloud tops in the range 10-50 $\mu \mathrm{m}$ (Fig. 34). The outgoing thermal flux depends on the temperature and aerosol distribution at the cloud top level. Recent progress in the observations of the temperature and cloud vertical structure and their variability over the planet enabled re-assessment of the radiative energy balance in the mesosphere including the cloud tops. Lee et al. (2014) performed detailed numerical analysis of the sensitivity of the outgoing thermal radiation to temperature and cloud structure in the Venus mesosphere using recent observation results (see also Limaye et al. 2018a, this Book and Sect. 2 above).

Sensitivity of the outgoing thermal flux on the cloud top altitude decreases with latitude due to decreasing temperature gradient in the mesosphere. Small aerosol scale height in polar regions (Fig. 11) is responsible for a pronounced cooling rate peak at the cloud top. This feature corresponds to sharp upper boundary of the cloud, making the cloud top an effective emitter of thermal radiation and providing a positive feedback between the temperature and cloud structures. The cooling rate value increases from $5 \mathrm{~K} /$ day to $\sim 30 \mathrm{~K} /$ day as the aerosol scale height decreases from $6 \mathrm{~km}$ to $1 \mathrm{~km}$ regardless of thermal structure. Effective cooling at the sharp cloud top can be considered as one of the factors maintaining temperature inversion in the "cold collar" regions that, in turn, creates convectively stable atmosphere with suppressed vertical mixing.

Solar heating also depends on the cloud structure and, first of all, on the presence of the unknown near-UV absorbers which contribution to the overall heating is $30-60 \%$. At low latitudes the solar heating at the cloud top is more than twice as strong as thermal cooling, meaning that at noon the solar heating at the cloud top dominates. In the "cold collar" region the solar heating and thermal cooling rates at the cloud top are comparable. In the polar regions thermal cooling prevails. Figure 35 shows the net radiative energy budget in the Venus mesosphere (Lee et al. 2014). Above the cloud top, the net cooling prevails poleward from $\sim 50^{\circ}$. At lower latitudes the mesosphere experiences slight net heating. This result is in agreement with the earlier studies in that the Venus mesosphere is in radiative disequilibrium and that meridional overturning of the atmosphere above the clouds is required to maintain the observed temperature field.

Haus et al. (2016) performed the most complete and comprehensive study of the radiative energy balance in the Venus atmosphere using state-of-the-art radiative transfer technique and improved atmospheric model based on the Venus Express observations. The clouds were found to strongly affect both atmospheric cooling in thermal-IR range and heating at 


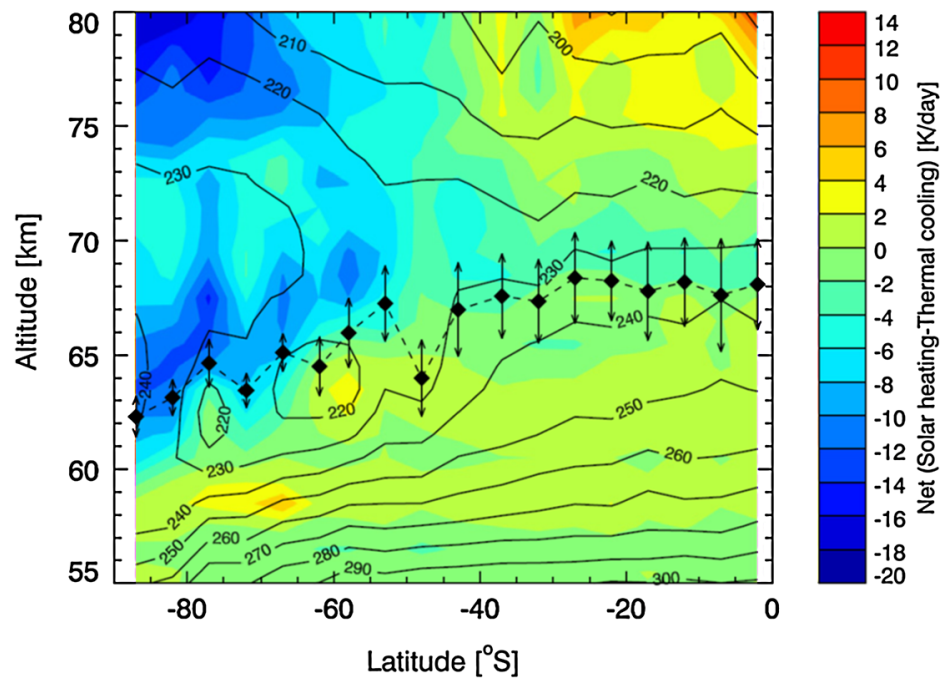

Fig. 35 Latitude-altitude field of the net radiative forcing in the Venus mesosphere (Lee et al. 2014)

UV to near-IR wavelengths mainly due to changes in cloud composition and distribution of the UV-blue absorbers with latitude. Cooling in the upper cloud and haze $(65-80 \mathrm{~km})$ increases with mode 2 particles abundance, while mode 3 enforces cooling at $55-65 \mathrm{~km}$. Solar heating rates strongly decrease with latitude due to decreasing Sun elevation angle while the effect of cloud structure is less significant that for cooling rates. The near-UV absorbers are responsible for up to $10 \mathrm{~K} /$ day additional heating at the cloud top. Its presence results in strong net heating in the upper cloud $(60-70 \mathrm{~km})$ during the day especially in low and middle latitudes vanishing towards the poles. Below about $53 \mathrm{~km}$ an excessive heating by the clouds results in overall very weak net heating at all latitudes. Comparison of radiative energy calculations by Lee et al. (2015) and Haus et al. (2016) at 60-80 km indicate that the results are very sensitive to the cloud model as well as latitudinal variations of the cloud structure and distribution of the near-UV absorbers.

Thermal radiation leaking from the hot lower atmosphere and the surface through the transparency "windows" gives minor contribution to the global radiative energy balance due to weakness of the emission escaping through the thick cloud layer (Fig. 34). However the radiative effect of the thermal emission from the hot lower atmosphere the deep cloud could be much stronger. Measurements of the flux in the near-IR transparency "windows" from orbit give an important clue on distribution of opacity over the globe (Figs. 12, 20). They indicate a factor of 5-7 decrease of the flux between tropics and polar regions that corresponds to about a factor of 2 increase in the cloud opacity.

\section{Lightning}

Conventional wisdom suggests that lightning should not occur in the atmosphere of Venus. However, the processes that lead to the build-up of charge and subsequent electric field breakdown in terrestrial lightning is still poorly known and is an emerging field of active research (see for example the recent joint ISSI-Europlanet workshop on Planetary Electricity (Bonnet and Blanc 2008)). These advances, along with more recent observational programs, 
have re-opened the case for lightning on Venus. We are only beginning to understand the requirements necessary for lightning on Earth, what does the application of that knowledge to Venus tell us? In order to trigger a lightning discharge, it is necessary to build up a sufficient quantity of charge that is separated by a distance of a few $\mathrm{km}$. Once the electric field produced by this charge build-up and separation exceeds the breakdown potential, a series of discharges occurs at a frequency of thousands per second (LF) to millions per second (HF), which the human eye perceives as a single lightning stroke (Zarka et al. 2008). Section 8.1 describes the evidence for and against the existence of potential mechanisms that can drive lightning processes in the Venus atmosphere. Nevertheless, as noted by Stolzenburg and Marshall (2008) in the aforementioned review on Planetary Electricity, "As is evident from this review, the electrical nature of thunderstorms on Earth is neither simple nor fully known."

The search for lightning on Venus has proceeded haltingly, with many reliable detections, and many reliable non-detections, across a range of observational techniques. A recent summary by Takahashi et al. (2008) guides the summary of past observations in Sect. 8.2, but a forthcoming review by Lorenz (2018) promises to pursue these observations and their intercomparisons in a far more comprehensive way than that of which we are capable in this more broadly focused review.

\subsection{Observational Evidence for and Against Venusian Lightning}

The first observational evidence of lightning on Venus was from the Venera 9/10 scanning spectrometer (Krasnopolsky 1983) that observed random flashing over a region of $5 \times 10^{4} \mathrm{~km}^{2}$. The mean flash duration was $0.25 \mathrm{~s}$, flash optical energy $2 \times 10^{7} \mathrm{~J}$, and a rate of $45 \mathrm{~km}^{-2} \mathrm{yr}^{-1}$ extrapolated over the whole planet. However, only one collection of events was observed during that mission. Subsequently, Venera-11, -12 detected radio emissions consistent with lightning discharges (Ksanfomaliti 1980). These tended to be at somewhat lower frequency than typical terrestrial discharges, however (Takahashi et al. 2008). The Pioneer Venus Orbiter Electric Field Detector (OEFD) also detected very low frequency signals (Scarf et al. 1980), but these signals were open to multiple interpretations.

The Galileo and Cassini spacecraft carried instrumentation designed to measure and characterize lightning on Jupiter and Saturn, respectively (Gurnett et al. 1991). During their Venus flybys, Galileo detected six pulses with radio frequency greater than $1 \mathrm{MHz}$, but the Cassini spacecraft detected nothing in the range $0.125 \mathrm{MHz}$ to $16 \mathrm{MHz}$, despite readily detecting signals of lightning during its Earth flyby and with flyby distances much closer to Venus than to Earth during each respective flyby. These discrepancies suggest that if lightning exists at Venus, then either Venusian lightning is much weaker than terrestrial in intensity (hence could not be detected), is a sporadic phenomenon (that Galileo was lucky enough to encounter, but Cassini was not), or occurs with much lower stroke frequencies during a discharge (hence detectable only in LF ranges (Zarka et al. 2008), which Cassini may not have been able to detect). Most recently, the Venus Express magnetometer has reported detection of low frequency radio detections of lightning at Venus. Circularly polarized electromagnetic waves with frequencies around $100 \mathrm{~Hz}$ have been interpreted by Russell et al. (2007) as whistler modes that would indicate a definitive detection of lightning in the atmosphere of Venus with frequency of occurrence being similar to that of Earth. More recent analysis suggests that both of these processes are likely occurring. Russell et al. (2013) concludes that linearly polarized signals detected by the Venus Express magnetometer at very low frequencies (less than about $20 \mathrm{~Hz}$ ) arise from interactions at the solar wind interface and cannot be attributed to lightning. However, they also conclude that the circularly polarized signals detected by Venus Express with slightly higher frequencies can only have an 
atmospheric source and remain consistent with an interpretation as whistler mode radiation having been generated by lightning in the atmosphere-likely the clouds-of Venus. It is difficult to calculate a lightning occurrence rate from the Venus Express data, because it could detect these signals only when within the ionosphere, low above the Northern hemisphere of the planet; however, an approximate estimate suggests that the lightning flash occurrence rate inferred from Whistler wave detections is of a similar order of magnitude to that found on Earth (Russell et al. 2007).

Optical searches for lightning - after the Venera-9, -10 observation mentioned abovealso include both positive and negative detections. The Pioneer Venus star tracker was utilized in a search for optical signatures of lightning in the Venus clouds, but was unsuccessful (Borucki et al. 1991). However, with only about $83 \mathrm{~s}$ of observing time over a two year search, this campaign was able to provide only an upper limit for lightning discharge frequency. Hansell et al. (1995) performed a ground-based optical search for lightning which resulted in 7 positive detections from about four hours of observation over eight nights, further suggesting either the low frequency of occurrence or the weak signal (or both). The only pre-planned and directed in situ optical search for lightning in the Venus clouds was carried out by the Soviet Vega balloons, which carried optical detectors pointed downward while the balloon floated at an equilibrium altitude of about $53 \mathrm{~km}$. In principle lightning occurring at altitudes near $57 \mathrm{~km}$ could have been detected by this search if not the strong background due to surface emission in $1 \mu \mathrm{m}$ transparency "window". Finally, Cardesín-Moinelo et al. (2016) conducted a search for lightning in the atmosphere of Venus in VIRTIS-M-Vis data between $0.3 \mu \mathrm{m}$ and $1.1 \mu \mathrm{m}$. They found a number of flash events in the data set; but none could be explained definitively and exclusively as having been produced by lightning. As a consequence, they report that the lightning rates reported by Russell et al. (2011) cannot be considered to be a global phenomenon. The Akatsuki orbiter, which arrived at Venus in 2016, carries a Lightning and Airglow camera which is designed to search for lightning in the $0.7774 \mu \mathrm{m}$ OI emission band (Takahashi et al. 2008); its initial results have yielded no lightning detections, but this still on the basis of a very small number of observations (Takahashi et al. 2018).

There have also been chemical arguments for existence of lightning. Krasnopolsky (2006) argued that if lightning would be the only source of nitric oxide in the lower atmosphere of Venus the observed NO mixing ratio of $5.5 \pm 1.5 \mathrm{ppb}$ requires the lightning energy deposition of $0.19 \pm 0.06 \mathrm{erg} \mathrm{cm}^{-2} \mathrm{~s}^{-1}$ that is even higher than that on the Earth.

\subsection{The Microphysics of Venusian Lightning}

For a complete discussion of the microphysics of the Venusian clouds, please see Sect. 6. Here we discuss only the processes relevant to the production of putative lightning discharges in the Venus clouds. Numerous charging mechanisms have been identified to have varying levels of importance on Earth and we discuss those which seem to be relevant to the Venusian atmosphere. The simplest case is ion-induced charging, which may be more important on Venus than Earth, due to the lack of an intrinsic magnetic field, which would allow greater numbers of cosmic rays and solar energetic particles to reach deeply into the atmosphere, possibly to the altitudes inhabited by the clouds (Nordheim et al. 2015). Ioninduced charging is a function of supersaturation and temperature (Aplin 2013), suggesting that the lower clouds are the ideal location for this type of charging process to occur. Furthermore, the lower vapour pressure of sulphuric acid and its larger permittivity than that of water mean that smaller supersaturations will be required to drive ion-induced charging in the Venus atmosphere. While Aplin (2013) suggests that the conditions for ion-induced 


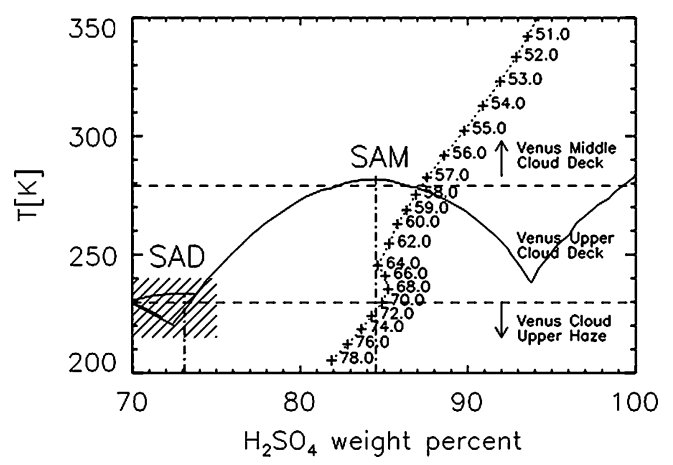

Fig. 36 The sulphuric acid freezing/melting phase diagram. The solid line represents the freezing temperature of sulfuric acid as a function of weight percent (by mass), from Gable et al. (1950). Sulfuric acid above the line is liquid, below is either frozen or supercooled liquid. Note that, in this diagram, temperature increases vertically, so altitude increases downwards. Finally, also plotted, with a dotted line, is the "cooling curve" of a typical Venus sulphuric acid aerosol, assuming temperature profile from the Venus International Reference Atmosphere (Kliore et al. 1986), and water vapor mixing ratio vertical profile from Fig. 16b of Pollack et al. (1993); individual Venus altitudes are indicated by symbols $(+)$. The weight percents of the monohydrate (SAM) and dihydrate (SAD) are indicated by the dash-dot vertical lines. For comparison, typical Earth Stratospheric conditions are indicated by the diagonal hatching on the lower left of the diagram. A similar version of this figure appeared in McGouldrick et al. (2011)

charging are best in the vicinity of the lower clouds (due to the higher temperatures), supersaturations can become very large indeed in the upper clouds and hazes (Gao et al. 2014; McGouldrick 2017). It may be possible that these large supersaturations may overcome the temperature effect to encourage ion-induced charging in the upper clouds of Venus.

Perhaps the most likely means of charge build-up on Venus aerosols would be triboelectric charging. On Earth, this usually requires co-existence of frozen and liquid phases of water; but can also proceed due to interactions of a compositionally homogeneous population with a range of sizes (e.g. triboelectric charging of volcanic dust during an eruption). On Venus, the solution of sulphuric acid and water that is the primary composition of the cloud particles has a freezing point that is a function of both the temperature and the acid mass concentration (which itself is a function of the water vapour concentration and the temperature). Note in Fig. 36 that for typical Venus conditions (as estimated from the VIRA equatorial model), the phase change occurs at $57 \mathrm{~km}$, around the level of the transition between the upper (photochemical) and middle and lower (condensational) clouds. Thus, interactions between frozen and melted sulphuric acid cloud droplets near $57 \mathrm{~km}$, followed by subsequent separation (whether gravitationally or via vertical shear of the zonal wind), could lead to build-up of sufficient charge to lead to lightning discharges on Venus. A complication is that in the laboratory, and in the terrestrial stratosphere, it has proven exceedingly difficult to freeze sulphuric acid (Zhang et al. 1993). On the other hand, supercooled sulphuric acid (and in the Venus atmosphere, SAM (see Fig. 36) may exist in conditions $50 \mathrm{~K}$ below its freezing point) is known to become highly viscous and glasslike (Horn and Sully 1999). In this case, collisions between cloud particles would behave more like homogeneous triboelectric charging, in which differences in particle radius drive the exchange of electrons (Forward et al. 2009). The smooth surfaces of the glasslike sulphuric acid would encourage charge separation, and the magnitude of this charge separation would be a function of the differences in the sizes of the colliding particles (Yair et al. 2008; Lacks and Levandovsky 2007). Thus, if triboelectric charging of sulphuric acid cloud particles is the source of the putative Venusian lightning, then the mostly likely place for the 
charge build-up and separation to be occurring would be the region between the upper and middle clouds.

A final possible mechanism for Venusian lightning is near-surface triboelectric charging due to collisions of sediments near the surface lofted either by Aeolian or Volcanic processes. This mechanism, however, has some challenges to overcome. For example, there is in the continued lack of direct evidence for volcanism near the surface. The population of particles suitable for saltation and the magnitudes of the near surface winds that would drive such transport are poorly known. Finally, the large dielectric constant of such a dense atmosphere suggests that very large charges must be accumulated on particles in order to achieve a breakdown of the electric field.

\section{Synthesis of the Cloud Properties}

Vertical Structure Venus possesses the largest and the most complex cloud system among the terrestrial planets. The clouds that completely shroud the planet are located in the altitude range of approximately 50-70 km with upper and lower haze extending up to about $100 \mathrm{~km}$ and $30 \mathrm{~km}$ correspondingly, thus occupying the upper troposphere and the entire mesosphere. The total opacity of the cloud at visible and near-IR wavelengths varies from 20 to 40 showing remarkable spatial and latitudinal variability. The vertical structure of the cloud was established by Venera, Pioneer-Venus and Vega descent probes with several layers identified from the measurements of extinction coefficient and number density (see Esposito et al. 1983, 1997 and references therein). Venus Express observations significantly complemented and detailed the earlier picture especially concerning the properties of the mesospheric haze as well as spatial and latitudinal variability of the cloud properties.

Figure 37 shows a synthesis of the latitude-altitude cloud structure and microphysical properties. The upper haze occupies almost the entire mesosphere from about $100 \mathrm{~km}$ down to the cloud top (blue line in Fig. 37), defined as the altitude of vertical opacity $\tau=1$ at visible wavelengths. This level is located at $\sim 70 \mathrm{~km}$ at low latitudes and gradually descends to $\sim 62 \mathrm{~km}$ at the poles (Figs. 12,37) thus changing by about two atmospheric scale heights and creating a vast polar depression The aerosol scale height in the upper cloud follows a similar trend decreasing from 4-5 km at low-middle latitudes to 1-2 km in the "cold collar" $\left(60-70^{\circ}\right)$ and polar regions correlating with the mesospheric temperature field (Fig. 37). Remarkably, the "cold collar" also marks the latitudinal boundary at which the total cloud opacity at $1 \mu \mathrm{m}$ abruptly increases by a factor of 2-3 (Fig. 20).

The green line in Fig. 37 marks the tropopause (Tellmann et al. 2009). This boundary separates the region of photochemical production of sulphuric acid (upper cloud and haze) from the condensational cloud below (see Fig. 27) and can be considered as the physical base of the upper cloud. The middle and lower clouds are located below the tropopause where convection dominates. The cloud base is located at $48-50 \mathrm{~km}$ at low and middle latitudes. There are evidences from the sounding in the near-IR transparency "windows" and radio-occultations that in the polar regions the cloud deck extends to even below $45 \mathrm{~km}$ (Barstow et al. 2011; Tellmann et al. 2009). At this altitude sulphuric acid becomes thermodynamically unstable but fine lower haze of presumably different composition exists down to $\sim 30 \mathrm{~km}$. There is also a tentative indication of near-surface haze (Grieger et al. 2004) which is not shown in Fig. 37.

Cloud Morphology Morphology of the cloud tops was recently studied by extensive imaging of the planet in the near-UV range by Venus Express and Akatsuki orbiters. The 
Fig. 37 Sketch of the Venus clouds latitude-altitude structure: upper haze (light blue), upper cloud (blue and yellow "droplets"), middle and lower clouds (blue and red "droplets"), lower haze (red "droplets"). Black contours show isolines of the Venera-15 temperature field (from Lellouch et al. 1997). Blue, green and red solid lines mark the cloud top ( $\tau=1$ level), the tropopause and the cloud base respectively. Mean parameters of the cloud layers are shown in semi-transparent inserts

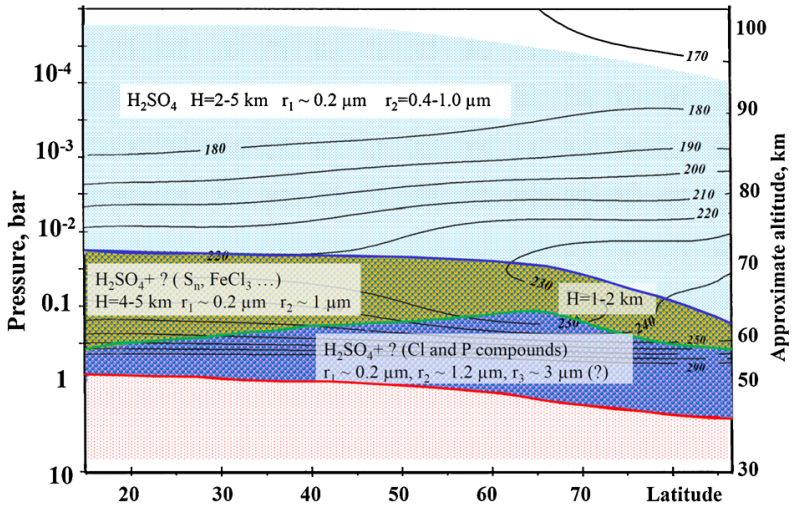

observations revealed in unprecedented detail and variability the well-known UV markings created by non-uniform distribution of the unknown absorber or absorbers. The low latitudes are dominated by mottled and fragmented clouds clearly indicating vivid convective activity centred in the sub-solar region (Figs. 13-18; Titov et al. 2012). The aerosol scale height in the upper cloud derived from IR observations is quite large here: $3.5-5 \mathrm{~km}$ (Figs. 3, 11). The low and middle latitudes are significantly darker at UV wavelengths than the polar regions suggesting continuous supply of UV-dark material from depth. The dark equatorial band whose shape resembles a "Y" or "V" letter is likely to be created by this process.

At $50-60^{\circ}$ latitude the mottled cloud pattern gives way to streaky morphology suggesting that horizontal, almost laminar, flow prevails here. The dark mid-latitude band has very sharp poleward boundary likely indicating strong jet-like flows right at the cloud tops. The streaks inclination with respect to the latitudinal circles is consistent with the measured zonal and meridional wind speeds.

At high latitudes the planet is covered by almost featureless UV-bright polar hood. Size of the "polar cap" varies, but usually it encompasses the "cold collar" and polar regions and approximately coincides with the cloud top depression. The "polar cap" appearance changes from transparent haze through which the main cloud is clearly visible to dense, bright and featureless hood (Fig. 17). The "polar cap" is often crossed by thin dark circular or spiral "grooves" a few hundred kilometres wide that are likely to be created by local jet flows. The most frequently observed polar feature is the UV-dark oval located at $\sim 70^{\circ} \mathrm{S}$. The "eye" of the hemispheric vortex - a strongly variable bright feature observed in the thermal-IR - is located inside the oval and is dynamically related to it. Since the cloud top is the deepest at the pole, it has the highest temperature here. After the Pioneer Venus mission this feature was dubbed "polar dipole", but recent imaging by Venus Express showed that the shape of the vortex eye can change from a simple oval to complex multi-centre structure (Fig. 19). Limaye et al. (2009) succeeded to simulate the "eye" morphology with an idealized nonlinear and non-divergent barotropic model and found similar structures in the modelled vorticity field. In general, the hemispheric vortex circulation on Venus has remarkable morphological similarities to the Earth's tropical cyclones and hurricanes, although the energy sources in two cases are different.

The latitudinal behavior of the cloud top altitude and aerosol structure is correlated with the mesospheric temperature field (Figs. 8, 37). The cloud top starts descending with latitude at the equatorward edge of the "cold collar" $\left(\sim 60^{\circ}\right)$ and approximately follows $220-230 \mathrm{~K}$ temperature isolines (Fig. 37). This trend is accompanied by a decrease of the aerosol scale height reaching less than $1 \mathrm{~km}$ value in the "cold collar". At higher latitudes the aerosol 
scale height is usually less than $2 \mathrm{~km}$, but in some warm locations clouds may be rather diffuse with scale height exceeding $5 \mathrm{~km}$ (Fig. 11). This indicates strong variability of the cloud and temperature structure in the polar regions.

The cloud vertical structure and morphology can be correlated with the observed temperature and dynamic features. Drastic changes in the cloud morphology, i.e. transition from patchy and mottled clouds in low latitudes to bright uniform polar hood, occurs in the "cold collar" region $\left(50-60^{\circ}\right)$. We suggest that this behavior is likely related to the Hadley circulation in the mesosphere that has upwelling branch at equator and downwelling motions at $\sim 60^{\circ}$ latitude. Very "sharp" cloud top with small aerosol scale height $(\leq 2 \mathrm{~km})$ in the "cold collar" coincides with the coldest regions in temperature inversions (Figs. 8, 37). This feature is likely of radiative origin. The sharp cloud top boundary provides effective cooling to space that maintains low temperatures. Strong temperature inversions in turn create convectively stable conditions above the cloud top thus preventing vertical mixing of aerosols and maintaining sharp cloud boundary. This negative feedback between dynamical conditions and radiative effects maintains a stable cloud top structure in the "cold collar" region. The middle and high latitudes are also characterized by vanishing vertical wind shear within the clouds (Sánchez-Lavega et al. 2008) that suppresses wind shear instabilities. Titov et al. (2008) used the peculiarities of stability distribution at the cloud top to qualitatively explain the global pattern of the UV markings.

High resolution imaging of the Venus cloud top enabled detailed study of small scale features (Fig. 18). In low latitudes the mottled clouds form convective cells and wave trains with typical scale of 100-200 km. "Column" clouds resembling Earth cumulus clouds few tens of kilometres across are often present. These structures as well as small streaks show signs of strong lateral advection right above the cloud top.

Imaging in the near-IR transparency "windows" on the night side showed significant variations of total cloud opacity thus revealing morphology of the middle and lower cloud. The general trend is that the cloud is the most transparent at $40-60^{\circ}$ latitude with opacity increasing towards the equator and the poles (Crisp et al. 1991). Poleward of $\sim 60^{\circ}$ the cloud becomes so opaque that almost no radiation can escape to space and no information on the deep cloud morphology can be derived from the observations (Fig. 20). The models that couple general circulation and cloud formation processes imply that meridional Hadley circulation can lead to opacity increase in both ascending branch at equator and descending flow at the poles (Imamura and Hashimoto 1998). The deep cloud has patchy or blocky structure equatorward of $\sim 40^{\circ}$. Opacity inhomogeneities can be as large as $2000 \mathrm{~km}$ (Fig. 12). Lifetime of the holes spans from few hours to several weeks with larger inhomogeneities living longer. At middle latitudes the features become elongated and tilted with respect to latitudinal circles that is consistent with vortex circulation converging at the poles (Belton et al. 1991; McGouldrick et al. 2008). The overall pattern of opacity inhomogeneities observed in the deep cloud suggests active convection equatorward of $\sim 40^{\circ}$ and laminar circulation at higher latitudes similar to what is seen at the cloud top.

Composition and Chemistry The Venus cloud is a complex chemical system in tight interaction with the gaseous chemistry and photochemistry of the atmosphere. Both observations and models provide strong evidence that at least aerosols of the upper cloud and upper haze are composed mainly of concentrated sulphuric acid $\mathrm{H}_{2} \mathrm{SO}_{4}$ with mass concentration of 75-83\% at the cloud tops (Esposito et al. 1997; Cottini et al. 2015; Krasnopolsky 2015) with tentative trend to increase up to $90 \%$ in the polar regions (Barstow et al. 2011). Sulphuric acid is formed from sulphur dioxide and water vapour under solar light. The photochemical "factory" is located in the upper cloud layer (Figs. 27, 37). Nature of additional 
components responsible for the near-UV absorption in the upper cloud is still a matter of debate but the most favourable candidates are iron chloride and sulphur allotropes or related sulphur species. Observations also suggest presence of more than one UV-blue absorbers. Sulphuric acid evaporates at the cloud bottom near $48 \mathrm{~km}$ and is thermally decomposed at about $40 \mathrm{~km}$ (Krasnopolsky 2013).

Several experiments on descent probes indicated presence of non-sulphuric acid aerosols in the deep atmosphere. In-situ chemical analysers onboard Venera and Vega probes detected presence of chlorine, phosphorous and iron compounds in relatively large amounts in addition to sulphur bearing particles. The optical measurements onboard Pioneer Venus tentatively suggested the presence of large $(r>3 \mu \mathrm{m})$ non-spherical particles for which sulphuric acid composition is excluded. The lower hazes detected at $33-48 \mathrm{~km}$ by several descent probes are found at temperatures too elevated for sulphuric acid droplets to exist.

Microphysical Properties Venus clouds consist of fine particles with sizes of up to about $10 \mu \mathrm{m}$. According to LCPS/Pioneer Venus cloud particle spectrometer (Knollenberg and Hunten 1980) the particle size distribution in the main cloud deck has up to three modes (Esposito et al. 1983). Mode 1 includes fine sub-micron aerosols $(r \sim 0.1-0.2 \mu \mathrm{m})$ with number density of few thousand particles per $\mathrm{cm}^{3}$ (Fig. 37). Mode 2 consists of micron size particles $(r \sim 1 \mu \mathrm{m})$ with number density $n \sim 50 \mathrm{~cm}^{-3}$. Modes 1 and 2 are ubiquitously present in the main cloud deck. Larger particles (mode 3) with $r \sim 3-4 \mu \mathrm{m}$ and number density of few tens of particles per $\mathrm{cm}^{-3}$ were found in the middle and lower cloud layers below $56 \mathrm{~km}$. However, the controversy whether large particles form a separate mode or they are just a "tail" of the mode 2 is still not resolved (Esposito et al. 1997). Also ISAV-A particle size spectrometer onboard Vega-1, -2 probes that descended close to equator detected very small number of particles with $r>2.5 \mu \mathrm{m}$ and did not confirm existence of mode 3 aerosols (Moshkin et al. 1986; Gnedykh et al. 1987).

All observations suggest that the cloud properties in the "cold collar" and polar regions significantly differ from those at low latitudes. Analysis of the near-infrared emissions on the Venus nightside revealed anomalous particles in the deep cloud in the polar regions (Wilson et al. 2008; Barstow et al. 2011; Haus et al. 2013). These particles are either larger or differ in composition from those elsewhere on the planet.

The upper haze is ubiquitously present in the mesosphere at altitude $70-100 \mathrm{~km}$. Microphysical properties of the aerosols in this region were extensively investigated in solar and stellar occultations onboard Venus Express (Wilquet et al. 2009; Luginin et al. 2016). Both submicron and micron size particles were found here. Gao et al. (2014) reproduced the observed size distribution and number density of aerosol particles in the main cloud and upper haze using coupled microphysical and vertical transport models. Interestingly, the model generated a quasi-periodically varying system rather than a system with a stable equilibrium distribution. The upper haze properties appear to result from a mixture of droplets formed from in situ nucleation of sulphuric acid vapor on meteoric dust and droplets upwelled from the cloud decks below.

\section{Open Issues and Future Studies}

The past couple of decades have seen remarkable progress in our understanding of the Venus cloud system. This was achieved mainly by remote sensing techniques that allowed detailed characterization of the morphology and vertical structure of the cloud layer including its 
spatial and temporal variations. The most important remaining open issues are related to the composition and chemistry of the cloud layer. The detection of chlorine and phosphorous compounds in amounts exceeding that of sulphur by the Vega descent probes still challenges chemical models. Moreover, the nature and origin of the unknown UV-blue absorbers that are of crucial importance for understanding of chemistry, radiative balance and dynamics of the Venus atmosphere still remains a mystery. This justifies the urgent need for an in-situ analysis of Venus aerosols onboard descent probes and especially long-living aerial platforms (balloons) with a capability of changing floating altitude in order to unambiguously resolve both open issues in composition of the Venus clouds. Middle-to-high-resolution Venus spectra would also be welcome, particularly if they provide spatial resolution to separate regions with higher and lower UV-blue absorption. The wavelength range of $0.4-0.5 \mu \mathrm{m}$ is of the highest interest, as it may provide very useful constraints on the nature of the near-UV absorption in Venus atmosphere. High-resolution spectra would also help to separate spectral features of gaseous and particulate species, thus constraining the physical state of the near-UV absorbers. High-resolution spectroscopy in the near-IR transparency "windows" still have a great potential in characterization of the atmospheric chemistry below the clouds that is strongly related to the clouds composition.

The Venus clouds appear to be a very variable system with many complex couplings that are far from being understood. Spatial and temporal variations of the planet albedo, especially in the UV-blue domain, as well as total cloud opacity need to be investigated to detect changes over various time scales. These studies are of great importance for understanding of energy balance and dynamics of the Venus atmosphere. Measurements in the cloud layer are needed to distinguish between inorganic and hypothetic organic/biologic absorbers.

These efforts should be supported by laboratory modelling of aerosol chemistry and study of optical properties of its particulate products. As future work, there are essentially two aspects that should be investigated. Laboratory spectra of already proposed or new candidates for the near-UV absorption at the conditions of the upper Venus atmosphere (temperature, pressure, and solar radiation) are required. Recent years witnessed development of sophisticated microphysical models simulating the processes of formation, growth and decomposition of sulphuric acid aerosols. These models should be expanded to the other species (for instance, elemental sulphur) that are the candidates for the unknown near-UV absorbers. The next step would be incorporation of the microphysical models in regional and global circulation models that would elucidate the feedbacks between microphysics, chemistry, and the momentum and energy balance.

Laboratory studies of sulphuric acid aerosols at high concentrations including phase behaviour are required in order to better constrain the microphysical properties of the aerosols under Venus conditions. The relative solubility between the sulphuric acid and potential cloud condensation nuclei has tremendous effects on the size and mass distributions of the Venus aerosol. The laboratory support is of high importance for developing consistent models of the cloud evolution.

In order to improve our understanding of the plausibility and, if it exists, the characteristics of Venus lightning, additional observations, as well as detailed laboratory and modelling studies are required. Search for optical detection of lightning at the cloud tops by orbiting spacecraft (Borucki et al. 1996; Takahashi et al. 2008) and in situ optical, radio wave and electric field monitoring can help elucidate the frequency and location of the occurrence of Venus lightning. These efforts should be complemented by laboratory studies exploring the charging properties of multi-phase sulphuric acid in Venus-like conditions, or of homogeneous triboelectric charging of glassy sulphuric acid are required. 
Acknowledgements This work significantly benefited from discussions within the Venus Clouds International Team supported by the International Space Science Institute in Bern, Switzerland. The authors are grateful to both reviewers for careful reading of the manuscript and useful comments and suggestions.

Open Access This article is distributed under the terms of the Creative Commons Attribution 4.0 International License (http://creativecommons.org/licenses/by/4.0/), which permits unrestricted use, distribution, and reproduction in any medium, provided you give appropriate credit to the original author(s) and the source, provide a link to the Creative Commons license, and indicate if changes were made.

\section{References}

D.A. Allen, J.W. Crawford, Nature 307, 222 (1984)

B.M. Andreichikov, Kosm. Issled. 25, 737 (1987) (in Russian)

K.L. Aplin, Electrifying Atmospheres: Charging, Ionisation and Lightning in the Solar System and Beyond, 1st edn. (Springer, Dordrecht, 2013), p. 13

G. Arney, V. Meadows, D. Crisp, S.J. Schmidt, J. Bailey, T. Robinson, J. Geophys. Res., Planets 119, 1860 (2014)

R.D. Baker et al., J. Atmos. Sci. 57, 184-199 (2000). https://doi.org/10.1175/1520-0469(2000)057<0200: CGIGWI $>2.0 . \mathrm{CO} ; 2$

J.K. Barstow, C.C.C. Tsang, C.F. Wilson, P.G.J. Irwin, F.W.K. McGouldrick, P. Drossart, G. Piccioni, S. Tellmann, Icarus 217, 542 (2011)

M.J.S. Belton, G.R. Smith, G. Schubert, A.D. Del Genio, J. Atmos. Sci. 33, 1394 (1976)

M.J.S. Belton, P.J. Gierasch, M.D. Smith, P. Hilfenstein, P.J. Schinder, J.B. Pollack, K.A. Rages, A.P. Ingersoll, K.P. Klaasen, J. Veverka, C.D. Anger, M.H. Carr, C.R. Chapman, M.E. Davies, F.P. Fanale, R. Geeley, R. Greenberg, J.W. Head III., D. Morrison, G. Neukum, C.B. Pilcher, Science 253, 1531 (1991)

D.A. Belyaev, F. Montmessin, J.-L. Bertaux, A. Mahieux, A. Fedorova, O.I. Korablev, E. Marcq, Y.L. Yung, X. Zhang, Icarus 217(2), 740-751 (2012). https://doi.org/10.1016/j.icarus.2011.09.025

J.-L. Bertaux, T. Widemann, A. Hauchecorne, V.I. Moroz, A.P. Ekonomov, J. Geophys. Res. 101, 12709 (1996)

J.-L. Bertaux, D. Nevejans, O. Korablev, E. Villard, E. Quémerais, E. Neefs, F. Montmessin, F. Leblanc, J.P. Dubois, E. Dimarellis, A. Hauchecorne, F. Lefèvre, P. Rannou, J.Y. Chaufray, M. Cabane, G. Cernogora, G. Souchon, F. Semelin, A. Reberac, E. Van Ransbeek, S. Berkenbosch, R. Clairquin, C. Muller, F. Forget, F. Hourdin, O. Talagrand, A. Rodin, A. Fedorova, A. Stepanov, I. Vinogradov, A. Kiselev, Yu. Kalinnikov, G. Durry, B. Sandel, A. Stern, J.C. Gérard, Planet. Space Sci. 55, 1673 (2007)

J.-L. Bertaux, I.V. Khatuntsev, A. Hauchecorne, W.J. Markiewicz, E. Marcq, S. Lebonnois, M. Patsaeva, A. Turin, A. Fedorova, J. Geophys. Res., Planets 121, 1087 (2016). https://doi.org/10.1002/2015JE004958

R.-M. Bonnet, M. Blanc, Space Sci. Rev. 137, 1 (2008)

W.J. Borucki, J.W. Dyer, J.R. Phillips, P.C. Pham, J. Geophys. Res. 96, 11033 (1991)

W.J. Borucki, C.P. McKay, D. Jebens, H.S. Lakkaraju, C.T. Vanajakshi, Icarus 123, 336 (1996)

C.J. Braak, J.F. de Haan, J.W. Hovenier, J. Geophys. Res. 107(E5), 5029 (2002)

A. Cardesín-Moinelo, G. Piccioni, E. Ammannito, G. Filacchione, P. Drossart, IEEE Trans. Geosci. Remote Sens. 48, 3941 (2010)

A. Cardesín-Moinelo, S. Abildgaard, A. García Muñoz, G. Piccioni, D. Grassi, Icarus 277, 395 (2016)

R.W. Carlson, K.H. Baines, T. Encrenaz, F.W. Taylor, P. Drossart, L.W. Kamp, J.B. Pollack, E. Lellouch, A.D. Collard, S.B. Calcutt, D. Grinspoon, P.R. Weismsman, W.D. Smythe, A.C. Ocampo, G.E. Danielson, F.P. Fanale, T.V. Johnson, H.H. Kiefer, D.L. Matson, T.B. McCord, L.A. Soderblom, Science 253, 1541 (1991)

R.W. Carlson, L.W. Kamp, K.H. Baines, J.B. Pollack, D.H. Grinspoon, Th. Encrenaz, P. Drossart, F.W. Taylor, Planet. Space Sci. 41, 477 (1993)

R.W. Carlson, G. Piccioni, G. Fillacchione, R. Mehlman, M.S. Anderson, Y. Yung, P. Gao, in Abstract at the International Venus Conference, Oxford, UK (2016)

S. Chamberlain, J. Bailey, D. Crisp, V. Meadows, Icarus 222, 364 (2013)

V. Cottini, N.I. Ignatiev, G. Piccioni, P. Drossart, D. Grassi, W.J. Markiewicz, Icarus 217, 561 (2012)

V. Cottini, N.I. Ignatiev, G. Piccioni, P. Drossart, Planet. Space Sci. 113, 219 (2015)

D. Crisp, Icarus 514, 484 (1986)

D. Crisp, D. Titov, in Venus-II, ed. by S.W. Bougher, D.M. Hunten, R.J. Phillips (University of Arizona Press, Tucson, 1997), p. 353

D. Crisp, A.T. Young, Icarus 35, 182 (1978) 
D. Crisp, W.M. Sinton, K.-W. Hodapp, B. Ragent, F. Gerbault, J.H. Goebel, R.G. Probst, D.A. Allen, K. Pierce, K.R. Stapelfeldt, Science 246, 506 (1989)

D. Crisp, A.P. Ingersoll, C.E. Hildebrand, R.A. Preston, Adv. Space Res. 10, 109 (1990)

D. Crisp, D.A. Allen, D.H. Grinspoon, J.B. Pollack, Science 253, 1263 (1991)

R. de Kok, P.G.J. Irwin, C.C.C. Tsang, G. Piccioni, P. Drossart, Icarus 211, 51 (2011)

P. Drossart, G. Piccioni et al., Planet. Space Sci. 55, 1653 (2007)

A.P. Ekonomov, V.I. Moroz, B.E. Moshkin, V.I. Gnedykh, Yu.M. Golovin, A.V. Grigoriev, Nature 307, 345 (1984)

T. Encrenaz, T.K. Greathouse, H. Roe, M. Richter, J. Lacy, B. Bézard, T. Fouchet, T. Widemann, Astron. Astrophys. A153, 543 (2012)

L.W. Esposito, L.D. Travis, Icarus 51, 374 (1982)

L.W. Esposito, J.R. Winick, A.I. Stewart, Geophys. Res. Lett. 6, 601 (1979)

L.W. Esposito, R.G. Knollenberg, M.Ya. Marov, R.B. Toon, R.P. Turko, in Venus, ed. by D.M. Hunten, L. Colin, T.M. Donahue, V.I. Moroz (University of Arizona Press, Tucson, 1983), p. 484

L.W. Esposito, J.-L. Bertaux, V. Krasnopolsky, V.I. Moroz, L.V. Zasova, in Venus II, ed. by S.W. Bougher, D.M. Hunten, R.J. Phillips (University of Arizona Press, Tucson, 1997), p. 415

A. Fedorova, E. Marcq, M. Luginin, O. Korablev, J.-L. Bertaux, F. Montmessin, Icarus 275, 143 (2016)

K.M. Forward, D.J. Lacks, R.M. Sankaran, Phys. Rev. Lett. 102, 028001 (2009). https://doi.org/10.1103/ PhysRevLett.102.028001

B.N. Frandsen, P.O. Wennberg, H.G. Kjaergaard, Geophys. Res. Lett. 43, 11146 (2016)

T. Fukuhara, M. Futaguchi, G.L. Hashimoto, T. Horinouchi, T. Imamura, N. Iwagaimi et al., Nat. Geosci. 10, 85 (2017). https://doi.org/10.1038/ngeo2873

C.M. Gable, H.M. Betz, S.H. Maron, J. Am. Chem. Soc. 72, 1445 (1950). https://doi.org/10.1021/ $\mathrm{ja} 01160 \mathrm{a} 005$

P. Gao, X. Zhang, D. Crisp, C.G. Bardeen, Y.L. Yung, Icarus 231, 83 (2014)

I. Garate-Lopez, A. García Muñoz, R. Hueso, A. Sánchez-Lavega, Icarus 245, 16 (2015)

A. García Muñoz, S. Pérez-Hoyos, A. Sánchez-Lavega, Astron. Astrophys. 566(L1), 1 (2014)

B.G. Gel'man, Yu.V. Drozdov, V.V. Mel'nikov, V.A. Rotin, V.N. Khokhlov, V.B. Bondarev, G.G. Dol'nikov, A.V. Dyachkov, A.A. Fursov, L.M. Mukhin, D.F. Nenarokov, N.V. Porshnev, Sov. Astron. Lett. 12, 42 (1986)

V.I. Gnedykh, L.V. Zasova, V.I. Moroz, B.E. Moshkin, A.P. Ekonomov, Kosm. Issled. 25, 707 (1987) (in Russian)

B. Grieger, N.I. Ignatiev, N.M. Hoekzema, H.U. Keller, in Proceedings of the International Workshop Planetary Probe Atmospheric Entry and Descent Trajectory Analysis and Science, ed. by A. Wilson, 69 October 2003, Lisbon, Portugal. ESA, vol. SP-544. ESA Publications Division, Noordwijk (2004), pp. 63-70. ISBN 92-9092-855-7

D.H. Grinspoon, J.B. Pollack, B.R. Sitton, R.W. Carlson, L.W. Kamp, K.H. Baines, Th. Encrenaz, F.W. Taylor, Planet. Space Sci. 41, 515 (1993)

D.A. Gurnett, W.S. Kurth, A. Roux, R. Gendrin, C.F. Kennel, S.J. Bolton, Science 253, 1522 (1991)

B.M. Haeusler, M. Paetzold, G.L. Tyler, R.A. Simpson, M.K. Bird, V. Dehant, J.-P. Barriot, W. Eidel, R. Mattei, S. Remus, J. Selle, S. Tellmann, T. Imamura, Planet. Space Sci. 54, 1315 (2006)

S.A. Hansell, W.K. Wells, D.M. Hunten, Icarus 117, 345 (1995)

J.E. Hansen, J.W. Hovenier, J. Atmos. Sci. 31, 1137 (1974)

B. Hapke, R. Nelson, J. Atmos. Sci. 32, 1212 (1975)

R. Haus, D. Kappel, G. Arnold, Planet. Space Sci. 89, 77 (2013)

R. Haus, D. Kappel, G. Arnold, Icarus 232, 232 (2014)

R. Haus, D. Kappel, S. Tellmann, G. Arnold, G. Piccioni, P. Drossart, B. Häusler, Icarus 272, 178 (2016)

J.H. Hoffman, V.I. Oyama, U. von Zahn, J. Geophys. Res. 85, 7871 (1980)

T. Horinouchi, S. Murakami, T. Satoh, J.K. Ogohara, T. Kouyama, T. Imamura, H. Kashimura, S.S. Limaye, K. McGouldrick, M. Nakamura, T.M. Sato, K. Sugiyama, M. Takagi, S. Watanabe, M. Yamada, A. Yamazaki, E.F. Young, Nat. Geosci. 10, 646 (2017)

A.B. Horn, K.J. Sully, Phys. Chem. Chem. Phys. 1, 3801 (1999)

R. Hueso, A. Sánchez-Lavega, Icarus 188, 305 (2007)

N.I. Ignatiev, D.V. Titov, G. Piccioni, P. Drossart, W.J. Markiewicz, V. Cottini, Th. Roatsch, M. Almeida, N. Manoel, J. Geophys. Res. 114, 405 (2009)

T. Imamura, G.L. Hashimoto, J. Geophys. Res. 103(E13), 31349 (1998)

T. Imamura, G.L. Hashimoto, J. Atmos. Sci. 58, 3597 (2001)

T. Imamura, T. Higuchi, Y. Maejima, M. Takagi, N. Sugimoto, K. Ikeda, H. Ando, Icarus 228, 181 (2014)

N. Iwagami, S. Takagi, S. Ohtsuki, M. Ueno, K. Uemizu, T. Satoh, T. Sakanoi, G.L. Hashimoto, Earth Planets Space 63, 487 (2011)

E.P. James, O.B. Toon, G. Schubert, Icarus 129, 147 (1997) 
T.V. Johnson, C.M. Yeates, R. Young, J. Dunne, Science 253, 1536 (1991)

K. Kawabata, D.L. Coffeen, J.E. Hansen, W.A. Lane, M. Sato, L.D. Travis, J. Geophys. Res. 85(A13), 8129 (1980)

I.V. Khatuntsev, M.V. Patsaeva, D.V. Titov, N.I. Ignatiev, A.V. Turin, S.S. Limaye, W.J. Markiewicz, M. Almeida, Th. Roatsch, R. Moissl, Icarus 226, 140 (2013)

A. Kliore et al., Venus International Reference Atmosphere (1986)

R.G. Knollenberg, D.M. Hunten, Science 203, 792 (1979)

R.G. Knollenberg, D.M. Hunten, J. Geophys. Res. 85, 8039 (1980)

M.E. Koukouli, P.G.J. Irwin, F.W. Taylor, Icarus 173, 84 (2005)

V.A. Krasnopolsky, in Venus, ed. by D.M. Hunten, L. Colin, T.M. Donahue, V.I. Moroz (University of Arizona Press, Tucson, 1983), p. 459

V.A. Krasnopolsky, Icarus 80, 202 (1989)

V.A. Krasnopolsky, Icarus 182, 80 (2006)

V.A. Krasnopolsky, Icarus 191, 25 (2007)

V.A. Krasnopolsky, Icarus 215, 197 (2011). https://doi.org/10.1016/j.icarus.2011.06.036

V.A. Krasnopolsky, Icarus 218, 230-246 (2012). https://doi.org/10.1016/j.icarus.2011.11.012

V.A. Krasnopolsky, Icarus 225, 570 (2013). https://doi.org/10.1016/j.icarus.2013.04.026

V.A. Krasnopolsky, Icarus 252, 327 (2015)

V.A. Krasnopolsky, Icarus 274, 33 (2016). https://doi.org/10.1016/j.icarus.2016.03.010

V.A. Krasnopolsky, Icarus 286, 134 (2017)

V.A. Krasnopolsky, Icarus 299, 294 (2018)

V.A. Krasnopolsky, J.B. Pollack, Icarus 109, 58 (1994)

L.V. Ksanfomaliti, Science 284, 244 (1980)

D.J. Lacks, A. Levandovsky, J. Electrost. 65, 107 (2007)

W.A. Lane, R. Opstbaum, Icarus 54, 48 (1983)

Y.J. Lee, D.V. Titov, S. Tellmann, A. Piccialli, N.I. Ignatiev, M. Pätzold, B. Häusler, G. Piccioni, P. Drossart, Icarus 217, 599 (2012)

Y.J. Lee, D.V. Titov, N.I. Ignatiev, S. Tellmann, M. Pätzold, G. Piccioni, Planet. Space Sci. (2014). https:// doi.org/10.1016/j.pss.2014.12.006i

Y.J. Lee, T. Imamura, S.E. Schröder, E. Marcq, Icarus 253, 1 (2015)

Y.J. Lee, A. Yamazaki, T. Imamura, M. Yamada, S. Watanabe, T.M. Sato, K. Ogohara, G.L. Hashimoto, S. Murakami, Astron. J. 154(2), 44 (2017). https://doi.org/10.3847/1538-3881/aa78a5

E. Lellouch, O. Witasse, Planet. Space Sci. 56, 1317 (2008)

E. Lellouch, T. Clancy, D. Crisp, A. Kliore, D. Titov, S.W. Bougher, in Venus II, ed. by S.W. Bougher, D.M. Hunten, R.J. Phillips (University of Arizona Press, Tucson, 1997), p. 295

S.S. Limaye, J.P. Kossin, C. Rozoff, G. Piccioni, D.V. Titov, W.J. Markiewicz, Geophys. Res. Lett. 36, L04204 (2009)

S.S. Limaye, D. Grassi, A. Mahieux, A. Migliorini, S. Tellmann, D. Titov, in Venus III, ed. by C. Russell et al. (2018a) (this book)

S.S. Limaye, S. Watanabe, A. Yamazaki, M. Yamada, T. Satoh, T.M. Sato, M. Nakamura, M. Taguchi, T. Fukuhara, T. Imamura, T. Kouyama, Y.J. Lee, T. Horinouchi, J.N. Iwagami, G.L. Hashimoto, S. Takagi, S. Ohtsuki, S. Murakami, Y. Yamamoto, K. Ogohara, H. Ando, K. Sugiyama, N. Ishii, T. Abe, C. Hirose, M. Suzuki, N. Hirata, E.F. Young, A.C. Ocampo, Earth Planets Space 70, 24 (2018b). https://doi.org/10.1186/s40623-018-0789-5

S.S. Limaye, R. Mogul, D.J. Smith, A.H. Ansari, G.P. Słowik, P. Vaishampayan, Astrobiology 18(9), 11811198 (2018c). https://doi.org/10.1089/ast.2017.1783

W.J. Lo, Y.-J. Wu, Y.-P. Lee, J. Phys. Chem. A 107, 6944 (2003)

R.D. Lorenz, Prog. Earth Planet. Sci. 5, 34 (2018). https://doi.org/10.1186/s40645-018-0181-x

R.D. Lorenz, D. Crisp, L. Huber, Icarus 305, 277 (2018)

M. Luginin et al., Icarus 311, 87-104 (2018). https://doi.org/10.1016/j.icarus.2018.03.018

M. Luginin, A. Fedorova, D. Belyaev, F. Montmessin, V. Wilquet, O. Korablev, J.-L. Bertaux, A.C. Vandaele, Icarus 277, 154 (2016)

D. Luz, D.L. Berry, G. Piccioni, P. Drossart, R. Politi, C.F. Wilson, S. Erard, F. Nuccilli, Science 332, 577 (2011)

A. Mallama, D. Wang, R.A. Howard, Icarus 182, 10 (2006)

E. Marcq, T. Encrenaz, B. Bézard, M. Birlan, Planet. Space Sci. 54, 1360 (2006). https://doi.org/10.1016/ j.pss.2006.04.024

E. Marcq, D. Belyaev, F. Montmessin, A. Fedorova, J.-L. Bertaux, A.C. Vandaele, E. Neefs, Icarus 211(1), 58-69 (2011). https://doi.org/10.1016/j.icarus.2010.08.021

E. Marcq, J.-L. Bertaux, F. Montmessin, D. Belyaev, Nat. Geosci. 6, 25 (2013) 
E. Marcq et al., Composition and chemistry of the neutral atmosphere, in Venus III, ed. by C. Russell et al. (2017) (this book)

W.J. Markiewicz, D.V. Titov, N.I. Ignatiev, H.U. Keller, D. Crisp, S.S. Limaye, R. Jaumann, R. Moissl, N. Thomas, L. Esposito, S. Watanabe, B. Fiethe, T. Behnke, I. Szemerey, H. Michalik, H. Perplies, M. Wedemeier, I. Sebastian, W. Boogaerts, S.F. Hviid, C. Dierker, B. Osterloh, W. Böker, M. Koch, H. Michaelis, D. Belyaev, A. Dannenberg, M. Tschimmel, P. Russo, T. Roatsch, K.-D. Matz, Planet. Space Sci. 55, 1701 (2007)

W.J. Markiewicz, D.V. Titov, B. Fiethe, T. Behnke, I. Szemerey, H. Perplies, M. Wedemeier et al., ESA SP-1295 (2011)

W.J. Markiewicz, E. Petrova, O. Shalygina, M. Almeida, D.V. Titov, S.S. Limaye, N. Ignatiev, T. Roatsch, K.-D. Matz, Icarus 234, 200 (2014)

W.J. Markiewicz, E.V. Petrova, O.S. Shalygina, Icarus 299, 272 (2018)

M.Ya. Marov, V.E. Lystsev, V.N. Lebedev, N.L. Lukashevich, V.P. Shari, Icarus 44, 608 (1980)

K. McGouldrick, Earth Planets Space 69, 161 (2017). https://doi.org/10.1186/s40623-017-0744-X

K. McGouldrick, R.B. Toon, Icarus 191, 1 (2007)

K. McGouldrick, O.B. Toon, Planet. Space Sci. 46, 1112 (2008)

K. McGouldrick, K.H. Baines, T.W. Momary, D.H. Grinspoon, J. Geophys. Res. 113, E00B14 (2008). https:// doi.org/10.1029/2008JE003113

K. McGouldrick et al., Planet. Space Sci. 59, 934 (2011). https://doi.org/10.1016/j.pss.2010.05.020

F.P. Mills, L.W. Esposito, Y.L. Yung, in Exploring Venus as a Terrestrial Planet, ed. by L.W. Esposito, E.R. Stofan, T.E. Cravens (American Geophysical, Union, Washington, 2007), p. 73

K. Molaverdikhani, K. McGouldrick, L.W. Esposito, Icarus 217, 648 (2012)

V.I. Moroz, Kosm. Issled. 25, 659 (1987) (in Russian)

V.I. Moroz, D. Spänkuch, V.M. Linkin, W. Döhler, I.A. Matsygorin, K. Schäfer, L.V. Zasova, D. Oertel, A.V. Dyachkov, R. Schuster, V.V. Kerzhanovich, H. Becker-Ross, E.A. Ustinov, W. Stadthaus, Appl. Opt. 25, 1710 (1986)

B.E. Moshkin, V.I. Moroz, V.I. Gnedykh, A.V. Grigor'ev, L.V. Zasova, A.P. Ekonomov, Astron. Lett. 12, 36 (1986)

M. Nakamura, T. Imamura, M. Ueno, N. Iwagami, T. Satoh, S. Watanabe, M. Taguchi, Y. Takahashi, M. Suzuki, T. Abe, G.L. Hashimoto, T. Sakanoi, S. Okano, Y. Kasaba, J. Yoshida, M. Yamada, N. Ishii, T. Yamada, K. Uemizu, T. Fukuhara, K. Oyamaa, Planet. Space Sci. 55, 1831 (2007)

T. Navarro, G. Schubert, S. Lebonnois, Nat. Geosci. 11, 487 (2018). https://doi.org/10.1038/s41561-0180157-X

T.A. Nordheim, L.R. Dartnell, L. Desorgher, A.J. Coates, G.H. Jones, Icarus 245, 80 (2015)

D. Oertel, D. Spänkuch, H. Jahn, H. Becker-Ross, W. Stadthaus, J. Nopirakowski, W. Döhler, K. Schäfer, J. Güldner, R. Dubois, V.I. Moroz, V.M. Linkin, V.V. Kerzhanovich, I.A. Matsgorin, A.N. Lipatov, A.A. Shurupov, L.V. Zasova, E.A. Ustinov, Adv. Space Res. 5, 25 (1987)

J. Oschlisniok, B. Häusler, M. Pätzold, G.L. Tyler, M.K. Bird, S. Tellmann, S. Remus, T. Andert, Icarus 221, 940 (2012)

C.D. Parkinson, P. Gao, R. Schulte, S.W. Bougher, Y.L. Yung, C.G. Bardeen, V. Wilquet, A.-C. Vandaele, A. Mahieux, S. Tellmann, M. Pätzold, Planet. Space Sci. 113-114, 205 (2015)

S. Pérez-Hoyos, A. Sánchez-Lavega, A. García-Muñoz, P.G.J. Irwin, J. Peralta, G. Holsclaw, W.M. McClintock, J.F. Sanz-Requena, J. Geophys. Res. 123, 145-162 (2018). https://doi.org/10.1002/2017JE005406

E.V. Petrova, O.S. Shalygina, W.J. Markiewicz, Planet. Space Sci. 113-114, 120-134 (2015). https://doi.org/ 10.1016/j.pss.2014.11.013

I.V. Petryanov, B.M. Andreychikov, B.N. Korchuganov, E.I. Ovsyankin, B.I. Ogorodnikov, V.I. Skitovich, V.K. Khristianov, Dokl. Akad. Nauk SSSR 260, 834 (1981) (in Russian)

A. Piccialli, S. Tellmann, D.V. Titov, S.S. Limaye, I.V. Khatuntsev, M. Pätzold, B. Häusler, Icarus 217, 669 (2011)

A. Piccialli, D.V. Titov, A. Sanchez-Lavega, J. Peralta, O. Shalygina, W.J. Markiewicz, H. Svedhem, Icarus 227, 94 (2014)

G. Piccioni, P. Drossart, A. Sanchez-Lavega, R. Hueso, F.W. Taylor, C.F. Wilson, D. Grassi, L. Zasova, M. Moriconi, A. Adriani, S. Lebonnois, A. Coradini, B. Bézard, F. Angrilli, G. Arnold, K.H. Baines, G. Bellucci, J. Benkhoff, J.P. Bibring, A. Blanco, M.I. Blecka, R.W. Carlson, A. Di Lellis, T. Encrenaz, S. Erard, S. Fonti, V. Formisano, T. Fouchet, R. Garcia, R. Haus, J. Helbert, N.I. Ignatiev, P.G.J. Irwin, Y. Langevin, M.A. Lopez-Valverde, D. Luz, L. Marinangeli, V. Orofino, A.V. Rodin, M.C. Roos-Serote, B. Saggin, D.M. Stam, D. Titov, G. Visconti, M. Zambelli (VIRTIS-Venus Express Technical Team), Nature 450, 641 (2007)

G. Piccioni, P. Drossart, E. Suetta, M. Cosi, E. Ammannito, A. Barbis, R. Berlin, A. Boccaccini, G. Bonello, M. Bouyé, F. Capaccioni, G. Cherubini, M. Dami, O. Dupuis, A. Fave, G. Filacchione, Y. Hello, F. Henry, S. Hofer, G. Huntzinger, R. Melchiorri, J. Parisot, C. Pasqui, G. Peter, C. Pompei, J.M. Rèess, 
A. Semery, A. Soufflot, and the The VIRTIS Co-I Team: A. Adriani, F. Angrilli, G. Arnold, K. Baines, G. Bellucci, J. Benkhoff, B. Bezard, J.-P. Bibring, A. Blanco, M.I. Blecka, R. Carlson, A. Coradini, A. Di Lellis, T. Encrenaz, S. Erard, S. Fonti, V. Formisano, T. Fouchet, R. Garcia, R. Haus, J. Helbert, N.I. Ignatiev, P. Irwin, Y. Langevin, S. Lebonnois, M.A. Lopez Valverde, D. Luz, L. Marinangeli, V. Orofino, A.V. Rodin, M.C. Roos-Serote, B. Saggin, A. Sanchez-Lavega, D.M. Stam, F. Taylor, D. Titov, G. Visconti, M. Zambelli, in: ESA SP-1295 (ESA, Noordwijk, 2011)

J.B. Pollack, J.B. Dalton, D. Grinspoon, R.B. Wattson, R. Freedman, D. Crisp, D.A. Allen, B. Bezard, C. DeBergh, L.P. Giver, Q. Ma, R. Tipping, Icarus 103, 1 (1993). https://doi.org/10.1006/icar.1993.1055

N.V. Porshnev, L.M. Mukhin, B.G. Gelman, D.F. Nenarokov, V.A. Rotin, A.V. Dyachkov, V.B. Bondarev, Cosm. Res. 25, 715 (1987)

B. Ragent et al. (Vega Balloon Science Team), Adv. Space Res. 7, 315 (1987)

B. Ragent, J. Blamont, J. Geophys. Res. 85(A13), 8089-8105 (1980). https://doi.org/10.1029/JA085iA13 p08089

B. Ragent, L.W. Esposito, M.G. Tomasko, M.Ya. Marov, V.P. Shari, V.N. Lebedev, Adv. Space Res. 5(11), 85-115 (1985). https://doi.org/10.1016/0273-1177(85)90199-1

M. Roos-Serote, P. Drossart, Th. Encrenaz, E. Lellouch, B. Bézard, R.W. Carlson, K.H. Baines, L.W. Kamp, F.W. Taylor, A.D. Collard, S.B. Calcutt, J.B. Pollack, D.H. Grinspoon, Planet. Space Sci. 41, 504-514 (1993)

M. Roos-Serote, V. Coupé, P. Drossart, E. Lellouch, O. Saint-Pé, Th. Encrenaz, Planet. Space Sci. 44, 509 (1996)

L. Rossi, E. Marcq, F. Montmessin, A. Fedorova, D. Stam, J.-L. Bertaux, O. Korablev, Planet. Space Sci. 113-114, 159 (2015)

W.B. Rossow, A.T. Del Genio, S.S. Limaye, L.D. Travis, P. Stone, J. Geophys. Res. 85, 8107 (1980)

C.T. Russell, T.L. Zhang, M. Delva, W. Magnes, R.J. Strangeway, H.Y. Wei, Nature 450, 661 (2007). https:// doi.org/10.1038/nature05930

C.T. Russell, R.J. Strangeway, J.T. Mayo Daniels, T.L. Zhang, H.Y. Wei, Planet. Space Sci. 59, 965 (2011)

C.T. Russell, H. Leinweber, R.A. Hart, H.Y. Wei, R.J. Strangeway, T.L. Zhang, Icarus 226, 1527 (2013). https://doi.org/10.1016/j.icarus.2013.08.019

R.Z. Sagdeev, V.M. Linkin, V.V. Kerzhanovich, A.N. Lipatov, A.A. Shurupov, J.E. Blamont, D. Crisp, A.P. Ingersoll, L.S. Elson, R.A. Preston, C.E. Hildebrand, B. Ragent, A. Sieff, R.E. Young, G. Petit, L. Boloh, Yu.N. Alexandrov, N.A. Armand, R.V. Rakitko, A.S. Selivanov, Science 231, 1411 (1986)

A. Sánchez-Lavega, R. Hueso, G. Piccioni, P. Drossart, J. Peralta, S. Perez-Hoyos, C.F. Wilson, F.W. Taylor, K.H. Baines, D. Luz, S. Erard, S. Lebonnois, Geophys. Res. Lett. 35, L13204 (2008). https://doi.org/ 10.1029/2008GL033817

A. Sánchez-Lavega, S. Lebonnois, T. Imamura, P. Read, D. Luz, in Venus III, vol. 212, ed. by B. Bézard, C.T. Russell, T. Satoh, S.E. Smrekar, C.F. Wilson (2017), pp. 1541-1616. https://doi.org/10.1007/s11214017-0389-X

B.J. Sandor, T.R. Clancy, Icarus 220, 618 (2012)

B.J. Sandor, T.R. Clancy, Icarus 290, 156 (2017)

M. Sato, L.D. Travis, K. Kawabata, Icarus 124, 569 (1996)

T. Satoh, T. Imamura, G.L. Hashimoto, N. Iwagami, K. Mitsuyama, S. Sorahana, P. Drossart, G. Piccioni, J. Geophys. Res. 114, E00B37 (2009). https://doi.org/10.1029/2008JE003184

T. Satoh, S. Ohtsuki, N. Iwagami, M. Ueno, K. Uemizu, M. Suzuki, G.L. Hashimoto, T. Sakanoi, Y. Kasaba, R. Nakamura, T. Imamura, M. Nakamura, T. Fukuhara, A. Yamazaki, M. Yamada, Icarus 248, 213 (2015)

T. Satoh, T.M. Sato, M. Nakamura, Y. Kasaba, M. Ueno, M. Suzuki, G.L. Hashimoto, T. Horinouchi, T. Imamura, A. Yamazaki, T. Enomoto, Y. Sakurai, K. Takami, K. Sawai, T. Nakakushi, T. Abe, N. Ishii, C. Hirose, N. Hirata, M. Yamada, S. Murakami, Y. Yamamoto, T. Fukuhara, K. Ogohara, H. Ando, K. Sugiyama, H. Kashimura, S. Ohtsuki, Earth Planets Space 69, 154 (2017). https://doi.org/10.1186/ s40623-017-0736-x

F.L. Scarf, W.W.L. Taylor, C.T. Russell, L.H. Brace, J. Geophys. Res. 85(A13), 8158-8166 (1980). https:// doi.org/10.1029/JA085iA13p08158

L. Schaefer, B. Fegley, Icarus 168(1), 215-219 (2004). https://doi.org/10.1016/j.icarus.2003.11.023

P.J. Schinder, P.J. Gierasch, S.S. Leroy, M. Smith, J. Atmos. Sci. 47, 2037 (1990)

A. Seiff, J.T. Schofield, A.J. Kliore, F.W. Taylor, S.S. Limaye, H.E. revercomb, L.A. Sromovsky, V.V. Kerzhanovich, V.I. Moroz, M.Ya. Marov, Adv. Space Res. 5, 3 (1985)

J.H. Seinfeld, S.N. Pandis, Air Pollution to Climate Change (Wiley, New York, 1998)

O.S. Shalygina, E.V. Petrova, W.J. Markiewicz, N.I. Ignatiev, Planet. Space Sci. 113-114, 135 (2015)

M. Stolzenburg, T.C. Marshall, Space Sci. Rev. 137, 355 (2008)

V.E. Suomi, S.S. Limaye, Science 201, 1009 (1978) 
Yu.A. Surkov, V.F. Ivanova, A.N. Pudov, V.P. Volkov, E.P. Sheretov, B.I. Kolotilin, M.P. Safonov, R. Thomas, J. Lespagnol, A. Hauser, G. Israël, D. Imbault, D. Caramelle, Sov. Astron. Lett. 12, 44 (1986)

H. Svedhem, D.V. Titov, D. McCoy, J.-P. Lebreton, S. Barabash, J.-L. Bertaux, P. Drossart et al., Planet. Space Sci. 55, 1636 (2007)

H. Svedhem, D.V. Titov, F.W. Taylor, O. Witasse, J. Geophys. Res. 114, 3 (2009)

H. Svedhem, D. McCoy, D.V. Titov, F.W. Taylor, O. Witasse, ESA SP-1295 (ESA, Noordwijk, 2011)

Y. Takahashi, J. Yoshida, Y. Yair, T. Imamura, M. Nakamura, Space Sci. Rev. 137, 317 (2008)

Y. Takahashi, M. Sato, M. Imai, R. Lorenz, Y. Yair, K. Aplin, G. Fischer, M. Nakamura, N. Ishii, T. Abe, T. Satoh, T. Imamura, C. Hirose, M. Suzuki, G.L. Hashimoto, N. Hirata, A. Yamazaki, T.M. Sato, M. Yamada, S. Murakami, Y. Yamamoto, T. Fukuhara, K. Ogohara, H. Ando, K. Sugiyama, H. Kashimura, S. Ohtsuki, Earth Planets Space 70, 88 (2018). https://doi.org/10.1186/s40623-018-0836-2

T. Tavenner, E.F. Young, M.A. Bullock, J. Murphya, S. Coyotec, Planet. Space Sci. 56, 1435 (2008)

F.W. Taylor, R. Beer, M.T. Chahine, D.J. Diner, L.S. Elson, R.D. Haskins, D.J. McCleese, J.V. Martonchik, P.E. Reichley, S.P. Bradley, J. Delderfield, J.T. Schofield, C.B. Farmer, L. Froidevaux, J. Leung, M.T. Coffey, J.C. Gille, J. Geophys. Res. 85, 7963 (1980)

N.A. Teanby, R. de Kok, P.G.J. Irwin, S. Osprey, S. Vinatier, P.J. Gierasch, P.L. Read, F.M. Flasar, B.J. Conrath, R.K. Achterberg, B. Bezard, C.A. Nixon, S.B. Calcutt, J. Geophys. Res. 113, E12003 (2008). https://doi.org/10.1029/2008JE003218

S. Tellmann, M. Pätzold, B. Häusler, M.K. Bird, G.L. Tyler, J. Geophys. Res., Planets 114, E00B36 (2009). https://doi.org/10.1029/2008JE003204

D.V. Titov, H. Svedhem, D. Koschny, R. Hoofs, S. Barabash, J.-L. Bertaux, P. Drossart, V. Formisano, B. Häusler, O. Korablev, W.J. Markiewicz, D. Nevejans, M. Pätzold, G. Piccioni, T.L. Zhang, D. Merritt, O. Witasse, J. Zender, A. Accommazzo, M. Sweeney, D. Trillard, M. Janvier, A. Clochet, Planet. Space Sci. 54, 1279 (2006)

D.V. Titov, M. Bullock, D. Crisp, N. Renno, F.W. Taylor, L.V. Zasova, in Exploring Venus as Terrestrial Planet, ed. by L.W. Esposito, E.R. Stofan, T.E. Cravens. AGU Geophysical Monograph, vol. 176 (2007), p. 121

D.V. Titov, F.W. Taylor, H. Svedhem, N.I. Ignatiev, W.J. Markiewicz, G. Piccioni, P. Drossart, Nature 456, 620 (2008)

D.V. Titov, H. Svedhem, F.W. Taylor, S. Barabash, J.-L. Bertaux, P. Drossart, V. Formisano, B. Häusler, O. Korablev, W.J. Markiewicz, D. Nevejans, M. Pätzold, G. Piccioni, J.-A. Sauvaud, T.L. Zhang, O. Witasse, J.-C. Gerard, A. Fedorov, A. Sanchez-Lavega, J. Helbert, R. Hoofs, Sol. Syst. Res. 43(3), 185-209 (2009). https://doi.org/10.1134/S0038094609030010

D.V. Titov, W.J. Markiewicz, N.I. Ignatiev, L. Song, S.S. Limaye, A. Sanchez-Lavega, J. Hesemann, M. Almeida, T. Roatsch, K.-D. Matz, F. Scholten, D. Crisp, L.W. Esposito, S.F. Hviid, R. Jaumann, H.U. Keller, R. Moissl, Icarus 217, 682 (2012)

D.V. Titov, G. Piccioni, P. Drossart, W.J. Markiewicz, Radiative energy balance in the Venus atmosphere, in Towards Understanding the Climate of Venus: Applications of Terrestrial Models to Our Sister Planet. ISSI Scientific Report, vol. 11, ed. by L. Bengtsson, R.-M. Bonnet, D. Grinspoon, S. Koumoutsaris, S. Lebonnois, D. Titov (Springer, Berlin, 2013), p. 23

M.G. Tomasko, L.R. Doose, P.H. Smith, A.P. Odell, J. Geophys. Res. 85, 8167 (1980)

O.B. Toon, B. Ragent, D. Colburn, J. Blamont, C. Cot, Icarus 57, 143 (1984)

C.C.C. Tsang, C.F. Wilson, J.K. Barstow, P.G.J. Irwin, F.W. Taylor, K. McGouldrick, G. Piccioni, P. Drossart, H. Svedhem, Geophys. Res. Lett. 37, L02202 (2010). https://doi.org/10.1029/2009GL041770

V. Vaida, D.J. Donaldson, Phys. Chem. Chem. Phys. 16, 827 (2014). https://doi.org/10.1039/C3CP53543F

V. Wilquet, A. Fedorova, F. Montmessin, R. Drummond, A. Mahieux, A.C. Vandaele, E. Villard, O. Korablev, J.-L. Bertaux, J. Geophys. Res. 114, E00B42 (2009). https://doi.org/10.1029/2008JE003186

V. Wilquet, R. Drummond, A. Mahieux, S. Robert, A.C. Vandaele, J.-L. Bertaux, Icarus 217, 875 (2012)

C.F. Wilson, S. Guerlet, P.G.J. Irwin, C.C.C. Tsang, F.W. Taylor, R.W. Carlson, P. Drossart, G. Piccioni, J. Geophys. Res. 113, E00B13 (2008). https://doi.org/10.1029/2008JE003108

Y. Yair, G. Fischer, F. Simões, N. Renno, P. Zarka, Space Sci. Rev. 137(1-4), 119-131 (2008). https://doi.org/ 10.1007/s11214-008-9348-X

A. Yamazaki, M. Yamada, Y.J. Lee, S. Watanabe, T. Horinouchi, S. Murakami, T. Kouyama, K. Ogohara, T. Imamura, T.M. Sato, Y. Yamamoto, T. Fukuhara, H. Ando, K. Sugiyama, S. Takagi, H. Kashimura, S. Ohtsuki, N. Hirata, G.L. Hashimoto, M. Suzuki, C. Hirose, M. Ueno, T. Satoh, T. Abe, N. Ishii, M. Nakamura, Earth Planets Space 70, 23 (2018). https://doi.org/10.1186/s40623-017-0772-6

A.T. Young, Icarus 18(4), 564-582 (1973). https://doi.org/10.1016/0019-1035(73)90059-6

A.T. Young, Icarus 56, 568-577 (1983). https://doi.org/10.1016/0019-1035(83)90174-4

L.D.G. Young, A.T. Young, Astrophys. J. 179, L39 (1973)

Y.L. Yung, W.B. DeMore, Icarus 51, 199 (1982) 
Y.L. Yung, M.-C. Liang, X. Jiang, C. Lee, B. Bezard, E. Marcq, J. Geophys. Res. 114, E00B34 (2009). https://doi.org/10.1029/2008JE003094

P. Zarka, W. Farrell, G. Fischer, A. Konovalenko, Space Sci. Rev. 137(1-4), 257-269 (2008). https://doi.org/ 10.1007/s11214-008-9366-8

L.V. Zasova, V.A. Krasnopolsky, V.I. Moroz, Adv. Space Res. 1, 13 (1981)

L.V. Zasova, V.I. Moroz, L.W. Esposito, C.Y. Na, Icarus 105, 92 (1993)

L.V. Zasova, V.I. Moroz, V.M. Linkin, Adv. Space Res. 17, 171 (1996)

L.V. Zasova, N.I. Ignatiev, I.V. Khatuntsev, V.M. Linkin, Planet. Space Sci. 55, 1712 (2007)

R. Zhang, P.J. Wooldridge, J.P.D. Abbatt, M.J. Molina, J. Phys. Chem. 97, 7351 (1993)

X. Zhang, M.C. Liang, F.P. Mills, D. Belyaev, Y.L. Yung, Icarus 217, 714 (2012)

Y.V. Zhulanov, L.M. Mukhin, D.F. Nenarokov, Sov. Astron. Lett. 12, 49 (1986) 